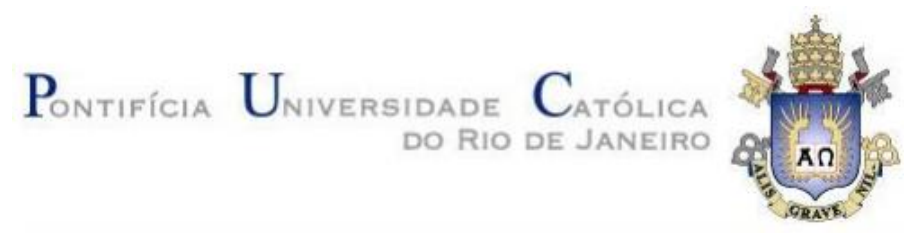

Thaís Lopes Guedes de Oliveira

\title{
Frameworks para a integração entre a Manufatura Enxuta e a Indústria 4.0
}

Dissertação de Mestrado

Dissertação apresentada como requisito parcial para obtenção do grau de Mestre pelo Programa de Pós-Graduação em Engenharia de Produção do Departamento de Engenharia Industrial da PUC-Rio.

Orientador: Prof. Luiz Felipe Roris Rodriguez Scavarda do Carmo Co-orientador: Prof. Rodrigo Goyannes Gusmão Caiado

Rio de Janeiro abril de 2020 


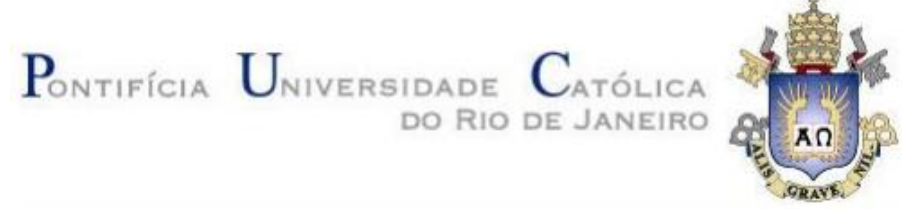

Thaís Lopes Guedes de Oliveira

\section{Frameworks para a integração entre a Manufatura Enxuta e a Indústria 4.0}

Dissertação apresentada como requisito parcial para obtenção do grau de Mestre pelo Programa de Pós-Graduação em Engenharia de Produção do Departamento de Engenharia Industrial da PUC-Rio. Aprovada pela Co-missão Examinadora abaixo.

Prof. Luiz Felipe Roris Rodriguez Scavarda do Carmo Orientador Departamento de Engenharia Industrial - PUC - Rio Prof. Rodrigo Goyannes Gusmão Caiado Co-orientador Departamento de Engenharia Industrial - PUC - Rio Prof.Guilherme Luz Tortorella UFSC

Prof.Paula Santos Ceryno UNIRIO

Rio de Janeiro, 14 de abril de 2020 
Todos os direitos reservados. É proibida a reprodução total ou parcial do trabalho sem autorização do autor, do orientador e da universidade.

\section{Thaís Lopes Guedes de Oliveira}

Graduou-se em Engenharia de Produção pela Universidade Federal

Fluminense em 2014.Aluna de mestrado com dedicação exclusiva no Departamento de Engenharia Industrial da PUC-Rio desde 2018.

Ficha Catalográfica

Oliveira, Thaís Lopes Guedes de

Frameworks para a integração entre a manufatura enxuta e a indústria 4.0 / Thaís Lopes Guedes de Oliveira ; orientador: Luiz Felipe Roris Rodriguez Scavarda do Carmo ; co-orientador: Rodrigo Goyannes Gusmão Caiado. - 2020.

87 f. : il. color. ; $30 \mathrm{~cm}$

Dissertação (mestrado)-Pontifícia Universidade Católica do Rio de Janeiro, Departamento de Engenharia Industrial, 2020.

Inclui bibliografia

1. Engenharia Industrial - Teses. 2. Lean. 3. Indústria 4.0. 4. Revisão sistemática da literatura. 5. Framework. I. Carmo, Luiz Felipe Roris Rodriguez Scavarda do. II. Caiado, Rodrigo Goyannes Gusmão. III. Pontifícia Universidade Católica do Rio de Janeiro. Departamento de Engenharia Industrial. IV. Título.

CDD: 658.5 


\section{Agradecimentos}

Agradeçoà minha mãe, mulher guerreira e batalhadora, por todo apoio e confiança. Por sempre acreditar em mim e nos meus sonhos. Não importa a situação, sempre está ao meu lado. Obrigada por nunca desistir de mim, te amo demais!

Agradeço à minha família e amigosportodoosuporte, compreensão e torcida.

Um agradecimento especial ao Leonel Tadeu. Por toda paciência, insistência, incentivo, ajuda e amizade. Por acreditar em mim, por me ajudar a conquistar os meus sonhos e por sempre querer o melhor para mim.

Um agradecimento especial ao meu grande amigo Alex Alves. Sempre ao meu lado, me dando conselhos, acreditando no meu potencial e me incentivando.

Ao meu orientador Luiz Felipe Scavarda pela confiança, pelos conhecimentos compartilhados e pelo apoio e compreensão nos momentosdifíceis.

Ao meu co-orientador Rodrigo Caiado por toda paciência em me ensinar, por toda preocupação em me ajudar a produzir um trabalho de qualidade e, também, pelo apoio e compreensão nos momentos difíceis.

Aos professores da PUC-Rio pelos conhecimentos que contribuíram para o meu desenvolvimento pessoal e profissional.

Aos funcionários da PUC-Rio pela solicitude e simpatia.

$\mathrm{E}$ às agências de fomento à pesquisa CNPq e FAPERJ, pelo suporte vital para a realização e conclusão do curso.

O presente trabalho foi realizado com apoio da Coordenação de Aperfeiçoamento de Pessoal de Nível Superior - Brasil (CAPES) - Código de Financiamento 001. 


\section{Resumo}

de Oliveira, Thaís Lopes Guedes; do Carmo, Luiz Felipe Roris Rodriguez Scavarda (Orientador); Caiado, Rodrigo Goyannes Gusmão (Co-orientador); Frameworks para a integração entre a Manufatura Enxuta e a Indústria 4.0.Rio de Janeiro, 2020. 87p. Dissertação de Mestrado - Departamento de Engenharia Industrial,Pontifícia Universidade Católicado do Rio de Janeiro.

A competitividade no mundo corporativo tem se elevado consideravelmente e para se manterem competitivas, as empresas devem inovar seus processos produtivos constantemente. O lean manufacturing(LM) surgiu como uma filosofia que preza pela eliminação dos desperdícios no meio de produção. Atualmente, o mundo vivência a quarta revolução industrial ou Indústria 4.0 (I4.0), que é baseada em uma alta conectividade. Para se atualizarem, as empresas estão integrando o $L M$ e a I 4.0. Para que a implementação das tecnologias da Indústria 4.0 seja um sucesso, é necessário analisar qual tecnologia se adapta melhor ao ambiente lean instalado. Neste contexto, a presente dissertação de mestrado tem por objetivo analisar os pontos de sinergia entre LM e I4.0 e melhorar a compreensão corporativa sob a implementação conjunta dessas duas vertentes na indústria de manufatura. Dois frameworks de integração entre o LM e a I4.0 são propostos, ambos com o intuito de auxiliar o processo de implementação conjunta dessas duas vertentes. Para atingir o objetivo de pesquisa, foram realizadas uma revisão sistemática da literatura e um Painel com Especialistas para o desenvolvimento e validação dos frameworks. São, também, apresentadas análises descritivas e de conteúdo sobre os temas propostos. Sugere-se, como pesquisa futura a realização de um estudo de caso em que esses frameworks sejam colocados em prática na indústria de manufatura.

\section{Palavras-chave}

lean, Indústria 4.0, revisão sistemática da literatura, framework 


\section{Abstract}

de Oliveira, Thaís Lopes Guedes; do Carmo, Luiz Felipe Roris Rodriguez Scavarda (Advisor); Caiado, Rodrigo Goyannes Gusmão (Co- Advisor); Frameworks for the integration between Lean manufacturing and Industry 4.0. Rio de Janeiro, 2020. 87p. Dissertação de Mestrado - Departamento de Engenharia Industrial, Pontifícia Universidade Católica do Rio de Janeiro

The competitiveness in the corporate world has increased considerably, and to keep competitive, companies must continuously innovate their production processes. Lean manufacturing (LM) emerged as a philosophy that replaces waste in the production environment. Currently, the world experiences the fourth industrial revolution or Industry 4.0, which is based on high connectivity. To keep themselves updated, companies are integrating lean and Industry 4.0. Towards the successful implementation of Industry 4.0 technologies, it is necessary to analyze which technology best adapts to the lean installed environment. Within this context, this Master's thesis aims to analyze the synergy points between LM and Industry 4.0 and to improve corporate understanding under the joint implementation of these two strands in the manufacturing industry. Two integration frameworks between the LM and I4.0 are proposed, both aiming to assist the process of joint implementation of these two strands. To achieve this objective, a systematic literature review and a Panel of Experts were carried out to develop and validate the frameworks. Descriptive and content analyses of the proposed topics are also presented. It is suggested for future research a case study in which these frameworks are used in practice in the manufacturing industry.

\section{Keywords}

lean, Industry 4.0, systematic literature review, framework 


\section{Sumário}

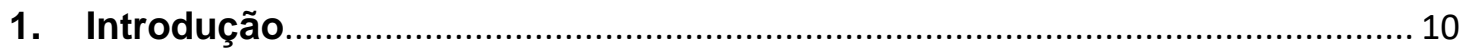

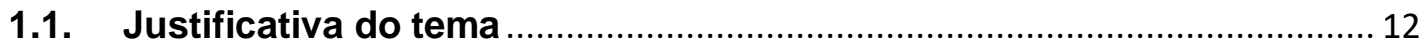

1.2. Objetivo geral e objetivos específicos …............................................ 12

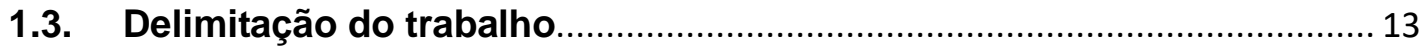

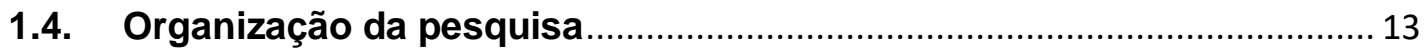

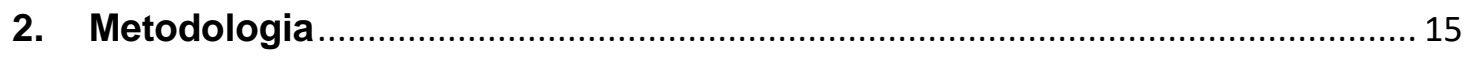

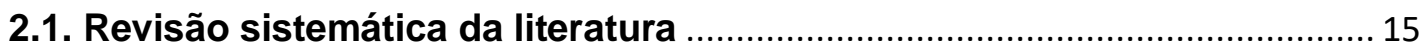

2.1.1. Formulação das questões de pesquisa.............................................. 17

2.1.2. Localização do estudo ..................................................................... 17

2.1.3. Seleção e avaliação do estudo............................................................. 18

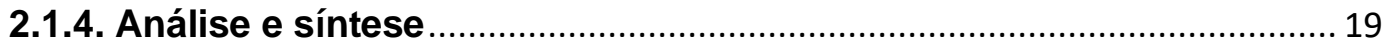

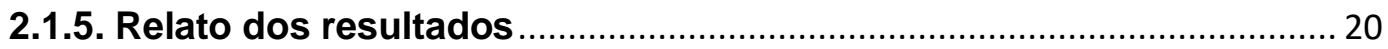

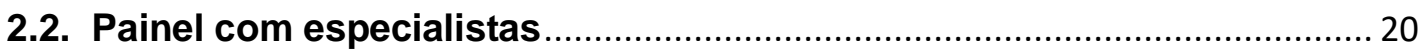

3. Conceituação e sinergia entre Lean Manufacturing e Indústria 4.0 …........ 22

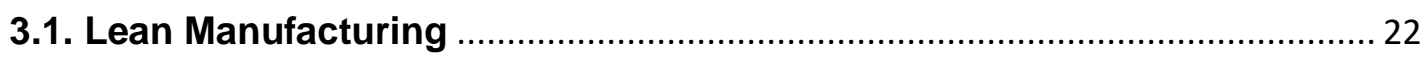

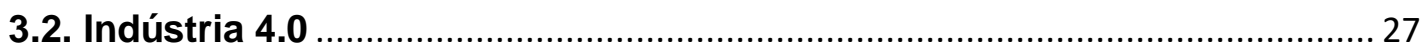

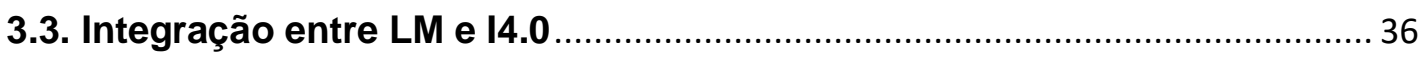

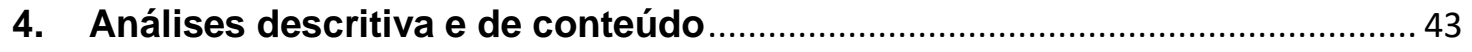

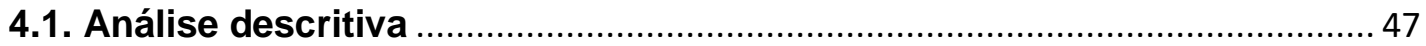

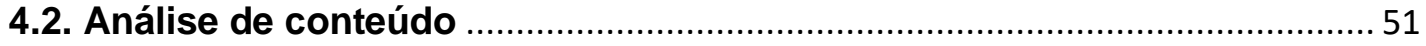

4.2.1. Fatores críticos de sucesso para o integração do LM com a 14.0 ....... 51

4.2.2. Barreiras e desafios para a implementação da integração do LM com

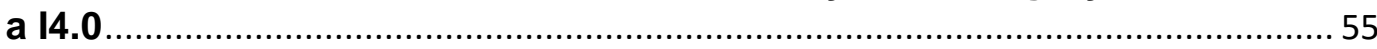

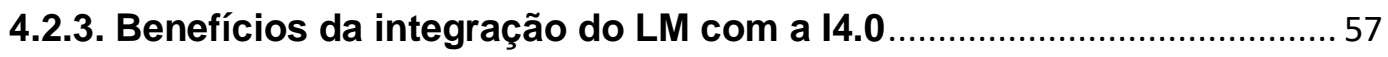

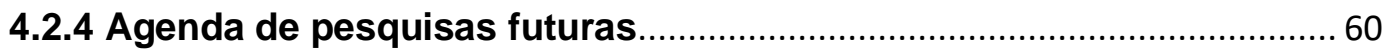

5. Frameworks para integração entre o Lean Manufacturing e a Indústria 4.063

5.1. Aperfeiçoamento e validação dos frameworks com base no Painel

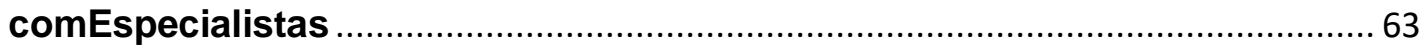

5.2. Framework1 :União dos princípios, práticas e tecnologias .................... 66

5.3. Framework2: Etapas de Implementação da Integração entre o LM e a 14.070

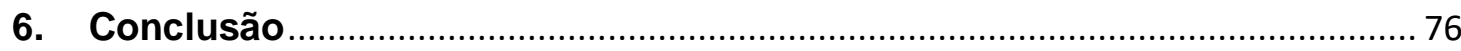

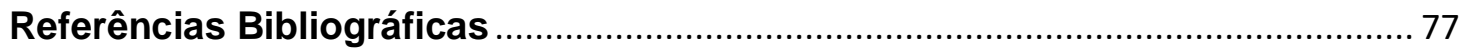


APÊNDICE I - Questionário da primeira rodada do Painel com Especialistas... 85 


\section{Lista de Figuras}

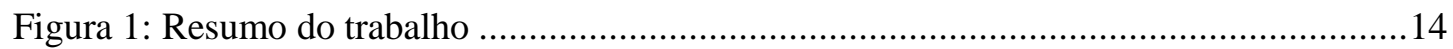

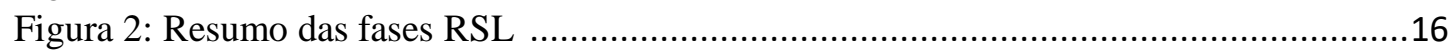

Figura 3: Etapas da seleção dos artigos....................................................................... 19

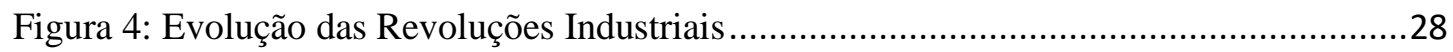

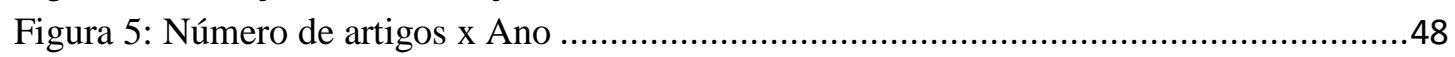

Figura 6: Quantidade de publicações por periódicos .......................................................49

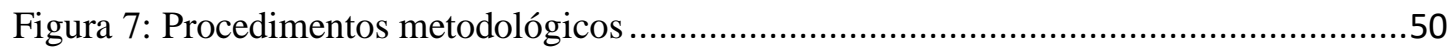

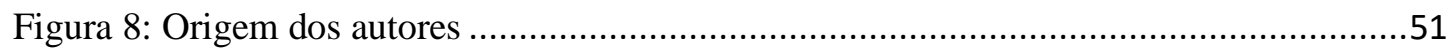

Figura 9: Framework 1- União de princípios, práticas e tecnologias...................................67

Figura 10: Framework 2 - Etapas de Implementação da Integração entre o LM e a I4.0 .....72

Figura 11: Exemplo do framework 2 - Etapas de Implementação da Integração entre o Lm e a

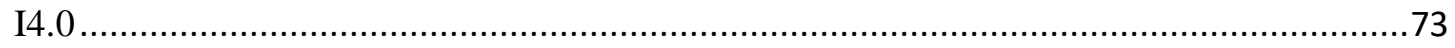




\section{Lista de Tabelas}

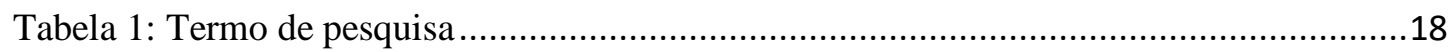

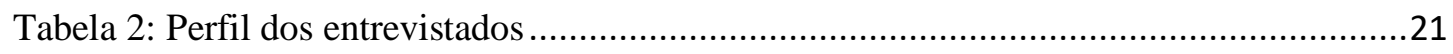

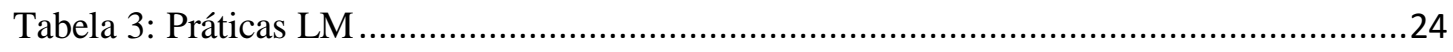

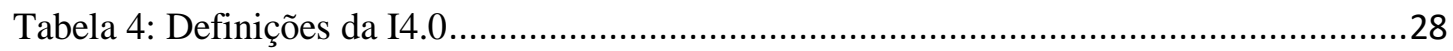

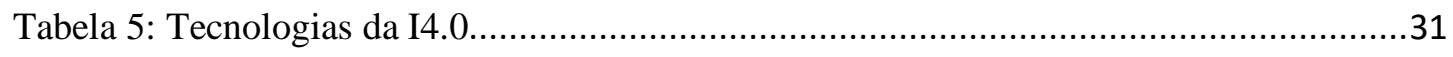

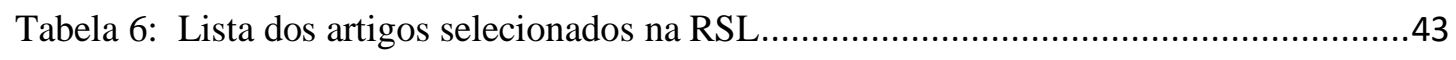

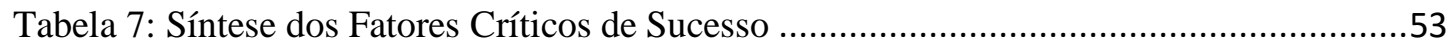

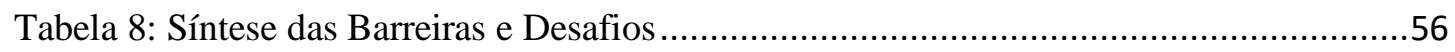




\section{Lista de Abreviaturas e Sigla}

LM - Lean Manufacturing

14.0 - Indústria 4.0

TIC - Tecnologias de Informação e Comunicação

LA - Lean Automation

RSL - Revisões Sistemáticas da Literatura

JIT - Just-In-Time

VSM - Value Stream Mapping

$5 S$ - 5 Sensos

SS - Six Sigma

DMAIC - Definir, Medir, Analisar, Melhorar e Controlar

LSS - Lean Six Sigma

CPS - Cyber Physical System

loT - Internet of Things

3D - 3 Dimensões

RFID - Identificação por Radiofrequência

IVC - Identificar o valor aos olhos do consumidor

IMV - Identificar e mapear o fluxo de valor

CFL - Criar um fluxo

DBC - Demanda baseada no cliente

BP - Buscar a perfeição

I - Interoperabilidade

V - Virtualização

D - Descentralização

CTR - Capacidade em tempo real

OAS - Orientado a serviço

M - Modularidade 


\section{Introdução}

A competitividade no mundo corporativo tem se elevado consideravelmente e os consumidores estão cada vez mais exigindo altos padrões de qualidade e rapidez na produção. Todavia, qualidade, eficiência, lead time e custo devem ser considerados quando se deseja melhorar a flexibilidade dos sistemas de produção que estão sob condições econômicas globais não favoráveis (MA et al., 2017).

Para se manterem competitivas, as empresas vêm inovando seus processos produtivos constantemente. No passado, as organizações implementaram a manufatura enxuta, em inglês lean manufacturing (LM), com o objetivo de criar sistemas eficientes e orientados para processos, possibilitando-as, assim, enfrentarem os desafios de custo, qualidade e tempo (DOMBROWSKI et al., 2017). O LM tem como propósito a eliminação de todos os tipos de desperdícios no processo de produção, através da identificação de atividades desnecessárias, da simplificação dos processos e da criação de rotinas padronizadas (BUER et al., 2018a). Devido à sua alta eficácia, o LM ainda é um sistema de produção bem-sucedido e adotado pelas empresas.

Novas tecnologias estão surgindo a todo momento. Devido a esse fato, ocorrem as revoluções industriais, que marcam as gerações. Seguindo a evolução do tempo, a primeira revolução industrial teve como principal característica o uso de máquinas a vapor, a segunda veio com o surgimento da eletricidade e da produção em massa e a terceira caracteriza-se por inovações tecnológicas, como a mudança do sistema analógico para o digital. Por fim, a quarta revolução industrial, ou Indústria 4.0 (I4.0), se baseia na transferência e na integração de tecnologias digitais e de computação para o benefício da indústria (SAIDI; SOULHI, 2018).

A intensificação da competição na cadeia de suprimentos levou as organizações a atualizarem seus sistemas de manufatura para um nível mais inteligente (KAMBLE et al., 2019). De acordo com Wang (2016), a I4.0 elabora produtos individuais e 
personalizados ao mesmo custo da produção em massa. Essa revolução integra as tecnologias de informação e comunicação (TIC) para permitir uma produção em massa de produtos customizados (TORTORELLA et al., 2019a).

Algumas empresas já iniciaram ou, ainda, estão iniciando esse processo de transição para as tecnologias da I4.0 e muitas estão integrando o seu sistema atual com essas novas tecnologias. A integração entre LM e a I4.0 já existe e pode ser denominada de lean automation (LA), que tem por objetivo uma maior capacidade de mutabilidade e um curto fluxo de informação para atendar as demandas do mercado (KOLBERG et al., 2017). A I4.0 e LM se apoiam mutuamente, onde LM serve como um ativador para a implementação da I4.0 e, inversamente, a I4.0 realiza uma versão avançada da produção enxuta (DAVIES et al., 2017).

A cada revolução industrial as empresas ganharam eficiência em seus processos produtivos e tiveram que adaptar seus processos às novas tecnologias. Nos dias de hoje, o processo de inovação é muito mais veloz e torna o meio organizacional mais competitivo, isso nos traz a I4.0. Ela trouxe inúmeros benefícios como:facilidade na análise dos dados das máquinas e melhoria da qualidade do processo produtivo, bem com sua prevenção de falhas (ANTE et al.,2018). Nesse contexto, o nível de habilidades dos trabalhadores tende a aumentar e eles tendem a se tornar cada vez mais especializados (TORTORELLA; FETTERMANN, 2018). Através das tecnologias da I4.0, o sistema produtivo passa a ter um potencial de promover o intercâmbio de dados e informações em cada uma das dimensões de variedade, volume e velocidade em um ambiente em tempo real (DAVIES et al., 2017). Para que a implementação das tecnologias da I4.0 seja exitosa, é necessário analisar qual tecnologia se adapta melhor ao ambiente LM instalado na empresa.

Como o aumento da flexibilidade é um requisito desejado, a adoção em conjunto do lean e da I4.0 ajuda a alcançar esse objetivo (LUGERT et al., 2018), sendo um meio de fomentar a sua competitividade. Além disso, as tecnologias da I4.0 podem apoiar a obtenção de novos padrões de desempenho (ROSSINI et al., 2019). A Indústria 4.0 possui tecnologias que agem como soluções integradas que se alinham aos objetivos do LM (KAMBLE et al., 2019). Segundo os resultados do trabalho de Rossini et al. (2019), uma alta aplicabilidade do LM e da I4.0, indica que os mais altos níveis de adoção da 
segunda podem ser mais fáceis de alcançar quando as práticas da primeira estão bem implementadas na empresa. Assim, este trabalho tem por tema a construção da integração entre o ambiente LM e I4.0 para que posteriormente seja aplicado no contexto de manufatura.

\subsection{Justificativa do tema}

Por ser um tema recente, não há muitas informações que façam a ligação entre o lean manufacturing e a I4.0, abrindo uma lacuna na literatura a ser endereçada por pesquisas futuras (SONY, 2018). De fato, a relação entre a I4.0 e LM é, ainda, bastante desconhecida (ROSSINI et al., 2019). Embora a integração entre o LM e a I4.0 esteja sendo pesquisada nos últimos anos, os impactos da implementação das novas tecnologias ainda não estão muito claros (PEREIRA et al., 2019). Existem muitas pesquisas individuais sobre as tecnologias da I4.0, mas o seu potencial de integração com LM ainda não foi totalmente investigado (SANDERS et al., 2016). A literatura carece também de frameworks para a implementação da integração da I4.0 com LM (BUER et al., 2018a). É neste contexto que a presente dissertação se situa, buscando endereçar este na literatura, conforme detalhado a seguir com a proposta de objetivo de pesquisa.

\subsection{Objetivo geral e objetivos específicos}

O objetivo principal dessa dissertação é analisar os pontos de sinergia entre LM e I4.0 e melhorar a compreensão corporativa e acadêmica sob a implementação conjunta dessas duas vertentes na indústria de manufatura.

Todo o potencial de integração entre as tecnologias do LM e da I4.0 é explorado, através de frameworks, com o objetivo de que esta relação seja bem conhecida. Além disso, busca-se apoiar o processo de transição, identificando as boas práticas necessárias inerentes ao sistema LM.

Como objetivos específicos, este trabalho possui: 
a) Identificar os fatores críticos para a implementação de um ambiente de integração entre o Lean Manufacturing e a Indústria 4.0;

b) Identificar as barreiras e os desafios para a implementação do ambiente de integração entre o Lean Manufacturing e a Indústria 4.0;

c) Identificar os benefícios que essa integração traz para a empresa;

\subsection{Delimitação do trabalho}

Este trabalho utilizou duas metodologias para a sua construção. Primeiro, foi realizada uma Revisão Sistemática da Literatura e em seguida foi realizado um Painel com Especialistas. Apesar de todo cuidado para garantir o caráter científico do trabalho, é importante ressaltar que ele apresenta algumas delimitações em relação aos métodos empregados. Essas limitações serão descritas a seguir.

Deve-se mencionar que a Revisão Sistemática da Literatura foi construída com base em uma gama de palavras-chave, estas visaram cobrir da melhor forma possível os dois assuntos propostos. É importante ressaltar que os resultados do presente trabalho não podem ser aplicados em outras cadeias de suprimentos, por se tratar de um estudo focado na cadeia manufatureira.

Por fim, cabe ressaltar que o este estudo pode ser aplicado na empresa como um todo ou em uma área em particular da empresa. Este trabalho não teve como foco a implementação de um ambiente de integração LM com I4.0 na relação empresafornecedor e empresa-cliente.

\subsection{Organização da pesquisa}

A figura 1 tem por objetivo sintetizar a evolução desta dissertação, sob o aspecto dos objetivos gerais, específicos e os frameworks. 


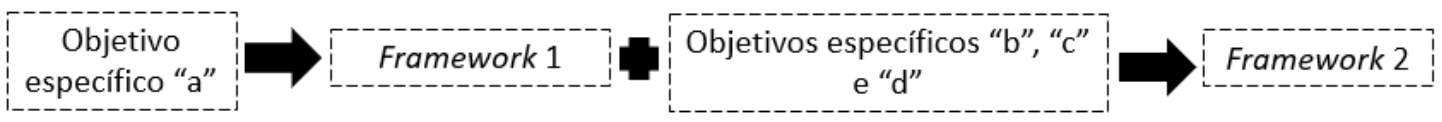

Figura 1: Resumo do trabalho

Através do estudo sobre as sinergias existentes entre o LM e I4.0 é oferecido o framework 1. Para a construção do framework 2, tem-se, como input, o framework 1, adicionado dos fatores críticos de sucesso, barreiras e desafios e benefícios da integração LM com I4.0. Sendo assim, essa dissertação está organizada em 6 capítulos, sendo este o capítulo introdutório. O segundo capítulo apresenta a metodologia adotada, destacando os métodos de revisão sistemática da literatura e do Painel com Especialistas. O Capítulo 3 fundamenta teoricamente lean manufacturing, Indústria 4.0 e alinhamento entre ambos. O quarto capítulo apresenta os resultados da análise descritiva e de conteúdo, enquanto que o capítulo 5 oferece os dois frameworks. Por fim, o sexto e último capítulo apresenta a conclusão e sugestões para pesquisas futuras. 


\section{Metodologia}

A dissertação combina duas metodologias para atingir o seu objetivo, sendo a primeirauma Revisão Sistemática da Literatura para a construção dos frameworks. A segunda metodologia consiste na aplicação de um painel com especialistas para efetuar um primeiro ciclo de aperfeiçoamento e validaçãodos frameworks propostos. Cada uma é apresentada a seguir.

\subsection{Revisão sistemática da literatura}

As revisões sistemáticas da literatura (RSL) são investigações sobre si mesmas, com métodos pré-planejados, sendo consideradas uma importante metodologia de pesquisa para gerência de operações (THOMÉ et al., 2012; MAGON et al., 2018).Segundo Denyer e Tranfield (2009), a RSL é uma metodologia que localiza os estudos existentes, seleciona e avalia ascontribuições, análises e sintetiza dados e relatórios que geram conclusões claras a serem alcançadas sobre o que é e não é conhecido.A RSL tem por objetivo responder questões de pesquisa ou testar hipóteses e envolve uma série de técnicas para minimizar o viés e o erro quesão amplamente consideradas como fornecedoras de provas de alta qualidade (TRANFIELD et al., 2003). Se uma revisão sistemática for realizada corretamente, ela sintetiza, fielmente, as evidências de todos os estudos relevantes sobre a área de interesse e faz isso de forma concisa e transparente (COOK et al., 1997; THOMÉ et al., 2016). Deve-se ressaltar o uso de métodos explícitos em uma RSL. Para Mulrow (1994), através do uso de métodos explícitos pode-se avaliar o que foi feito e, assim, aumentar a capacidade de replicar os resultados ou a compreensão do motivo pelo qual os resultados e as conclusões de algumas revisões diferem. Ao contrário da revisão tradicional ou da narrativa, as RSL 
são mais rigorosas e usam critérios bem definidos para rever a literatura (CRONIN et al., 2008).

Baseado nos passos de Denyer e Tranfield (2009) e no estudo de Garza-Reyes (2015), essa RSL irá seguir as seguintes fases: formulação das questões de pesquisa (1), localização do estudo (2), seleção e avaliação do estudo (3), análise e síntese (4) e relatos dos resultados (5). A figura 2 apresenta estas fases da RSL em sua primeira coluna, seus objetivos na segunda coluna, os métodos e as ferramentas utilizadas para apoiar cada etapa e as análises nas terceira, quarta e quinta colunas, e a seção da dissertação em que são endereçadas nessa dissertação na última coluna. Sua construção foi baseada nos trabalhos de Garza-Reyes (2015) e Saieg et al. (2018).

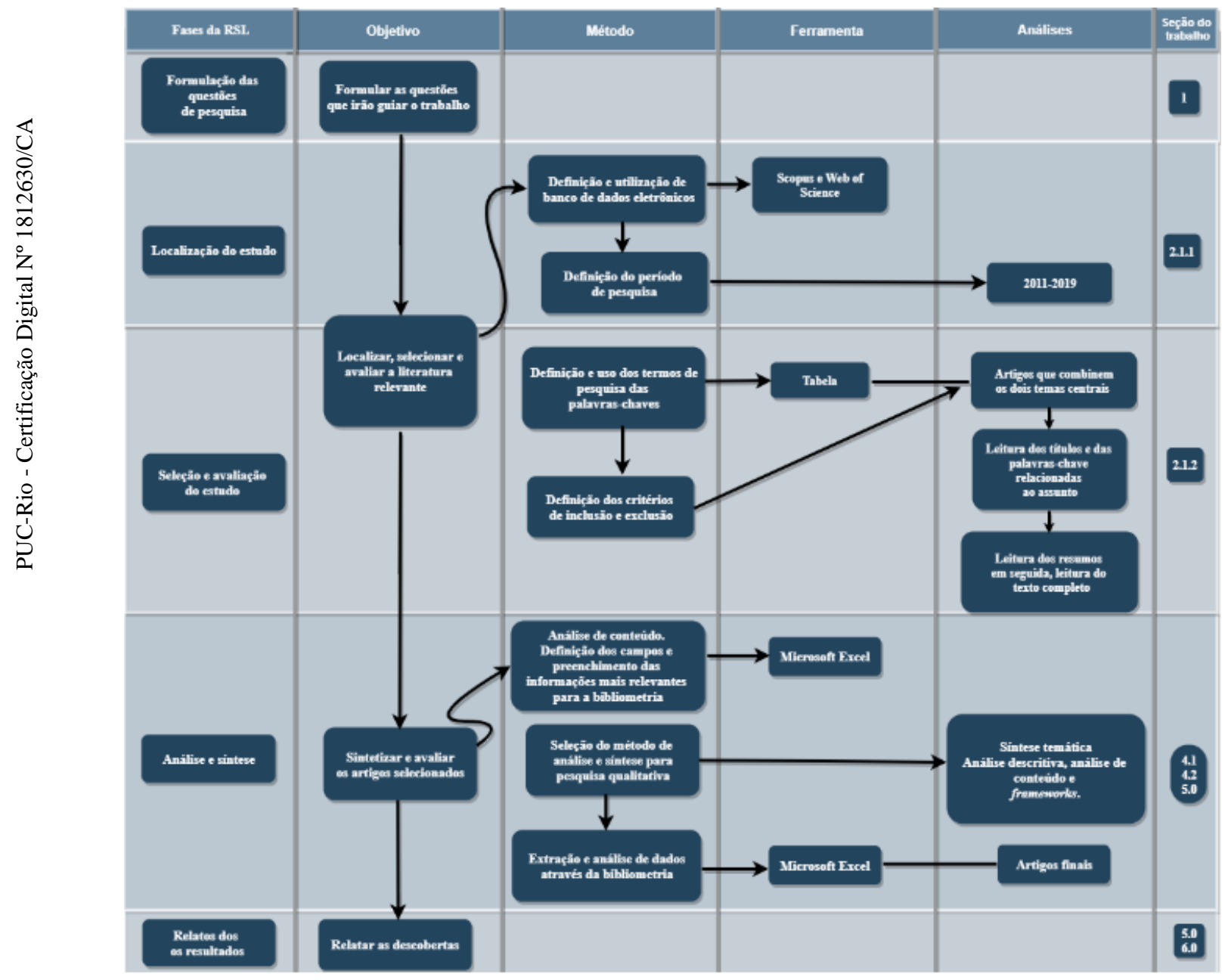

Figura 2: Resumo das fases RSL Fonte: Adaptado de Garza-Reyes (2015) e Saieg et al.(2018) 


\subsubsection{Formulação das questões de pesquisa}

O primeiro capítulo desta dissertação apresenta a caracterização do problema de pesquisa, a lacuna na literatura, os objetivos e perguntas de pesquisa.

\subsubsection{Localização do estudo}

Os bancos de dados selecionados para o presente trabalho foram Scopus e Web of Science, pois eles possuem uma ampla cobertura, abrangência de periódicos e são complementares (THOMÉ et al., 2016; MAGON et al., 2018). Embora o uso de múltiplos bancos de dados possa gerar uma grande quantidade de artigos duplicados, isto aumenta a chance de se obter um amplo conjunto de estudos que devem ser considerados para representar o que está disponível na literatura, uma vez que não existe um banco de dados único que contemple todos os artigos de um determinado assunto (SAIEG et al., 2018).

De acordo com Siddaway (2014), os termos de pesquisa operacionalizam as questões de pesquisa e ajudam a encontrar uma quantidade significante de artigos potencialmente relevantes para o trabalho. Em relação às palavras-chave, elas devem ser suficientemente amplas para não restringir artificialmente o número de estudos, mas específicas suficientemente para trazer apenas os estudos relacionado aos temas selecionados (COOPER, 2010; THOMÉ et al., 2016). O termo de pesquisa foi definido usando operadores booleanos "and" e "or" conforme explicado na tabela 1. 
Tabela 1: Termo de pesquisa

\begin{tabular}{ll}
\hline Banco de dados & Palavras-chave \\
\hline & \\
& TITLE-ABS-KEY ( "Industry 4.0" OR "machine learning" OR \\
& "additive manufacturing" OR "3D print*" OR "big data" OR "IoT" \\
& OR "augmented reality" OR "smart manufacturing" OR "cloud \\
& manufacturing" OR "cloud computing" OR "advanced robotics" OR \\
& "smart factory" OR "Cyber-physical Systems" ) AND TITLE-ABS- \\
& KEY ( "Lean approach" OR "Lean process" OR "Lean methodology" \\
& OR "Lean method" OR "Lean transformation" OR "Lean philosophy" \\
& OR "Lean principles" OR "Lean practices" OR "Lean process \\
& improvement" OR "Lean theory" OR "Lean management"' OR "Lean \\
thinking" OR "Lean production" OR "Lean manufacturing" OR "Lean & \\
& service" OR "Six Sigma" OR "Lean Six Sigma" OR "Toyota \\
& management system" OR "kaizen" OR "value stream mapping" OR \\
& "Lean sigma" OR "Lean technologies" OR "lean automation" )
\end{tabular}

$\mathrm{TS}=($ "Industry 4.0" OR "machine learning" OR "additive manufacturing" OR "3D print*" OR "big data" OR "IoT" OR "augmented reality" OR "smart manufacturing" OR "cloud manufacturing" OR "cloud computing" OR "advanced robotics" OR "smart factory" OR "CyberWEB physical Systems" ) AND TS=( "Lean approach" OR "Lean process" OR OF "Lean methodology" OR "Lean method" OR "Lean transformation" OR SCIENCE "Lean philosophy" OR "Lean principles" OR "Lean practices" OR "Lean process improvement" OR "Lean theory" OR "Lean management"' OR "Lean thinking" OR "Lean production" OR "Lean manufacturing" OR "Lean service" OR "Six Sigma" OR "Lean Six Sigma" OR "Toyota management system" OR "kaizen" OR "value stream mapping" OR "Lean sigma" OR "Lean technologies" OR "lean automation" )

\subsubsection{Seleção e avaliação do estudo}

Foram aplicados alguns filtros para limitar a pesquisa. Primeiro: foram selecionados apenas artigos a partir de 2011, ano de surgimento da I4.0, até o ano de 2019. Segundo: foram selecionados artigos apenas de periódicos científicos. Através da seleção apenas de artigos revisados por pares obtém-se fontes mais úteis e confiáveis para revisões de literatura (SAUNDERS et al., 2012). Terceiro: foram selecionados apenas artigos de língua inglesa. Por fim, foram selecionados documentos do tipo Article, Article in press e Review. 
Para a seleção dos artigos foram seguidas três etapas. A primeira é a união das duas primeiras etapas de Siddaway (2014). Para ele, primeiro deve-se ler o título e as palavras-chave. Segundo, ler o resumo. Os artigos incluídos e os excluídos devem se basear nos critérios definidos pelo pesquisador. Para este trabalho, os artigos deviam abordar de forma detalhada os temas estudados, LM e I4.0. Por fim, a leitura do texto completo com extração das informações relevantes. A figura 3apresenta o número final de artigos selecionados de acordo com as etapas de seleção.

\section{$N=156(104+69)$}

Retirada dos artigos duplicados

\section{$N=107$}

Filtro realizado através do título, palavras-chave e resumo

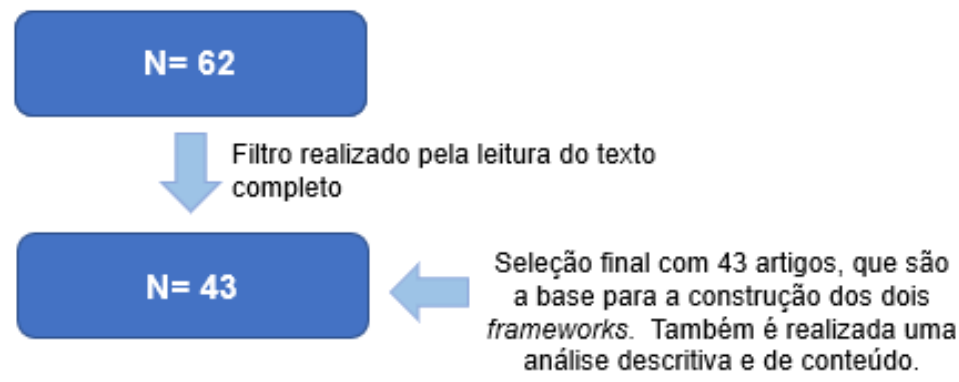

Figura 3: Etapas da seleção dos artigos

Ao final, para a deste trabalho foram utilizados como base apenas 43 artigos. A seleção deles se baseia no fato de abordarem, paralelamente, os temas centrais desse trabalho, LM e I4.0. Artigos que não abordavam os dois temas em conjunto foram descartados. Esses artigos são utilizados para a realização de uma análise descritiva, uma análise de conteúdo e, também, para a construção dos dois frameworks. A lista final dos artigos selecionados encontra-se no capítulo 4.

\subsubsection{Análise e síntese}

A pesquisa utilizou a técnica de análise de conteúdo (SEURING; GOLD, 2012). A primeira categoria analisada foi a de Procedimento Metodológico. Os artigos foram 
classificados de acordo com Farias et al.(2019). Este autor classificou sua pesquisa em survey, estudo de caso, revisão da literatura, pesquisa-ação e, modelagem e simulação. A segunda categoria apresentada foi a de Fatores Críticos de Sucesso. Estes são usados para que a empresa concentre sua atenção em questões organizacionais que são vitais para ela (BOYNTON; ZMUD, 1984). A terceira categoria abrange as Barreiras e os Desafios. As barreiras podem ser encontradas após as empresas implementarem uma nova tecnologia, como a I4.0 (TÜRKES et al., 2019). No caso deste estudo, as barreiras estão relacionadas à implementação conjunta do LM e da I4.0. Os desafios são questões que podem atrapalhar a implementação de algo novo para a empresa, por exemplo, o LM e a identificação precoce de pontos fracos que fazcom que a organização esteja mais bem preparada para novas tecnologias (RYMASZEWSKA, 2014). Por fim, a última categoria estudada foram os Aspectos Sociais e Econômicos do alinhamento LM com I4.0. Essa categoria apresenta as questões sociais e econômicas derivadas do alinhamento LM com a I4.0.

\subsubsection{Relato dos resultados}

Os resultados da RSL, assim como análises e discussões, são apresentados nos próximos capítulos deste trabalho.

\subsection{Painel com especialistas}

O modelo de pesquisa escolhido para aperfeiçoar e realizar uma primeira validação dos dois frameworksfoi um Painel. O Painel foi realizado com seis especialistas brasileiros e estrangeiros dos dois temas estudados, LM e I4.0.Esse modelo de pesquisa é recomendado por diversos estudiosos (e.g., ALFALLA-LUQUEet al., 2015; FERREIRAet al., 2018). O Painel consistiu com entrevistas interativas e sequenciais estruturadas com os especialistas, porém todos possuíam a liberdade de dar suas opiniões, livremente. Após cada entrevista, os frameworks eram validados e redesenhados para serem apresentados ao próximo entrevistado. A tabela 2 sintetiza os perfis dos entrevistados, bem como suas características e o tempo que cadaentrevista durou. 
Tabela 2: Perfil dos entrevistados

\begin{tabular}{llcccc}
\hline ID & \multicolumn{1}{c}{ Cargo } & País & $\begin{array}{c}\text { Tempo de } \\
\text { experiência } \\
\text { em LM }\end{array}$ & $\begin{array}{c}\text { Tempo de } \\
\text { experiência } \\
\text { em I4.0 }\end{array}$ & $\begin{array}{c}\text { Tempo de } \\
\text { entrevista } \\
\text { (horas) }\end{array}$ \\
\hline 1 & Pesquisador científico & Brasil & 15 anos & 2 anos & $1: 20$ \\
\hline 2 & Consultor Científico & Brasil & 6 anos & 2 anos & $1: 15$ \\
\hline 3 & $\begin{array}{l}\text { Pesquisadorem Sistemas de } \\
\text { Informação }\end{array}$ & Alemanha & 10 anos & 3 anos & $1: 30$ \\
\hline $\begin{array}{l}\text { Consultor Científico e } \\
\text { Tecnológico/Desenvolvedor } \\
\text { de softwares }\end{array}$ & Brasil & 5 anos & 5 anos & $1: 04$ \\
\hline 5 & $\begin{array}{l}\text { Professor Universitário e } \\
\text { Consultor }\end{array}$ & Alemanha & 15 anos & 5 anos & $1: 22$ \\
\hline $\begin{array}{l}\text { Professor Universitário e } \\
\text { Coordenador de Pesquisa e } \\
\text { Desenvolvimento }\end{array}$ & Brasil & 14 anos & 8 anos & $1: 43$ \\
\hline
\end{tabular}

Duas rodadas de entrevista foram realizadas. Esta parte da metodologia seguiu Mason (2002) para a condução de entrevistas. As entrevistas foram conduzidas baseadas em um questionário apresentado no Apêndice I.A segunda rodada teve o objetivo de validar as alterações realizadas durante a primeira rodada. As duas rodadas contaram com as mesmas pessoas. Em cada uma das duas etapas, cada integrante podia emitir sua opinião pessoal, complementando, assim, o trabalho inicial.

A primeira rodada de entrevistas foi baseada na apresentação dos dois frameworks propostos e na coleta de informações/opiniões dos profissionais participantes. A cada entrevista o ponto de vista do participante antecessor era citado para o entrevistado do momento. O objetivo era confrontar, desde o começo, as diversas opiniões acerca do assunto. Ao final da primeira rodada, as reflexões recebidas foramanalisadas e os frameworks foram adaptados. Os pontos que possuíam grande influência no processo, são discutidos e detalhados no capítulo 5.

A segunda rodada do Painel com Especialistas teve o objetivo de apresentar os novos frameworks, detalhando todas as mudanças realizadas e explicando a motivação delas. Novamente, as opiniões foram coletadas para validar uma versão final após essa segunda rodada. 


\section{Conceituação e sinergia entre Lean Manufacturing e Indústria 4.0}

O presente capítulo apresenta conceitos teóricos relacionados ao tema da pesquisa. Primeiramente, é apresentado Lean Manufacturing, em seguida Indústria 4.0. O capítulo finaliza com a integração entre esses dois conceitos.

\subsection{Lean Manufacturing}

Ao longo de todas as revoluções industriais, as indústrias vêm acrescentando mais inovações tecnológicas. As indústrias japonesas elaboraram um método focado no cliente chamado lean manufacturing (LM) que foca na eliminação de todos os tipos de desperdícios do processo produtivo, identificando qualquer atividade desnecessária, agilizando o processo e criando rotinas padronizadas (SANDERS et al., 2016; BUER et al., 2018a).

A empresa Toyota Motor Corporation conseguiu implementar LM com sucesso, gerando ganhos de produtividade e diminuição de desperdícios (SANDERS et al., 2016).LM também é conhecido como lean thinking, e é umas das estratégias mais amplamente utilizadas nas últimas três décadas (SONY, 2018). Veza et al. (2016) destacam que LM tem por objetivo a melhoria contínua, também conhecida como kaizen.

LM envolve mudanças nas práticas de gerencimentodos processos produtivos, em seus diversos estágios e níveis. De acordo com Lugert et al. (2018), o LMtenta reduzir desperdícios e simplificar os processos industriais e uma de suas estratégias é a minimização da complexidade que poderia ser gerada pelo uso de tecnologias da informação. Ao se mencionar desperdícios, há sete tipos que devem ser identificados 
pelas empresas, são eles: de superprodução, de tempo de espera, de transporte, de processamento, de estoque, de movimentação e de produtos defeituosos (OHNO,1988).

Segundo Pogačnik et al. (2017), há dois segmentos chaves para que uma empresa comece a introduzir LM, são eles: entender o que representa o valor agregado para o cliente e criar esse valor agregado. LM é fundamentado na resolução de problemas, que foca em melhoria contínua e inovação para que se possa criar valor para os clientes (BELL;BELL,2016).

Uma forma de alcançar os objetivos que o LM almeja é mapeando bem o seus conceitos. Shah e Ward (2007) chegaram a 10 fatores que conseguem mapear olean, são eles:

1. Feedback ao fornecedor: proporcionar, regularmente, aos fornecedores um feedback sobre o seu desempenho;

2. Entrega Just-In-Time (JIT) pelos fornecedores: tem por objetivo assegurar que os fornecedores entregarão apenas a quantidade certa, no momento certo e no lugar certo;

3. Desenvolvimento de fornecedores: tem por objetivo desenvolvê-los para que possam estar mais envolvidos no processo de produção e, assim, evitar possíveis erros;

4. Envolvimento do cliente: focar nas necessidades e expectativas dos clientes;

5. Produção puxada $(P U L L)$ : visa facilitar a produção JIT, utilizando os cartões kanban, que servem como um sinal para iniciar ou parar a produção;

6. Fluxo Contínuo: instalar mecanismos que possam permitir e facilitar o fluxo contínuo de produtos;

7. Redução do tempo de troca ( et up): visa reduzir o tempo de troca entre as variações de produtos;

8. Manutenção produtiva / preventiva total: as falhas devem ser evitadas com manutenção periódica. Caso ocorra alguma falha, esta deve ser consertada no menor tempo possível;

9. Controle estatístico de processo: garantir que cada processo fornecerá produtos livres de defeitos ao processo subsequente;

10. Envolvimento dos funcionários: eles devem ser capacitados e motivados para a resolução de problemas. 
LM possui diversas práticas que o auxiliam a alcançar o objetivo de reduzir os desperdícios. A tabela 3 lista algumas dessas práticas.

Tabela 3: Práticas LM

\begin{tabular}{|c|c|c|}
\hline Nome & Descrição & Referências \\
\hline Kanban & $\begin{array}{l}\text { É um sinal usado na produção puxada, } \\
\text { indicandopara a estação de trabalho que ela deve } \\
\text { fornecer material para outra a downstream do } \\
\text { processo(BUER } \text { et al., 2018b). }\end{array}$ & $\begin{array}{l}\text { Tortorella et al., 2019b } \\
\text { Pereira } \text { et al., } 2019 \\
\text { Li, } 2019 \\
\text { Pagliosa } \text { et al., } 2019 \\
\text { Rosin } \text { et al.,2019 } \\
\text { Huang } \text { et al., } 2019 \\
\text { Kamble } \text { et al., } 2019 \\
\text { Pekarčíková } \text { et al., } 2019 \\
\text { Rossini } \text { et al., } 2019 \\
\text { Zhang } \text { et al., } 2019 \\
\text { Ante } \text { et al., } 2018 \\
\text { Buer } \text { et al., 2018a } \\
\text { Buer } \text { et al., 2018b } \\
\text { Lugert } \text { et al., } 2018 \\
\text { Sony, 2018 } \\
\text { Tortorella e Fettermann, } 2018 \\
\text { Davies } \text { et al., } 2017 \\
\text { Kolberg } \text { et al., } 2017 \\
\text { Ma } \text { et al., 2017 } \\
\text { Oliveira } \text { et al., } 2017 \\
\text { Sahin } \text { et al., } 2017 \\
\text { Tezel e Aziz, } 2017 \\
\text { Dave et al., } 2016 \\
\text { Lee } \text { et al., 2016 } \\
\text { Sanders } \text { et al., } 2016\end{array}$ \\
\hline $\begin{array}{l}\text { Jidoka } \\
\text { (automatização) }\end{array}$ & $\begin{array}{l}\text { Um dos dois pilares LM, é responsável pela } \\
\text { implementação de algumas funções de } \\
\text { supervisão em vez de funções de produção; } \\
\text { estas funções param as máquinas se surgir uma } \\
\text { situação anormal e o trabalhador irá parar a } \\
\text { linha de produção (MA et al., } \\
\text { 2017;OHNO,1988). }\end{array}$ & $\begin{array}{l}\text { Pereira } \text { et al., } 2019 \\
\text { Li, } 2019 \\
\text { Pagliosa } \text { et al., } 2019 \\
\text { Rosin } \text { et al.,2019 } \\
\text { Pekarčíková } \text { et al., } 2019 \\
\text { Buer } \text { et al., 2018a } \\
\text { Lugert } \text { et al, } 2018 \\
\text { Sony, } 2018 \\
\text { Ma } \text { et al., } 2017 \\
\text { Veza } \text { et al., } 2016 \\
\end{array}$ \\
\hline Andon & $\begin{array}{l}\text { Cada estação de trabalho possui um botão que } \\
\text { ilumina uma lâmpada. Quando o empregado } \\
\text { encontra um problema, ele para a linha de } \\
\text { produção e aciona o botão para sinalizar a } \\
\text { interrupção e, assim, os engenheiros notarão e } \\
\text { irão solucionar o defeito (BAMBER;DALE, } \\
\text { 2000). }\end{array}$ & $\begin{array}{l}\text { Pereira } \text { et al., } 2019 \\
\text { Li, } 2019 \\
\text { Pagliosa } \text { et al., } 2019 \\
\text { Rosin } \text { et al.,2019 } \\
\text { Buer } \text { et al., } 2018 \mathrm{a} \\
\text { Tezel e Aziz,2017 } \\
\text { Ma } \text { et al.,2017 } \\
\text { Oliveira } \text { et al.,2017 } \\
\text { Dave } \text { et al., } 2016\end{array}$ \\
\hline
\end{tabular}




\begin{tabular}{|c|c|c|}
\hline Nome & Descrição & Referências \\
\hline JIT & $\begin{array}{l}\text { É o outro pilar LM e é a prática lean mais } \\
\text { comum, que baseada no tempo e procura } \\
\text { realizar a entrega de um material ou produto o } \\
\text { mais próximo possível do padrão exigido pela } \\
\text { demanda(OHNO,1988; ZHANG et al., 2019). É } \\
\text { uma medida comum para reduzir o lead time da } \\
\text { produção (KAMBLE } \text { et al., 2019). }\end{array}$ & $\begin{array}{l}\text { Pereira } \text { et al., } 2019 \\
\text { Li, } 2019 \\
\text { Hotrawaisaya } \text { et al., } 2019 \\
\text { Tortorella } \text { et al., } 2019 \mathrm{~b} \\
\text { Pagliosa } \text { et al., } 2019 \\
\text { Rosin } \text { et al.,2019 } \\
\text { Kamble } \text { et al., } 2019 \\
\text { Pekarčíková et al., } 2019 \\
\text { Rossini } \text { et al., 2019 } \\
\text { Tortorella } \text { et al., } 2019 \mathrm{a} \\
\text { Zhang } \text { et al., } 2019 \\
\text { Buer } \text { et al., 2018a } \\
\text { Sony, 2018 } \\
\text { Tortorella e Fettermann, } 2018 \\
\text { Chen e Lin, } 2017 \\
\text { Ma } \text { et al., 2017 } \\
\text { Sahin } \text { et al., } 2017 \\
\text { Tezel e Aziz, } 2017 \\
\text { Veza } \text { et al., } 2016 \\
\text { Sanders } \text { et al., } 2016\end{array}$ \\
\hline $\begin{array}{l}\text { Mapeamento do } \\
\text { fluxo de valor } \\
\text { (Value Stream } \\
\text { Mapping - } \\
\text { VSM) }\end{array}$ & $\begin{array}{l}\text { LM começa a ser implementado a partir da } \\
\text { análise da situação atual, classificando as } \\
\text { atividades que agregam e as que não agregam } \\
\text { valor ao produto, desenhando uma situação } \\
\text { futura e o VSM é umas das formas mais } \\
\text { eficientes de se fazer essa classificação } \\
\text { (CAMGÖZ-AKDAĞ et al., 2018). }\end{array}$ & $\begin{array}{l}\text { Pereira et al., } 2019 \\
\text { Pagliosa } \text { et al., } 2019 \\
\text { Rosin } \text { et al.,2019 } \\
\text { Huang } \text { et al., } 2019 \\
\text { Kamble } \text { et al., } 2019 \\
\text { Ante } \text { et al., } 2018 \\
\text { Buer } \text { et al., 2018a } \\
\text { Camgöz-Akdağ } \text { et al., } 2018 \\
\text { Sony, } 2018 \\
\text { Lugert } \text { et al., } 2018 \\
\text { Chen, 2017 } \\
\text { Davies } \text { et al., } 2017 \\
\text { Oliveira } \text { et al., } 2017 \\
\text { Pogačnik } \text { et al., } 2017 \\
\text { Bell e Bell, } 2016 \\
\text { Veza } \text { et al., } 2016\end{array}$ \\
\hline Heijunka board & $\begin{array}{l}\text { Sua função é controlar a variabilidade da } \\
\text { chegada de trabalho para permitir uma maior } \\
\text { utilização da capacidade produtiva da indústria } \\
\text { (HÜTTMEIR et al., 2009). }\end{array}$ & $\begin{array}{l}\text { Pereira et al., } 2019 \\
\text { Pagliosa } \text { et al., } 2019 \\
\text { Rosin } \text { et al.,2019 } \\
\text { Huang } \text { et al., } 2019 \\
\text { Pekarćíková } \text { et al.., } 2019 \\
\text { Ante } \text { et al., } 2018 \\
\text { Buer } \text { et al., } 2018 \text { a } \\
\text { Kolberg } \text { et al., } 2017 \\
\text { Ma } \text { et al., 2017 } \\
\text { Tezel e Aziz, } 2017 \\
\text { Veza } \text { et al., } 2016\end{array}$ \\
\hline
\end{tabular}




\begin{tabular}{|c|c|c|}
\hline Nome & Descrição & Referências \\
\hline $5 \mathrm{~S}$ & $\begin{array}{l}\text { Significam seiri, seiton, seiso, seiketsu e } \\
\text { shisuke. São cinco etapas precisas para ter uma } \\
\text { área limpa e em ordem: primeiro se classificam } \\
\text { os itens em necessários e desnecessários; } \\
\text { segundo deve-se colocar-los em ordem, cada } \\
\text { objeto em seu devido lugar; terceiro, realizar a } \\
\text { limpeza do locar de trabalho; quarto passo é a } \\
\text { padronização das três primeiras etapas; e, por } \\
\text { fim, sustentar, fazendo do 5S uma parte da sua } \\
\text { rotina (CHIARINI, 2011). }\end{array}$ & $\begin{array}{l}\text { Pagliosa et al., } 2019 \\
\text { Rosin et al.,2019 } \\
\text { Pekarćíková et al., } 2019 \\
\text { Zhang } \text { et al., } 2019 \\
\text { Buer } \text { et al., 2018a } \\
\text { Sony, 2018 } \\
\text { Chen e Lin, } 2017 \\
\text { Tezel e Aziz, } 2017 \\
\text { Oliveira } \text { et al., } 2017 \\
\text { Veza } \text { et al., } 2016\end{array}$ \\
\hline Poka-Yoke & $\begin{array}{l}\text { É um dispositivo que possui a capacidade de } \\
\text { detectar ou de prevenir anormalidades, que } \\
\text { podem ser prejudiciais para a qualidade do } \\
\text { produto ou para a saúde/segurança dos } \\
\text { empregados (SAURIN et al., 2012). }\end{array}$ & $\begin{array}{l}\text { Li, } 2019 \\
\text { Pagliosa } \text { et al., } 2019 \\
\text { Buer } \text { et al., 2018a } \\
\text { Tezel e Aziz, } 2017 \\
\text { Ma } \text { et al., } 2017 \\
\text { Veza } \text { et al., } 2016\end{array}$ \\
\hline
\end{tabular}

Além dos fatores que mapeiam o LM e das suas práticas, pode-se afirmar que o lean é baseado em cinco princípios. De acordo com Womack e Jones (1996), eles são:

1. Identificar o valor aos olhos do consumidor: produto desejado e definições de preço e tempo devem ser estabelecidas;

2. Identificar e mapear o fluxo de valor: para cada produto e/ou família de produto deve-se eliminar as etapas desnecessárias. Esse princípio engloba a fabricação e até a entrega do produto;

3. Criar um fluxo: seguir o passo a passo do fluxo para que não haja espera ou inatividade entre as etapas;

4. Demanda baseada no cliente: projetar e fornecer o que o cliente deseja apenas quando ele quer;

5. Buscar a perfeição: melhorar continuadamente, entregando valor para o cliente.

Posteriormente, surgiu o conceito de six sigma (SS), originalmente criado pela Motorola. Este é o mecanismo ideal para a identificação e eliminação de variabilidade em ambientes produtivos controlados (SAIDI; SOULHI, 2018). De acordo com Davies et al. (2017), o SS é uma metodologia estruturada de resolução de problemas baseada no DMAIC (Definir, Medir, Analisar, Melhorar, Controlar), procedimento que é implementado por fases. 
O SS também é focado no cliente, tem como base o uso de análises estatísticas e, com isso, consegue melhorar a satisfação dos clientes, reduzir a taxa de feitos e o tempo de ciclo (LAUX et al., 2017). Deve-se destacar que as empresas passaram a unir os conceitos de six sigmas e lean manufacturing, formando, assim, o Lean Six Sigma (LSS), com o intuito de obterem maiores benefícios, como otimizar processos. Ao integrar essas duas metodologias, o LSS incluirá a rapidez do LM, através do fluxo de processos, e a robustez do SS, através de uma abordagem disciplinada e sistemática para a resolução de problemas(ANTONY et al., 2018).

Por fim, nos anos 90, quando uma nova tecnologia eraadicionada ao LM essa união passou a receber o nome de lean automation (ROSSINI et al., 2019). Através dessa mudança, as soluções de problemas e os esforços com integrações menores puderamser realizados (KOLBERG et al., 2016).

Resumindo, a adoção das práticas LM compreende um conjunto de tecnologias em que suas abordagens primam pela simplicidade e efetividade (TORTORELLA; FETTERMANN, 2017). Novas tecnologias surgem a todo momento e,com isso, as

empresas estão vivendo a quarta revolução industrial, ou Indústria 4.0, que será discutida na próxima seção.

\subsection{Indústria 4.0}

Atualmente, as empresas estão vivenciando a quarta revolução industrial, ou Indústria 4.0 (I4.0). O termo "Indústria 4.0" foi criado em 2011 na feira de Hannover, na Alemanha e apoia a transição das indústrias atuais para cenários mais digitalizados, cujas principais características compreendem máquinas conectadas, produtos e sistemas inteligentes e soluções inter-relacionadas (TORTORELLA; FETTERMANN,2017; LUGERT et al.,2018). Devido ao seu surgimento, empresas vêm se esforçando para obter desempenho superior ao avançar os níveis de automação e interconectividade (TORTORELLA et al., 2019b).A figura 4sintetiza a evolução das quatro revoluções: 


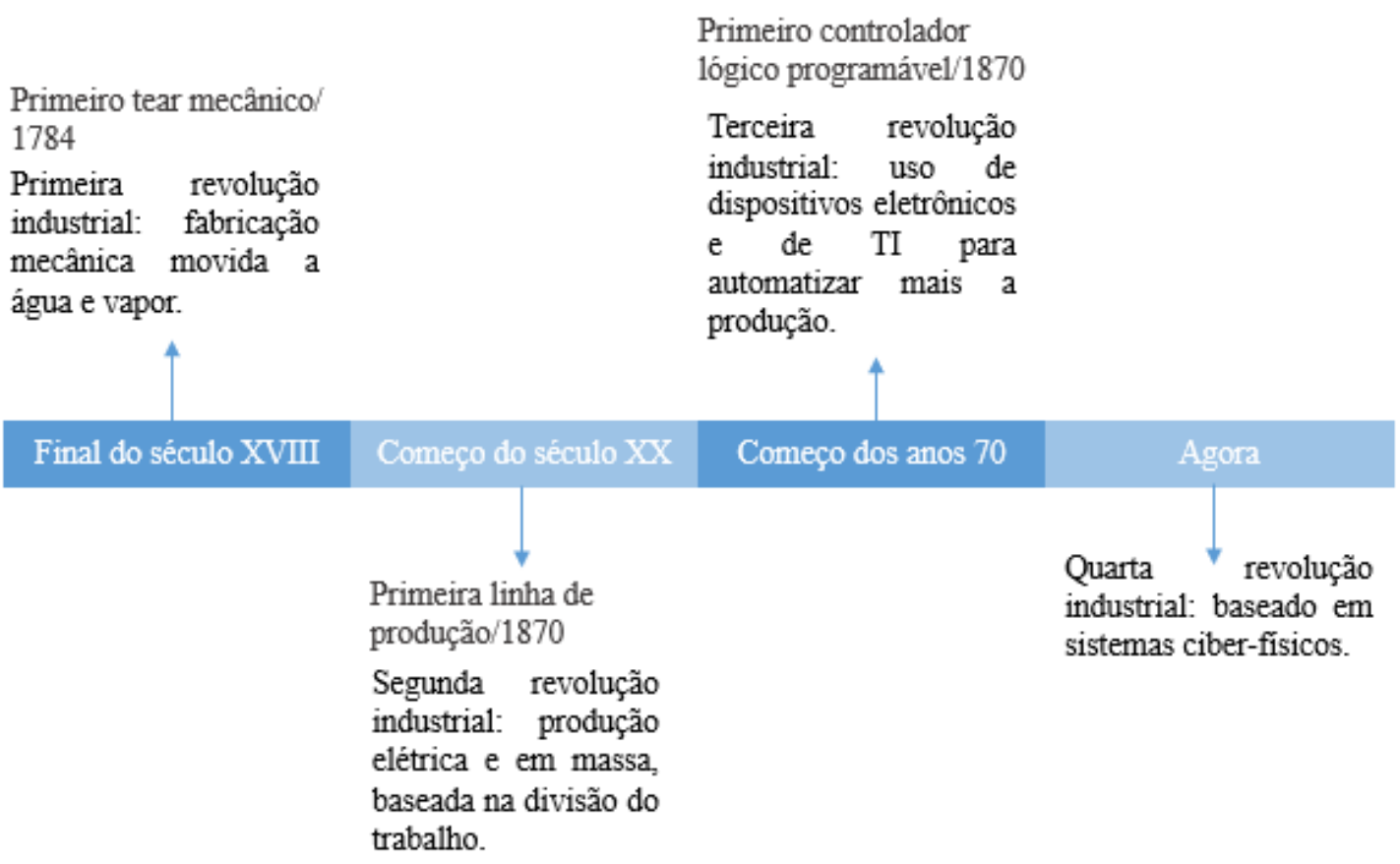

Figura 4: Evolução das Revoluções Industriais Fonte: Adaptado de Kagermann et al. (2013)

O termo I4.0 pode ser definido de diversas formas, conforme apresentado na tabela 4:

Tabela 4: Definições da I4.0

\begin{tabular}{ll}
\hline \multicolumn{1}{c}{ Definição } & \multicolumn{1}{c}{ Autor } \\
\hline $\begin{array}{l}\text { Éuma revolução em que suas tecnologias podem ser usadas para encontrar } \\
\text { diferentes níveis de autonomia da empresa ou soluções de capacidade, dependendo } \\
\text { das necessidades. }\end{array}$ & $\begin{array}{l}\text { ROSIN } \text { et al., } \\
2019\end{array}$ \\
\hline $\begin{array}{l}\text { É uma mudança de paradigma de um ciclo de produto centrado no cliente para um } \\
\text { ciclo de experiência centrado no cliente e é envolvido em todo o ciclo de vida do } \\
\text { produto desde a concepção até o feedback pós-compra em que a experiência vivida } \\
\text { por ele torna-se fundamental para o sucesso das empresas. }\end{array}$ & ARCIDIACON; \\
\hline $\begin{array}{l}\text { É definida por através do uso de produtos e processosinteligentes que permitem a } \\
\text { coleta e a análise de dados autônomos, a interação entre produtos, processos, } \\
\text { fornecedores e clientes, através da internet. }\end{array}$ & $\begin{array}{l}\text { BUER } \text { et } \\
\text { al.,2018a }\end{array}$ \\
\hline $\begin{array}{l}\text { É uma visão de fábricas inteligentemente automatizadas nas quais trabalhadores, o } \\
\text { sistema produtivo e os clientes estão conectados e por estarem ligados, todos irão } \\
\text { cooperar estreitamente. }\end{array}$ & $\begin{array}{l}\text { KARRE } \text { et al., } \\
\text { 2017 }\end{array}$ \\
\hline $\begin{array}{l}\text { É a união de pessoas e máquinas digitalmente com a internet e a tecnologia da } \\
\text { informação, conectando sensores que observam as funções dos equipamentos em } \\
\text { tempo real. }\end{array}$ & $\begin{array}{l}\text { OLIVEIRA et } \\
\text { al., 2017 }\end{array}$ \\
\hline $\begin{array}{l}\text { É uma revolução em que os serviços dinâmicos e os processos de engenharia } \\
\text { permitem mudanças de última hora na produção e fazem com que a capacidade de } \\
\text { responder a interrupções e falhas sejam mais flexíveis. }\end{array}$ & $\begin{array}{l}\text { VEZA } \text { et al., } \\
\text { 2016 }\end{array}$ \\
\hline
\end{tabular}


Podemos definir a I4.0 como uma revolução em que as pessoas, os produtos e os processos estão conectados à internet de forma inteligente e autonôma com isso, os dados são analisados em tempo real conferindo robustez ao sistema e garantindo melhores decisões gerenciais para as empresas. As empresas sempre visam garantir um bom desempenho financeiro e operacional e isso está se tornando a principal razão para a implementação da I4.0(HOTRAWAISAYA et al., 2019). Através da I4.0 os processos se tornam mais rápidos e mais eficientes com a agregação e a análise de dados a partir de máquinas, permitindo, assim, tomar decisões eficazes e otimizadas, e como produto final têm-se uma mercadoria de qualidade superior e com menor custo (LI, 2019).

O marco da chegada da I4.0 é o uso de diversas tecnologias disruptivas existentes e é acompanhada do rápido desenvolvimento das informações e da comunicação (ZHENG et al., 2018). Segundo Arcidiacono e Pieroni (2018), o resultado dessa revolução pode ser um objeto, mas também um serviço projetado para um consumidor final, cujo desenvolvimento foi impulsionado pela inovação em diversas áreas que, combinadas, entregam sistemas mais complexos.

A I4.0 é marcada pela integração e há três tipos possíveis: horizontal, vertical e engenharia de ponta a ponta. Detalhando cada uma, têm-se:

- Integração horizontal: visa uma melhor integração entre clientes e fornecedores ao longo da cadeia de valor e em que os usuários poderão acompanhar cada passo do seu produto encomendado (FOIDL;FELDERER, 2016);

- Integração vertical: realiza a integração de vários subsistemas hierárquicos dentro da organização para criar um sistema de manufatura flexível e reconfigurável, resultando em máquinas que se configuram autonomamente para se adaptar a diferentes produtos (SONY, 2018);

- Engenharia de ponta a ponta: é a interligação de todas as partes interessadas com os produtos e equipamentos ao longo do ciclo de vida do produto, ocorre uma integração digital entre toda a cadeia de valor (STOCK;SELIGER,2016; KAGERMANN et al., 2013). 
Deve-se ressaltar que a implementação da integração horizontal e vertical pela I4.0 permite uma melhor integração de clientes e fornecedores no processo (DOMBROWSKI et al., 2017).

A I4.0 exige uma alta velocidade e uma grande capacidade de processamento de dados, altos níveis de digitalização em todos os processos da empresa; isso é apoiado pelas suas diversas tecnologias (VARELA et al., 2019). Porém, I4.0 possui dois componentes-chaves: sistemas ciber-físicos (cyber physical system - CPS) e internetdas coisas (internet of things- IoT); ambos permitem uma autonomia que, normalmente, não é encontrada em sistemas TIC tradicionais e centralizados (Buer et al.,2018a).

Frank et al. (2019) basearam sua pesquisa em quatro tecnologias básicas da I4.0: Internet of Things (IoT), cloud computing, biga data e tecnologias de análises. A IoT é um caso especial do CPS, segundo Davies et al.(2017). Logo, este trabalho substituiu a IoT por CPS na seleção das tecnologias a serem estudadas. As análises podem ser feitas, por exemplo, com o auxílio de tecnologias, como o Machine Learning (AHUETTGARZA; KURFESS, 2018; FRANK et al.,2019). Com isso, decidiu-se por estudar mais profundamente a tecnologia Machine Learning em relação às análises.

Kamble et al. (2018) detalharam, em sua pesquisa, uma gama maior de tecnologias, tais como: IoT, big data, cloud, simulações e protótipos, impressão 3D, realidade aumentada, sistemas robóticos e cyber-security. Algumas delas já foram citadas e selecionadas anteriormente. As tecnologias de sistemas robóticos e simulações e protótipos foram menos mencionadas dentro desta pesquisa por isso, não foram selecionadas. Com isso, a tabela 5 apresenta a listagem final das tecnologias da I4.0 que foram estudadas neste trabalho. 
Tabela 5: Tecnologias da I4.0

\begin{tabular}{|c|c|c|}
\hline Nome & Descrição & Referências \\
\hline CPS & $\begin{array}{l}\text { É uma rede de sensores fisicamente distribuídos e } \\
\text { embutidos em máquinas e equipados com um sistema } \\
\text { de computação. Resumindo, ele faz a ligação entre o } \\
\text { meio físico e o virtual que, juntos, criam um mundo } \\
\text { conectado no qual objetos inteligentes se comunicam } \\
\text { e integram-se uns com os outros. As características } \\
\text { dele envolvem transparência e interoperabilidade } \\
\text { ( KARGEMANN et al.,2013;CHEN,2017; } \\
\text { MA et al., 2017). }\end{array}$ & $\begin{array}{l}\text { Pereira } \text { et al., } 2019 \\
\text { Li, } 2019 \\
\text { Kipper } \text { et al., } 2019 \\
\text { Pagliosa } \text { et al., } 2019 \\
\text { Rosin } \text { et al., } 2019 \\
\text { Huang } \text { et al., } 2019 \\
\text { Kamble } \text { et al., } 2019 \\
\text { Rossini } \text { et al., } 2019 \\
\text { Tortorella } \text { et al., 2019a } \\
\text { Tortorella } \text { et al., 2019b } \\
\text { Buer } \text { et al., 2018a } \\
\text { Buer } \text { et al., 2018b } \\
\text { Lugert } \text { et al., } 2018 \\
\text { Sony, 2018 } \\
\text { Tortorella e Fettermann, } \\
\text { 2018 } \\
\text { Chen, 2017 } \\
\text { Chen e Lin, } 2017 \\
\text { Davies } \text { et al., } 2017 \\
\text { Dombrowski } \text { et al., } 2017 \\
\text { Kolberg } \text { et al., } 2017 \\
\text { Ma } \text { et al., 2017 } \\
\text { Müller } \text { et al., } 2017 \\
\text { Sanders } \text { et al., } 2016 \\
\text { Veza } \text { et al., } 2016\end{array}$ \\
\hline Cyber-security & $\begin{array}{l}\text { A necessidade de proteger sistemas industriais } \\
\text { críticos e linhas de fabricação de ameaças de } \\
\text { segurança cibernética aumentou. É necessária uma } \\
\text { rede de comunicação segura e confiável, bem como } \\
\text { um gerenciamento sofisticado de identidade e acesso } \\
\text { a máquinas são essenciais (Rüßmann } \text { et al., 2015) }\end{array}$ & $\begin{array}{l}\text { Kipper } \text { et al., } 2019 \\
\text { Rosin } \text { et al., } 2019 \\
\text { Kamble } \text { et al., } 2019 \\
\text { Tortorella } \text { et al, } 2019 \text { a } \\
\text { Zhao } \text { et al., } 2019\end{array}$ \\
\hline $\begin{array}{l}\text { Realidade } \\
\text { aumentada }\end{array}$ & $\begin{array}{l}\text { São modelos virtuais de componentes de um projeto } \\
\text { que podem ser sobrepostos a uma imagem do mundo } \\
\text { real em tempo real, isso se torna possível através do } \\
\text { uso de diversas tecnologias, tais como smartphones e } \\
\text { tablets (TEZEL;AZIZ, 2017). }\end{array}$ & $\begin{array}{l}\text { Pereira } \text { et al., } 2019 \\
\text { Li, } 2019 \\
\text { Zhao } \text { et al., } 2019 \\
\text { Kipper } \text { et al., } 2019 \\
\text { Pagliosa } \text { et al., } 2019 \\
\text { Rosin } \text { et al., } 2019 \\
\text { Kamble et al., } 2019 \\
\text { Pekarčíková } \text { et al., } 2019 \\
\text { Rossini } \text { et al., } 2019 \\
\text { Torotorella } \text { et al., } 2019 \\
\text { Ma } \text { et al., 2017 } \\
\text { Tezel e Aziz, } 2017\end{array}$ \\
\hline
\end{tabular}




\begin{tabular}{|c|c|c|}
\hline Nome & Descrição & Referências \\
\hline Big data & $\begin{array}{l}\text { É um termo que pode ser descrito através de três } \\
\text { características: volume, velocidade e variedade; no } \\
\text { seu coração estão a análise e o refinamento de dados, } \\
\text { que levam à tomada de decisão eficaz. Essa } \\
\text { tecnologia coleta dados brutos e os transforma em } \\
\text { informações (LAUX et al., 2017; LEEet al., 2016). }\end{array}$ & $\begin{array}{l}\text { Pereira et al., } 2019 \\
\text { Li, } 2019 \\
\text { Kipper } \text { et al., } 2019 \\
\text { Pagliosa } \text { et al., } 2019 \\
\text { Rosin } \text { et al., } 2019 \\
\text { Kamble } \text { et al.,2019 } \\
\text { Pekarčíková } \text { et al., } 2019 \\
\text { Rossini } \text { et al., } 2019 \\
\text { Tortorella } \text { et al.,2019a } \\
\text { Varela } \text { et al., } 2019 \\
\text { Tortorella } \text { et al., } 2019 \mathrm{~b} \\
\text { Antony } \text { et al., } 2018 \\
\text { Arcidiacono e } \\
\text { Pieroni,2018 } \\
\text { Buer } \text { et al., } 2018 \mathrm{a} \\
\text { Buer } \text { et al., 2018b } \\
\text { Sony,2018 } \\
\text { Tortorella e Fettermann, } \\
\text { 2018 } \\
\text { Chen e Lin,2017 } \\
\text { Dombrowski } \text { et al.,2017 } \\
\text { Karre } \text { et al., } 2017 \\
\text { Laux } \text { et al., } 2017 \\
\text { Oliveira } \text { et al.,2017 } \\
\text { Sahin } \text { et al., } 2017 \\
\text { Bell e Bell, } 2016 \\
\text { Lee } \text { et al.,2016 } \\
\text { Sanders } \text { et al.,2016 }\end{array}$ \\
\hline $\begin{array}{l}\text { Machine } \\
\text { learning }\end{array}$ & $\begin{array}{l}\text { É uma ferramenta que prevê dados futuros com base } \\
\text { em dados anteriores, é usada para melhorar decisões } \\
\text { de negócios, aumentar a produtividade, detectar } \\
\text { doenças e muitas outras coisas (HARRINGTON, } \\
\text { 2012). ). É uma tecnologia que extrai conhecimento } \\
\text { útil e tomar as decisões apropriadas a partir do big } \\
\text { data (AHUETT-GARZA; KURFESS, 2018). }\end{array}$ & $\begin{array}{l}\text { Pereira } \text { et al., } 2019 \\
\text { Hotrawaisaya } \text { et al., } 2019 \\
\text { Kipper } \text { et al., } 2019 \\
\text { Pagliosa } \text { et al., } 2019 \\
\text { Rossini } \text { et al.,2019 } \\
\text { Tortorella } \text { et al., } 2019 \mathrm{~b} \\
\text { Saidi e Soulhi,2018 } \\
\text { Pogačnik } \text { et al., } 2017 \\
\text { Bell e Bell, 2016 } \\
\text { Sanders } \text { et al.,2016 }\end{array}$ \\
\hline
\end{tabular}




\begin{tabular}{|c|c|c|}
\hline Nome & Descrição & Referências \\
\hline $\begin{array}{l}\text { Cloud } \\
\text { computing }\end{array}$ & $\begin{array}{l}\text { É um serviço de TI (tecnologia da informação) no } \\
\text { qual os serviços de hardware e software são } \\
\text { entregues aos usuários, independentemente da sua } \\
\text { localização ou do dispositivo que está sendo usado } \\
\text { (SAHIN et al., 2017). }\end{array}$ & $\begin{array}{l}\text { Pereira } \text { et al., } 2019 \\
\text { Li, } 2019 \\
\text { Hotrawaisaya } \text { et al., } 2019 \\
\text { Kipper } \text { et al., } 2019 \\
\text { Pagliosa } \text { et al., } 2019 \\
\text { Rosin } \text { et al., } 2019 \\
\text { Huang } \text { et al., } 2019 \\
\text { Kamble } \text { et al., } 2019 \\
\text { Pekarčíková } \text { et al., } 2019 \\
\text { Rossini } \text { et al., } 2019 \\
\text { Tortorella } \text { et al., 2019a } \\
\text { Tortorella } \text { et al., 2019b } \\
\text { Varela } \text { et al., } 2019 \\
\text { Zhang } \text { et al., } 2019 \\
\text { Arcidiacono e Pieroni, } \\
\text { 2018 } \\
\text { Buer } \text { et al., 2018b } \\
\text { Sony, 2018 } \\
\text { Tortorella e Fetermann, } \\
\text { 2018 } \\
\text { Chen, 2017 } \\
\text { Chen e Lin, } 2017 \\
\text { Dombrowski } \text { et al., } 2017 \\
\text { Ma } \text { et al., } 2017 \\
\text { Müller } \text { et al., } 2017 \\
\text { Tezel e Aziz, } 2017 \\
\text { Sahin } \text { et al., } 2017 \\
\text { Sanders } \text { et al., } 2016 \\
\text { Veza } \text { et al., } 2016\end{array}$ \\
\hline $\begin{array}{l}\text { Manufatura } \\
\text { aditiva (ou } \\
\text { impressão } 3 \\
\text { D) }\end{array}$ & $\begin{array}{l}\text { É um instrumento usado para produzir protótipos e } \\
\text { maquetes, peças de reposição, coroas dentárias, } \\
\text { membros artificiais e até pontes; contribui para a } \\
\text { relação custo-eficácia (CHEN;LIN, 2017). }\end{array}$ & $\begin{array}{l}\text { Pereira } \text { et al., } 2019 \\
\text { Kipper } \text { et al., } 2019 \\
\text { Pagliosa } \text { et al., } 2019 \\
\text { Rosin } \text { et al., } 2019 \\
\text { Kamble } \text { et al., } 2019 \\
\text { Pekarčíková } \text { et al., } 2019 \\
\text { Rossini } \text { et al., } 2019 \\
\text { Varela } \text { et al., } 2019 \\
\text { Tortorella } \text { et al., } 2019 \mathrm{~b} \\
\text { Arcidiacono e Pieroni, } \\
2018 \\
\text { Buer } \text { et al., 2018a } \\
\text { Lugert } \text { et al., 2018 } \\
\text { Tortorella e Fettermann, } \\
\text { 2018 } \\
\text { Chen e Lin, } 2017 \\
\text { Karre } \text { et al., } 2017 \\
\text { Müller } \text { et al., } 2017 \\
\text { Tezel e Aziz, } 2017\end{array}$ \\
\hline
\end{tabular}


Todas essas tecnologias trazem mudanças no ambiente de trabalho como umtodo. De acordo com Müller et al.(2017), a interface homem-máquina deve ser repensada em todas as formas de organizações de trabalho existentes e design eficiente no local de trabalho. Ao se mudar as formas de se trabalhar, a mão de obra deve ser reciclada.

Deve-se ainda mencionar algumas observações oriundas dessas tecnologias. Como mencionado anteriormente, a IoT é um caso especial do CPS, onde o meio de comunicação é a internet; o termo "things" refere-se a cenários nos quais a conectividade de rede e a capacidade de computação se estendem a objetos, sensores e itens do dia a dia que não são considerados como computadores (DAVIES et al., 2017).

IoT é auxiliada por outros dispositivos como por exemplo, a Identificação por Radiofrequência (RFID). Este dispositivo se conecta a internet e é usado para monitorar o status, número e localização de lotes de materiais, através do seu uso, pode-se obter uma identificação e um rastreamento de uma área ampla de forma rápida (SANDERS et al., 2016; TEZEL;AZIZ, 2017).

O resultado da adoção das tecnologias da I4.0 é uma Smart Factory. É uma fábrica que responde, eficientemente, aos clientes, criando uma replicação virtual do sistema físico e que permite a análise inteligente e em tempo real de um grande conjunto de dados (DAVIES et al., 2017). Uma de suas vantagens é permitir que os requisitos individuais dos clientes sejam atendidos e isso significa que, mesmo que os itens sejam únicos, eles podem ser fabricados de forma lucrativa(VEZA et al.,2016).

Além das suas tecnologias, pode-se afirmar que a I4.0 é baseada em seis princípios. De acordo com Hermann et al. (2016), eles são:

1. Interoperabilidade: todos os CPS dentro de uma unidade fabril são capazes de se comunicar uns com os outros;

2. Virtualização: CPS é um meio de monitorar os processos físicos e os dados obtidos são vinculados a modelos de plantas virtuais e modelos de simulação. Uma cópia do mundo físico é criada no mundo virtual;

3. Descentralização: através de computadores integrados ocorre a permissão para que o CPS tome suas próprias decisões. Deve-se ressaltar que para garantir a qualidade e rastreabilidade, é necessário manter o controle de todo o sistema a qualquer momento; 
4. Capacidade em tempo real: é fundamental que os dados sejam coletados e analisados em tempo real para o funcionamento da I4.0;

5. Orientado a serviço: o CPS, os serviços fornecidos pela empresa e os empregados estão disponíveis e podem ser utilizados por outros participantes. Eles podem ser fornecidos para dentro ou fora da empresa;

6. Modularidade: são sistemas capazes de se adaptar de forma flexível às mudanças dos requisitos. Logo, podem ser facilmente ajustados em caso de flutuações sazonais e/ou alterações nas características dos produtos.

Um dos benefícios gerados pela I4.0 é o fato de produtos agora serem inteligentes. Eles vêm com detalhes sobre as sequências de operações que devem ser feitas sobre eles, toda essa informação é passada para a máquina; é um apoio eficiente que ajuda na execução de tarefas sem erros pelo pessoal da produção (SCHUH et al., 2015; SANDERS et al., 2016).

Além da empresa obter dados em tempo real, toda a cadeia de suprimentos, também, troca dados desta forma. Segundo Lugert et al. (2018), isso permite que as elas aumentem a velocidade de produção, que os desperdícios sejam reduzidos, os inventários baixados e que o fluxo de uma peça seja facilitado. A diminuição dos desperdícios causa um impacto na redução dos custos. A I4.0 facilita a coleta e análise de dados de máquinas e de campo, isso melhora a qualidade e evita falhas no processo de produção do chão de fábrica (ANTE et al., 2018).

Deve-se ressaltar que existe uma diferença em relação a prontidão para a adoção dessas novas tecnologias comparando as pequenas e médias empresas com as empresas de grande porte. Segundo Kagermann et al. (2013), diversas pequenas e médias empresas não estão preparadas paras as mudanças estruturais dessa revolução, pois não possuem a mão de obra especializada necessária ou porque são céticas em relação à adoção de tecnologias com as quais ainda não estão familiarizadas. Além disso, existe um grande custo para se instalar essas tecnologias disruptivas.

Outro fato importante é a existência de um facilitador para a I4.0, que é a digitalização (BUER et al., 2018b). A facilidade de acesso à internet e a redução do seu custo são alguns dos motivos para a disseminação da IoT, logo da I4.0 (PAGLIOSA et al., 2019). 
Kipper et al. (2019) resumiu de forma clara a importância de algumas tecnologias da I4.0. Segundo esses autores, é primeiro necessário fazer a união entre o mundo físico com o virtual (usa-se o CPS), em seguida, fazer a conexão entre dispositivos, sistemas, produtos, máquinas e pessoas (com a IoT) e, por fim, essa integração gerará uma grande quantidade de dados que serão tratados/analisados através do big data. Nota-se assim, o grande potencial da I4.0.

Com isso, este capítulo apresentou diversos pontos importantes sobre a quarta revolução industrial. Foramabordadas questões relacionadas àintegração horizontal, vertical e engenharia de ponta a ponta, as novas tecnologias que a I4.0 trouxe e os princípios nos quais ela está baseada.

\subsection{Integração entre LM e 14.0}

O termo lean automation tem recebido novamente atenção devido ao surgimento da I4.0 (ROSSINI et al., 2019). Além disso, existe o LSS que, em sua integração com a I4.0,tornar-se-á um campo de pesquisa que deve ser profundamente explorado pelas empresas (ARCIDIACONO; PIERONI, 2018).

Cada empresa deve analisar seu processo produtivo LM e selecionar as tecnologias da Indústria 4.0 que serão mais promissoras em termos de resultados. Antes de decidir e implementar qualquer método de melhoria de produtividade, a organização deve, primeiro, examinar sua estratégia de negócios e verificar se essa melhoria, realmente, contribuirá positivamente para a empresa (TORTORELLA; FETTERMANN,2017). Escolher as tecnologias apropriadas alinhadas aos objetivos de negócios não é uma tarefa fácil, isso ocorre devido à ausência de simetria de informações entre melhores práticas industriais e percepções dos participantes (LEE $e t$ al., 2016).

Muitas empresas possuem dificuldades em analisar e selecionar qual a tecnologia da Indústria 4.0 é mais favorável para o seu processo (DOMBROWSKI et al., 2017). Apesar dessa dificuldade, Tortorella e Ferttemann (2017) afirmam que as práticas de LM estão positivamente associadas às tecnologias da Indústria 4.0 e a implementação conjunta delas leva a melhorias de desempenho para as empresas. Esse pensamento está 
alinhado ao resultado do trabalho de Kamble et al.(2019), estes afirmam que a I4.0 possui uma influência positiva no LM, pois através da implementação da I4.0 as fábricas se tornarão além de enxutas, também inteligentes.

A digitalização também é um importante aliado do LM, pois através dela os empregados podem notificar as alterações, simultaneamente, ao processo produtivo (MÜLLER et al., 2017). Isto permitirá o alcancede economia financeira e de tempo, pois reduzirá o retrabalho. Para Zhao et al. (2019) o LM deve priorizar tarefas como, por exemplo, a digitalização do espaço de negócios global.

Através da elaboração de um framework, Buer et al.(2018a) chegaram a quatro relações envolvendo LM e I4, são elas: as tecnologias da I4.0 podem apoiar e desenvolver ainda mais LM, o lean facilita a implementação da I4.0.. Porém, deve-se ressaltar que a implementação da I4.0 é bastante vinculada à adoção das práticas LM, mas, por outro lado, a adoção do LM é independente e, geralmente, ocorre antes da adoção da I4.0 (ROSSINI et al., 2019).

Sony (2018) também elaborou um framework unindo os cinco princípios LM e os três tipos de integração existentes na I4.0. Analisando de forma mais detalhada as tecnologias existentes na I4.0 e no LM.Zhang et al. (2018) propôs um Lean-Oriented Optimum State Control Theory, (L-OSCT) que integra métodos e práticaslean na teoria de controle ótimo e faz sua união da IoT da I4.0. Ela é usada para construir um ambiente de informação. Como resultado, o desempenho da produção, da armazenagem e da empresa como um todo alcançou um nível lean mais alto. Nota-se uma alta aplicabilidade em termo de eficiência operacional.

Arcadiacono e Pieroni (2018), uniram as vertentes de LSS com a I4.0 e suas tecnologias. A I4.0 ajuda a coletar mais dados em tempo real para toda cadeia de valor com o apoio das práticas LSS e, ainda, reduz os desperdícios de recursos e melhora a experiência dos clientes. Através da ligação com a IoT, o sistema de coleta de dados passa a ser baseado em análise preditiva e diferentes processos podem alimentar, em tempo real, um algoritmo que gera facilidade para o monitoramento da empresa e, consequentemente, o envolvimento dos clientes se torna mais relevante devido ao fato do feedback contínuo ser facilitado por essa ferramenta. 
Outro destaque é que a IoT cria uma ligação entre diferentes atores/sistemas, através do acesso completo a dados atualizados de uma fase de ciclo de vida para outra (DAVE et al., 2016). Camgöz-Akdağ et al. (2018) estudaram os benefícios do VSM com a I4.0 e a IoT no setor de saúde. Os benefícios da I4.0 são o encurtamento do tempo de espera e a facilidade do processamento de dados. Através da IoT pode-se alcançar dispositivos em todo o mundo e em alta velocidade. O processo pode ser melhorado com o VSM, que é facilitado pela I4.0 e a IoT. Para Pagliosa et al. (2019) um VSM digitalmente integrado com dados em tempo real permite uma maior compreensão do status da empresa e do design do fluxo de valor lean.

Através da integração da IoT em máquinas, materias, componentes e dispositivos a comunicação em dispositivos móveis por ser programada para divulgar informações importantes e atuar como umpoka-yokede segurança e qualidade (TEZEL, AZIZ, 2017). Na sua revisão de literatura Rosin et al. (2019) constataram que a IoT possui bastante sinergia e melhora o sistema quando combinado com o Jidoka.

Aprofundando o campo de pesquisa em direção ao SS e a Smart Factory, encontra-se o trabalho de Saidi e Soulhi (2018). Pode-se observar neste estudo que as principais práticas SS não estão adaptadas a esse novo conceito de fábrica. Porém, a ligação da Smart Factory com LM é positiva. Lee et al. (2016) relatam que a Smart Factory transforma LM em uma gestão mais proativa e com maior qualidade ela não lida, apenas, com os desperdícios atuais, mas, também, prevê o potencial futuro de desperdícios e toma medidas proativamente.

Através do uso de produtos inteligentes, RFID e IoT pode-se melhorar o processo SS. Os primeiros carregam todos os detalhes do que deve ser feito com eles, o segundo permite a detecção automática de variações nos processos e o último combina informações de diferentes máquinas (SANDERS et al., 2016). Utilizando outra ferramenta, o big data, o SS pode ser melhorado. O uso integrado do big data com o SS pode resultar em um sistema de melhoria mais integrado, o primeiro consegue captar um grande volume de dados e o segundo consegue estruturar melhor esses dados (LAUX et al., 2017).

O alinhamento entre LSS e big data possui aspectos positivos. As práticas analíticas do LSS permitem extrair melhores insights do big data, por exemplo, 
fornecendo informações sobre toda experiência vivida pelos clientes (ARCADIACONO;PIERONI,2018). Esse pensamento vai de acordo com Bell e Bell (2016) e Antony et al.(2018), que nos dizem que a análise de big data pode desempenhar um papel vital, pois envolve equipes de todos os níveis da empresa com a voz do cliente, que é o centro do trabalho. Outro uso do big data é como facilitador para a manutenção preditiva e para o controle/monitoramento remoto da produção (KARRE et al., 2017).

Os dados históricos podem ser coletados pelo big data e seu processamento pode ser feito por outra ferramenta. Em seu trabalho, Pogačnik et al. (2017) constataram que os dados históricos podem ser processados através de machine learning, gerando redução de custos logísticos de reposição de peças/ferramentas e previsão de falhas.

Através do estudo de caso realizado por Ante et al. (2018), a união do heijunka board com o kanban, mais as tecnologias da I4.0, permite o controle do processo em tempo real. Neste caso, os cartões kanban são gerados automaticamente. O heijunka board passa a ser digital, logo, o desempenho é calculado automaticamente, sem intervenção humana. Com isso, temos uma diminuição da probabilidade de erro.

Com os kanbans eletrônicos, uma ordem de produção é automaticamente transmitida para o processo a jusante quando é detectado que o nível mínimo de estoque foi atingido (DAVIES et al., 2017). Esses kanbans digitalizados fazem parte da união do kanban com as seguintes tecnologias da I4.0: IoT, cloud computing e big data; os planos de trabalho e o tempo de ciclo tendem a ser mais fáceis com o uso dessa tecnologia (TORTORELLA et al., 2019b).

Apesar da geração ser automática dos cartões kanban, o reabastecimento dos cartões ainda é manual (BUER et al., 2018b). Ainda dentro deste trabalho, os autores relatam a existência de cartões kanban autônomos que são capazes de automatizar a decisão de reabastecimento e de transmissão do sinal. Porém, esse tipo de kanban não é aprimorado de forma contínua. Por fim, os autores relatam que existe um kanban autootimizado que usa os dados coletados para analisar e priorizar melhorias.

Algumas ligações do LM com a IoT já foram relatadas, mas essa tecnologia da I4.0 possui diversas oportunidades de ligação com o lean. Através da conciliação entre heijunka e IoT pode-se criar, automaticamente, a solicitação por materiais/ferramentas/máquinas, sem o envolvimento de um operador humano 
(TEZEL;AZIZ, 2017). Através da IoT, cada item pode ser rastreado, com dados sobre sua origem, estado atual e destino eessa marcação garante o envio de produtos certos para destinos corretoscom redução dos prazos de distribuição, ou seja, assegurandoo JIT (SANDERS et al., 2016).

Tezel e Aziz (2017) em seu trabalho propõem que através do uso conjunto do kanban com a IoT, objetos inanimados podem gerar, automaticamente, sinais kanban para diferentes propósitos, como reabastecimento de material, segurança das máquinas e manutenção de equipamentos.

O CPS é um dos componentes-chaves da I4.0. Através dele os dados de envio e progresso do kanban podem ser atualizados automaticamente; caso o estoque de uma estação de trabalho atinja um nível para se realizar um novo pedido, o CPS enviará automaticamente um kanban ao antecessor (KOLBERG et al., 2017). Chen (2016)realizou um estudo que fazia uso combinado do CPS e do VSM, como resultado houve uma melhoria na rastreabilidade em uma cadeia de alimentos. Huang et al. (2019) foram além, combinaram CPS, VSM, heijunka e e-kanban.Esse sistema fornece informações importantes para o tomador de decisão e faz a empresa progredir para uma manufatura enxuta digital.

Abordando a tecnologia de cloud computing, Dombrowski et al. (2017) chegaram à conclusão de que isto, na maioria dos casos, era implementado com o objetivo de evitar os desperdícios. LM pode ser potencializado pelo uso do RFID. Ele declara automaticamente as mercadorias enquanto elas passam, com isso, tem-se a possibilidade de realizar uma comparação imediata entre o inventário físico e os dados dos sistemas (ANTE et al., 2018). Através da sua implementação pode-se se adquirir dados da produção e, com isso possibilitar uma troca rápida entre produtos (KARRE et al., 2017).

O uso de uma plataforma que combina LM com cloud computing e RFID reduz o atraso no trabalho, o nível médio de estoque e o custo total anual de estoque; fornece benefícios como rastreabilidade em tempo real e visibilidade permitindo que os usuários mudem prontamente o planejamento de estoque/fabricação/instalação/expedição (SAHIN et al., 2017). 
Utilizando um dos pilares LM, Ma et al. (2017) realizaram um estudo de caso, nele eles afirmam que jidoka é uma forma eficiente e eficaz, em relação a custos, para melhorar a flexibilidade da I4.0. Sob outra perspectiva a I4.0 pode acelerar o desenvolvimento jidoka e ampliar seu conteúdo e torná-lo inteligente.

O outro pilar do LM, JIT pode ser relacionado com a impressão 3D. Através desse tipo de impressão um produto pode ser fabricado de forma impressa a pedido do cliente, logo elimina-se a necessidade de se construir um inventário para o produto acabado, o que vai de encontro com o conceito PULL e JIT (CHEN;LIN, 2017).

Como mencionado anteriormente, a I4.0 possui dispositivos móveis. Sensores conectados aos equipamentos suportam a manutenção produtiva total, os operadores e engenheiros de manutenção conseguem aumentar a velocidade e a qualidade de todos os tipos de manutenção, observando as funções em tempo real e, com isso, a manutenção será feita quando necessária (OLIVEIRA et al., 2017).

Através da realidade aumentada são criados modelos virtuais para projetos. Davies et al. (2017) relatam que em um ambiente de realidade virtual a compreensão do VSM convencional não será necessária, pois as partes interessadas estarão imersas em um VSM virtual onde os estados atuais e futuros dos projetos poderão ser observados.

A realidade aumentada também pode ser combinada com sistemas móveis e os $5 \mathrm{~S}$ do LM. Através dessa ligação é possível comunicar onde, realmente, cada elemento deve estar no local de trabalho e como executar várias verificações preventivas de saúde, segurança e manutenção corretamente (TEZEL;AZIZ,2017). Para Zhao et al. (2019) a partir da realidade aumentada se pode eliminar os pontos fracos do LM, além de melhorar o desenvolvimento da equipe empresarial, aprimorar a imagem da empresa e desenvolver a liderança estratégica.

Algumas observações ainda devem ser feitas. Por exemplo, deve-se ressaltar que ao se incorporar uma tecnologia no desenvolvimento de produtos mal estruturados não trará os resultados esperados (TORTORELLA et al.,2019a). Empresas que implementaram de forma erradas as práticas LM acabam adotando mal as tecnologias da I4.0 (ROSSINI et al., 2019). Além disso, a experiência da empresa na implementação das práticas LM foi um fator importante ao associar as práticas de LM com a I4.0. 
É importante ter um ambiente de mudança favorável na empresa em direção a modernização que a I4.0 pode oferecer. Com isso, as empresas devem garantir que seus funcionários não serão demitidos e, sim, que eles terão que se reciclar, ou seja, aumentar seu o nível de qualificação (BUER et al., 2018a). É importante conseguir uma contribuição da força de trabalho em direção à mudança tecnológica e organizacional (MÜLLER et al., 2017). Para Veza et al. (2016), é importante conectar os empregados e as tecnologias para obter uma melhor competitividade.

Em relação ao porte das empresas, muitas vezes fica a dúvida em relação à adoção de novas práticas ou não. Tortorella e Fettermann (2017) realizaram uma survey e constataram que a associação entre LM e I4.0 é independente do tamanho das empresas, o tamanho não deve ser visto como um impedimento para a adoção simultânea das duas práticas. LM constrói a base para a I4.0 e esta, por sua vez, é capaz de melhorar com seus avanços tecnológicos (DOMBROWSKI et al., 2017).

A I4.0 fará com que as empresas já adotantes do LM a níveis de excelência melhores (TORTORELLA; FETTERMANN,2017). Por fim, deve-se destacar que o LM não irá desaparecer devido a I4.0, o primeiro se tornará ainda mais importante, sofisticado e inteligente sob a ótica das novas tecnologias que serão incorporadas com essa revolução (LI, 2019).

Esta subseção apresentou o alinhamento entre os temas da revisão da literatura, sendo uma base para desenvolver um framework que integra LM e I4.0. O próximo capítulo apresenta os resultados dessa revisão e os doisframeworks propostos. 


\section{Análises descritiva e de conteúdo}

O presente capítulo apresenta as análises descritiva e de conteúdo com base na amostra de artigos selecionados para a pesquisa. A tabela 6 apresenta esta amostra com seus respectivos objetivos. Os artigos estão numerados em ordem cronológica para facilitar parte das discussões ao longo do texto que se segue.

Tabela 6: Lista dos artigos selecionados na RSL

\begin{tabular}{|c|c|c|}
\hline $\mathbf{N}^{0}$ & Artigo & Objetivo da pesquisa \\
\hline 1 & $\begin{array}{l}\text { Bell e } \\
\text { Bell,2016 } \\
\text { (página 7) }\end{array}$ & $\begin{array}{l}\text { "Então a premissa desse artigo é a seguinte: como garantir que estamos } \\
\text { recebendo o melhor do big data da computação cognitiva e de qualquer outra } \\
\text { coisa para aumentar a probabilidade de tornar o decisões corretas, no contexto } \\
\text { certo?" }\end{array}$ \\
\hline 2 & $\begin{array}{l}\text { Dave } e t \\
\text { al.,2016 } \\
\text { (página 1) }\end{array}$ & $\begin{array}{l}\text { "O objetivo do artigo é duplo: o primeiro, considera a estrutura de comunicação } \\
\text { inicial da construção atual de sistemas de gestão, como o sistema VisiLean;o } \\
\text { segundo. investiga as principais oportunidades e desafios, integrando } \\
\text { comunicação IoT padronizada e interfaces para "empurrar" e "puxar" as } \\
\text { informações corretas (de produção) para as pessoas e sistemas certos." }\end{array}$ \\
\hline 3 & $\begin{array}{l}\text { Lee } e t \\
\text { al..,2016 } \\
\text { (página 1) }\end{array}$ & $\begin{array}{l}\text { "Para incorporar efetivamente os processos necessários à análise, uma nova } \\
\text { maneira de modelar os fluxos do processo é essencial para atingir o objetivo da } \\
\text { produção enxuta preditiva. Para atingir tais objetivos, este artigo apresenta uma } \\
\text { nova abordagem de modelagem de processos para análises, que é vital para os } \\
\text { profissionais e as indústrias." }\end{array}$ \\
\hline 4 & $\begin{array}{l}\text { Sanders et } \\
\text { al.,2016 } \\
\text { (página 1) }\end{array}$ & $\begin{array}{l}\text { "Este artigo analisa o elo incompleto entre o link da Indústria } 4.0 \text { e a manufatura } \\
\text { enxuta e investiga se a Indústria } 4.0 \text { é capaz de implementar o lean." }\end{array}$ \\
\hline 5 & $\begin{array}{l}\text { Veza } e t \\
\text { al.,2016 } \\
\text { (página 1) }\end{array}$ & $\begin{array}{l}\text { "O objetivo era entender como as empresas manufatureiras da Croácia } \\
\text { adquirem novas tecnologias de fabricação, integração das TIC nos processos, } \\
\text { novos conceitos organizacionais na produção, como trabalho em grupo ou } \\
\text { realocação da produção, novos produtos que emergem do processo e inovação } \\
\text { organizacional, como serviços relacionados à produção, e outras demandas } \\
\text { relacionadas à Indústria 4.0." }\end{array}$ \\
\hline 6 & $\begin{array}{l}\text { Chen, } 2017 \\
\text { (página 1) }\end{array}$ & $\begin{array}{l}\text { "Nesse sentido, este estudo apresenta uma nova abordagem inteligente do cyber } \\
\text { physical system de rastreabilidade de alimentos baseado em fluxo de valor com } \\
\text { arquiteturas corporativas, EPC global e método de mapeamento do fluxo de } \\
\text { valor pela rede de computação e eficiência colaborativa de rastreabilidade" }\end{array}$ \\
\hline
\end{tabular}




\section{$N^{0}$ Artigo Objetivo da pesquisa}

\begin{tabular}{|c|c|c|}
\hline 7 & $\begin{array}{l}\text { Chen e Lin, } \\
2017 \text { (página } \\
\text { 1) }\end{array}$ & $\begin{array}{l}\text { "Neste estudo, quatro desafios técnicos são revisados da seguinte forma: design } \\
\text { de objetos 3D, tipos limitados de materiais, baixa precisão e baixa } \\
\text { produtividade. Sete preocupações gerenciais também são discutidas, como: } \\
\text { gerenciamento de banco de dados de objetos } 3 \mathrm{D} \text {, direitos de propriedade } \\
\text { intelectual da impressão 3D, inovação de negócios, manufatura onipresente, } \\
\text { manufatura enxuta, globalização e desglobalização e avaliação de viabilidade e } \\
\text { otimização." }\end{array}$ \\
\hline 8 & $\begin{array}{l}\text { Davies } e t \\
\text { al.,2017 } \\
\text { (página 1) }\end{array}$ & $\begin{array}{l}\text { "O artigo analisa a infraestrutura da Indústria } 4.0 \text { que, além dos ganhos } \\
\text { potenciais de custo e eficiência de implementação, argumenta em favor da } \\
\text { adoção da perspectiva de alavancar recursos internos para devolver a Indústria } \\
4.0 \text { como driver para criar vantagem competitiva." }\end{array}$ \\
\hline 9 & $\begin{array}{l}\text { Dombrowski } \\
\text { et al.,2017 } \\
\text { (página 1) }\end{array}$ & $\begin{array}{l}\text { "Para permitir uma análise detalhada das interdependências entre a produção } \\
\text { enxuta Systems (LPS) e Industrie 4.0, vários elementos da Industrie } 4.0 \text { foram } \\
\text { estruturados em tecnologias, sistemas e processos características } \\
\text { relacionadas(...)" }\end{array}$ \\
\hline 10 & $\begin{array}{l}\text { Karre et al., } \\
2017\end{array}$ & $\begin{array}{l}\text { "O objetivo é possibilitar a aprendizagem orientada para a prática em um } \\
\text { ambiente próximo à realidade industrial para facilitar a transferência efetiva de } \\
\text { conhecimento." }\end{array}$ \\
\hline 11 & $\begin{array}{l}\text { Kolberg et } \\
\text { al.,2017 } \\
\text { (página 1) }\end{array}$ & $\begin{array}{l}\text { "Este artigo apresenta o trabalho em andamento no sentido de } \\
\text { interface para a digitalização de métodos de produção enxuta usando o Cyber } \\
\text { Physical Systems." }\end{array}$ \\
\hline 12 & $\begin{array}{l}\text { Laux et al., } \\
2017 \text { (página } \\
\text { 1) }\end{array}$ & $\begin{array}{l}\text { "O objetivo deste artigo é desenvolver um framework para a utilização dos } \\
\text { princípios Six Sigma (SS) e Análise de Big Data em uma universidade pública } \\
\text { dos EUA para melhorar o sucesso do aluno." }\end{array}$ \\
\hline 13 & $\begin{array}{l}\text { Ma et } \\
\text { al.,2017 } \\
\text { (página 3) }\end{array}$ & $\begin{array}{l}\text { "Este estudo tem como objetivo fornecer uma abordagem integrada e } \\
\text { padronizada para projetar e implementar um sistema Jidoka inteligente baseado } \\
\text { em CPS." }\end{array}$ \\
\hline 14 & $\begin{array}{l}\text { Müller } e t \\
\text { al.,2017 } \\
\text { (página 1) }\end{array}$ & $\begin{array}{l}\text { "Para superar esse processo ineficaz, um sistema informatizado de aplicação de } \\
\text { produção em combinação de dispositivos inteligentes foi desenvolvido." }\end{array}$ \\
\hline 15 & $\begin{array}{l}\text { Oliveira et } \\
\text { al.,2017 } \\
\text { (página 3) }\end{array}$ & $\begin{array}{l}\text { "Este artigo tem como objetivo contribuir para as organizações, mostrando } \\
\text { como elas podem detectar os resíduos no fluxo produtivo através do VSM. } \\
\text { Além da deteção de resíduos, este artigo pretende mostrar várias ferramentas } \\
\text { enxutas que podem ser aplicadas em diferentes situações, bem como os resíduos } \\
\text { que cada um pode eliminar e os benefícios que são obtidos de cada um." }\end{array}$ \\
\hline 16 & $\begin{array}{l}\text { Pogačnik et } \\
\text { al.,2017 } \\
\text { (página 2) }\end{array}$ & $\begin{array}{l}\text { "(...) um algoritmo foi desenvolvido para previsão de falhas e foi integrado à } \\
\text { logística de peças de reposição e à todos projetos de manutenção de aeronaves." }\end{array}$ \\
\hline 17 & $\begin{array}{l}\text { Sahin } e t \\
\text { al.,2017 } \\
\text { (página 5) }\end{array}$ & $\begin{array}{l}\text { "O objetivo deste estudo é investigar a viabilidade de um serviço baseado em } \\
\text { nuvem, sistema de informação integrado ao RFID como uma solução } \\
\text { econômica para pequenas e médias empresas de construção." }\end{array}$ \\
\hline 18 & $\begin{array}{l}\text { Tezel e } \\
\text { Aziz,2017 } \\
\text { (página 2) }\end{array}$ & $\begin{array}{l}\text { "Este artigo tem como objetivo explorar essas conexões entre o Gerenciamento } \\
\text { Visual (VM), um recurso fundamental do gerenciamento da estratégia de } \\
\text { informações na construção enxuta e em tecnologias emergentes, demonstrando } \\
\text { a sinergia entre os dois conceitos sobre possíveis cenários de implementação. } \\
\text { com estabelecimento de suas conexões conceituais em construção." }\end{array}$ \\
\hline
\end{tabular}




\section{No Artigo Objetivo da pesquisa}

\begin{tabular}{|c|c|c|}
\hline 19 & $\begin{array}{l}\text { Tortorella e } \\
\text { Fettermann, } \\
2017 \text { (página } \\
\text { 2) }\end{array}$ & $\begin{array}{l}\text { "Assim, este artigo tem como objetivo examinar a relação entre práticas de } \\
\text { produção enxuta (LP) e a implementação da Indústria 4.0, em empresas } \\
\text { manufatureiras brasileiras" }\end{array}$ \\
\hline 20 & $\begin{array}{l}\text { Ante } \text { et } \\
\text { al.,2018 } \\
\text { (página 1) }\end{array}$ & $\begin{array}{l}\text { "Neste artigo, uma estrutura em árvore dos principais indicadores de } \\
\text { desempenho (KPIs) é proposta para descrever o Sistema de Medição de } \\
\text { Desempenho (PMS) de um sistema de produção enxuta." }\end{array}$ \\
\hline 21 & $\begin{array}{l}\text { Antony et al., } \\
2018 \text { (página } \\
\text { 1) }\end{array}$ & $\begin{array}{l}\text { "O objetivo deste artigo é fornecer profissionais e pesquisadores de lean e six } \\
\text { sigma de acordo com os dez mandamentos do Lean Six Sigma (LSS)." }\end{array}$ \\
\hline 22 & $\begin{array}{l}\text { Arcidiacono } \\
\text { e Pieroni, } \\
2018 \\
\text { (página 3) }\end{array}$ & $\begin{array}{l}\text { "Este artigo tem por objetivo fornecer um conjunto original e inovador de } \\
\text { diretrizes para apoiar os profissionais e pesquisadores na concepção de } \\
\text { sistemas, ciclo de processo otimizado, eficaz e eficiente e otimização de } \\
\text { processos através desta nova e revolucionária abordagem que chamamos de } \\
\text { Lean Six Sigma4.0." }\end{array}$ \\
\hline 23 & $\begin{array}{l}\text { Buer } e t \\
\text { al.,2018a } \\
\text { (página 3) }\end{array}$ & $\begin{array}{l}\text { "O objetivo do presente artigo é explorar essa área inovadora e apresentar o } \\
\text { status atual da pesquisa em relação à ligação entre a Indústria } 4.0 \text { e a manufatura } \\
\text { enxuta." }\end{array}$ \\
\hline 24 & $\begin{array}{l}\text { Buer } e t \\
\text { al.,2018b } \\
\text { (página 1) }\end{array}$ & $\begin{array}{l}\text { "Este artigo tem como objetivo definir claramente a digitalização, um } \\
\text { facilitador essencial da Indústria } 4.0 \text { e ilustrar como ela pode ser usada para } \\
\text { melhoria, propondo um ciclo de melhoria e uma tipologia de digitalização } \\
\text { associada." }\end{array}$ \\
\hline 25 & $\begin{array}{l}\text { Camgöz- } \\
\text { Akdağ et al., } \\
2018 \text { (página } \\
\text { 1) }\end{array}$ & $\begin{array}{l}\text { "O estado atual dos departamentos dos hospitais pode ser fornecido por algumas } \\
\text { ferramentas de gerenciamento lean. Com a ajuda do mapeamento do fluxo de } \\
\text { valor, pode-se ver o panorama geral de um processo inteiro. Esta figura mostra } \\
\text { todas as etapas que o paciente seguirá e informa sobre o tempo de ciclo de cada } \\
\text { serviço." }\end{array}$ \\
\hline 26 & $\begin{array}{l}\text { Lugert et } \\
\text { al.,2018 } \\
\text { (página 2) }\end{array}$ & $\begin{array}{l}\text { "O mapeamento do fluxo de valor (VSM) é muito comum na indústria de } \\
\text { transformação para aprimorar transparência e melhorias de suporte no processo } \\
\text { de produção. O objetivo deste artigo é avaliar o status atual do método do ponto } \\
\text { de vista do usuário e abordar sua sustentabilidade futura no contexto da } \\
\text { digitalização que está em andamento." }\end{array}$ \\
\hline 27 & $\begin{array}{l}\text { Saidi e } \\
\text { Soulhi,2018 } \\
\text { (página 1) }\end{array}$ & $\begin{array}{l}\text { "Este artigo enfoca os limites da abordagem do six sigma através de um } \\
\text { relatório da Indústria 4.0." }\end{array}$ \\
\hline 28 & $\begin{array}{l}\text { Sony, } 2018 \\
\text { (página 2) }\end{array}$ & $\begin{array}{l}\text { "O objetivo deste artigo é propor uma integração modelo da Indústria } 4.0 \text { e } \\
\text { LM." }\end{array}$ \\
\hline 29 & $\begin{array}{l}\text { Zhao et al., } \\
2019 \text { (página } \\
\text { 2) }\end{array}$ & $\begin{array}{l}\text { "O objetivo geral do estudo é explorar questões relacionadas ao uso de } \\
\text { tecnologias de AR / VR na gestão do desenvolvimento sustentável e } \\
\text { digitalização de HR e outros processos operacionais de empresas corporativas } \\
\text { na China e no mundo." }\end{array}$ \\
\hline 30 & $\begin{array}{l}\text { Pagliosa et } \\
\text { al., } 2019 \\
\text { (página 1) }\end{array}$ & $\begin{array}{l}\text { "O objetivo deste artigo é identificar as relações entre a Indústria } 4.0 \text { (I4.0) } \\
\text { tecnologias e práticas Lean Manufacturing (LM)." }\end{array}$ \\
\hline 31 & $\begin{array}{l}\text { Huang et al., } \\
2019 \text { (página } \\
\text { 2) }\end{array}$ & $\begin{array}{l}\text { "Este estudo explora a combinação de um multi-agente em um sistema ciber- } \\
\text { físico com manufatura enxuta no contexto da Indústria 4.0." }\end{array}$ \\
\hline
\end{tabular}




\section{No Artigo Objetivo da pesquisa}

\begin{tabular}{|c|c|c|}
\hline 32 & $\begin{array}{l}\text { Kamble et } \\
\text { al.,2019 } \\
\text { (página 2) }\end{array}$ & $\begin{array}{l}\text { "(...) este estudo investiga os efeitos indiretos de I } 4 \text { T no SOP com LMP como } \\
\text { variável mediadora; além disso, visa confirmar, ou } \\
\text { não, os efeitos diretos de I4 T em LMP e SOP." }\end{array}$ \\
\hline 33 & $\begin{array}{l}\text { Pekarčíková } \\
\text { et al., } 2019 \\
\text { (página 1) }\end{array}$ & $\begin{array}{l}\text { "O artigo trata dos efeitos da digitalização em ferramentas de manufatura } \\
\text { enxuta que são frequentemente usadas em prática." }\end{array}$ \\
\hline 34 & $\begin{array}{l}\text { Rossini et } \\
\text { al.,2019 } \\
\text { (página 1) }\end{array}$ & $\begin{array}{l}\text { "Este estudo tem por objetivo examinar o impacto da inter-relação entre a } \\
\text { adoção das tecnologias da Indústria } 4.0 \text { e a implementação depráticas de } \\
\text { produção enxuta (LP), no nível de melhoria do desempenho operacional das } \\
\text { manufaturas europeias." }\end{array}$ \\
\hline 35 & $\begin{array}{l}\text { Tortorella } e t \\
\text { al.,2019a } \\
\text { (página 2) }\end{array}$ & $\begin{array}{l}\text { "Este artigo tem como objetivo investigar o efeito moderador da adoção das } \\
\text { tecnologias da Indústria } 4.0 \text { na relação entre o lean práticas de gerenciamento } \\
\text { da cadeia de suprimentos (LSCM) e melhoria do desempenho da cadeia de } \\
\text { suprimentos na indústria brasileira." }\end{array}$ \\
\hline 36 & $\begin{array}{l}\text { Varela et } \\
\text { al.,2019 } \\
\text { (página 1) }\end{array}$ & $\begin{array}{l}\text { “(...)esta pesquisa propõe um modelo de equações estruturais, com seis } \\
\text { hipóteses, para quantificar e medir os efeitos do Lean Manufacturing e Indústria } \\
4.0 \text { em Sustentabilidade." }\end{array}$ \\
\hline 37 & $\begin{array}{l}\text { Zhang et } \\
\text { al.,2019 } \\
\text { (página 2) }\end{array}$ & $\begin{array}{l}\text { "O objetivo principal deste artigo é investigar como a Teoria do Controle do } \\
\text { Estado Ótimo (OSCT), proposta pela equipe dos autores, pode ser estendida } \\
\text { para integrar sistematicamente os vários métodos e ferramentas de LP em um } \\
\text { ambiente unificado e quadro teórico extensível designado como orientado para } \\
\text { o Lean - Teoria do controle do Estado ótimo (L-OSCT)." }\end{array}$ \\
\hline 38 & $\begin{array}{l}\text { Kipper et al., } \\
2019 \text { (página } \\
1 \text { ) }\end{array}$ & $\begin{array}{l}\text { "Neste estudo, identificamos a evolução dos temas inerentes à indústria } 4.0 \\
\text { usando um software bibliométrico, o SciMAT (Science Mapping Analysis } \\
\text { Software Tool)." }\end{array}$ \\
\hline 39 & $\begin{array}{l}\text { Tortorella } e t \\
\text { al., 2019b } \\
\text { (página 1) }\end{array}$ & $\begin{array}{l}\text { "O objetivo deste artigo é examinar o papel moderador das tecnologias da } \\
\text { Indústria } 4.0 \text { na relação entre produção enxuta (LP) e melhoria do desempenho } \\
\text { operacional no Brasil, no contexto de uma economia em desenvolvimento." }\end{array}$ \\
\hline 40 & $\begin{array}{l}\text { Rosin et al., } \\
2019 \text { (página } \\
\text { 1) }\end{array}$ & $\begin{array}{l}\text { "O objetivo deste artigo é destacar os vínculos entre os princípios e ferramentas } \\
\text { propostos pela Indústria } 4.0 \text { e os propostos pela abordagem de gerenciamento } \\
\text { Lean, com um foco particular em como algumas das tecnologias da Indústria } \\
4.0 \text { estão melhorando a implementação dos princípios Lean, dependendo dos } \\
\text { níveis de capacidade das tecnologias." }\end{array}$ \\
\hline 41 & $\begin{array}{l}\text { Hotrawaisava } \\
\text { et al., } 2019 \\
\text { (página 1) }\end{array}$ & $\begin{array}{l}\text { "Este estudo teve como objetivo analisar o impacto do lean práticas de produção } \\
\text { nas áreas operacional e financeira das firmas de manufatura na Tailândia em } \\
\text { papel mediador da implementação da indústria 4.0." }\end{array}$ \\
\hline 42 & $\begin{array}{l}\text { Pereira et al., } \\
2019 \text { (página } \\
\text { 1) }\end{array}$ & $\begin{array}{l}\text { "O objetivo deste estudo consiste em uma revisão sistemática da literatura para } \\
\text { avaliar como as tecnologias disruptivas emergentes podem aprimorar as } \\
\text { práticas lean e analisar seus impactos e benefícios para as organizações que } \\
\text { estão caminhando para esse novo paradigma industrial." }\end{array}$ \\
\hline 43 & $\begin{array}{l}\mathrm{Li}, 2019 \\
\text { (página 2) }\end{array}$ & $\begin{array}{l}\text { "Este artigo tem como objetivo aplicar a arquitetura 'Lean smart manufacturing } \\
\text { a conceptual framework and solution-based co-creative platform' proposta } \\
\text { pelos autores, que combina Lean Manufacturing e Indústria 4.0, para realizar } \\
\text { um estudo empírico (...)" }\end{array}$ \\
\hline
\end{tabular}


A maioria dos artigos da amostra [4,9,23,28,30,32,34,35,36,39,40,41,42,43] aborda em seus objetivos, questões generalistas de analisar o link entre LM e I4.0. Cerca de oito artigos[1,5,8,13,17,24,29,38] possuem como alvo principal a I4.0 mas abordam o tema LM em seu escopo enquanto um número reduzido de artigos aborda, em seu objetivo principalmente, o tema LM, mas discutem I4.0 em seu texto [3,15,16,25,37].

Apenas dois artigos abordam objetivamente o link entre uma ferramenta específica LM e uma tecnologia específica I4.0 [6,26]. Porém, nota-se, ainda, um uso mais generalista desse link,seja em relação ao LM e uma tecnologia I4.0 ou uma ferramenta LM com a I4.0 [2,7,11,31,33]. Quatro artigos misturam a abordagem six sigma com os temas propostos, LM e I4.0 [12,14,22,27]. Três artigos não mencionam em seus objetivos nada sobre os temas desta dissertação, mas no decorrer da sua evolução trabalham eles de forma satisfatória [10,18,20]. Deve-se ressaltar, inclusive, a interessante mistura entre LM e I4.0 com Sustentabilidade [32, 36].

Quatro artigos fazem estudos especificamentes em determinados países, tais como: Brasil, China e Tailândia [29,35,39,41]. Nota-se a preocupação dos cientistas em estudar/desenvolver a ligação do LM com as tecnolgias mais recentes que fazem parte da I4.0 no contexto de econômias específicas. Para finalizar, nota-se, ainda, uma abordagem bem generalista da união desses dois conceitos, mas deve-se destacar uma tendência em pesquisas com sustentabilidade, um tema que possui grande destaque no cenário atual.

\subsection{Análise descritiva}

Através da observação da figura 5, nota-se a evolução do número de artigos publicados que unem os temas LM e I4.0. Apesar desta revisão considerar publicações desde ano de 2011, foi somente a partir de 2016 que começaram a surgir estudos que combinassem os temas LM e I4.0, reforçando a novidade sobre o tema destacada na introdução desta dissertação. Destaque para o ano de 2017, no qual houve um grande número de publicações. Após esse ano houve um decrescimento de trabalhos que abordavam ambos os assuntos, porém, deve-se ressaltar que em 2017 houve um grande números de publicações(cinco) em um periódico específico, o "Procedia 
Manufacturing" em função de um special issue em Learning Factories. Isso explica a grande discrepância em relação ao ano de 2018.Porém, nota-se que em 2019 o número de artigos cresceu significativamente e ultrapassou 2017. Os artigos foram classificados em teóricos e aplicados. Nota-se o aumento de artigos aplicados ao longo dos anos, sugerindo que existe um grande interesse em se colocar em prática o resultado da união das práticas LM com as tecnologias da I4.0.

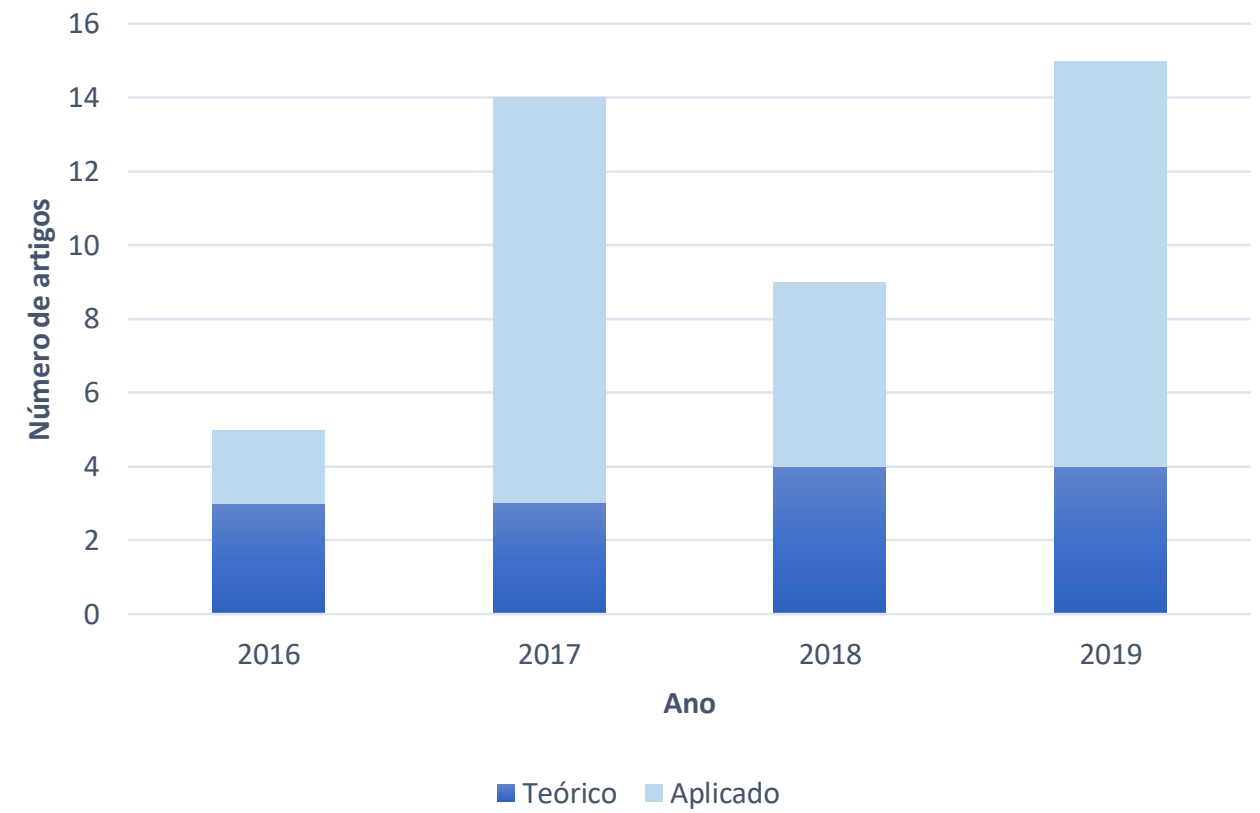

Figura 5: Número de artigos x Ano

A figura 6 apresenta a frequência das publicações por periódico.Nota-se que "Internacional Journal of Production Research" e "Procedia Manufacturing" (este em função do special issue de 2017) são aqueles com maior número de publicações. Como pode-se observar, nenhum outro periódico possui o monopólio deste conteúdo. O tema também é abrangente e interdisciplinar, estando disponível em periódicos de várias disciplinas como: gerência de operações, logística, sistemas de informações, sustentabilidade e construção. 


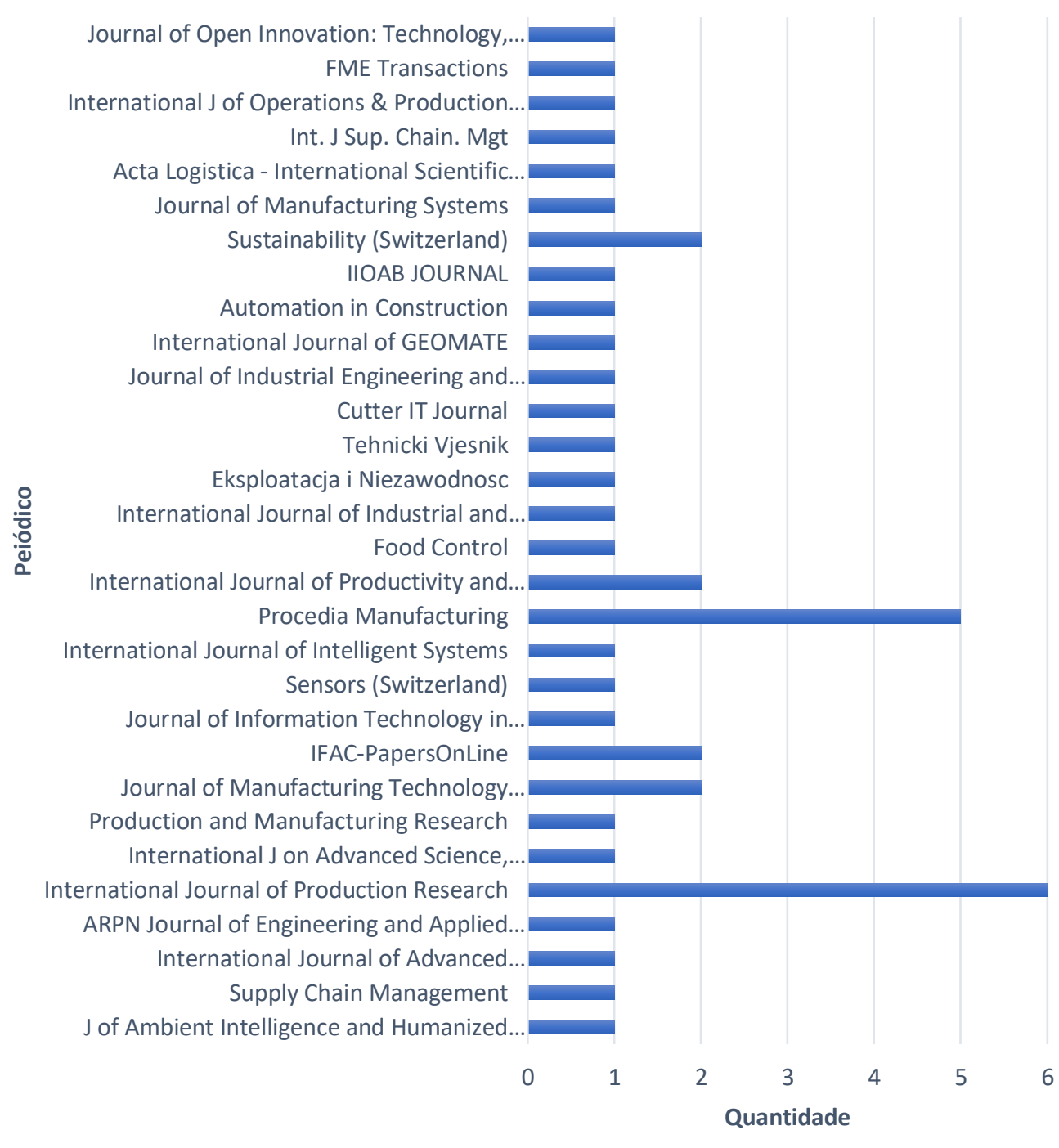

Figura 6: Quantidade de publicações por periódicos

O procedimento metodológico de cada artigo é identificado com base no artigo de Farias et al. (2019). Através da análise da figura 7, pode-se observar que a maioria dos autores utiliza o estudo de caso como fonte de produção científica. Logo, nota-se um crescente interesse sobre adoção dessas tecnologias, pois seu estudo não fica apenas no campo teórico. A adoção metodológica está em linha com as mais utilizadas em gerência das operações (THOMÉ et al., 2016). 


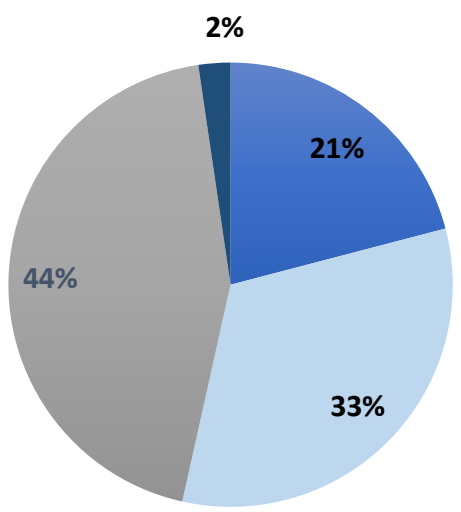

- Survey $\square$ Revisão da Literatura Estudo de Caso

Modelagem e Simulação

Figura 7: Procedimentos metodológicos

A figura 8 apresenta os países que realizaram pesquisas sobre os temas escolhidos para esse trabalho. No total, 28 países pesquisaram sobre a união LM com I4.0. Destaque para o Brasil, pois seus autores são citados 15 vezes em publicações relacionadas aos temas propostos. Apesar de ser uma economia emergente, este país já está procurando se atualizar sobre as novas tendências tecnológicas. Em seguida,China e Reino Unido, duas grande potências mudiais, possuem 13. A Alemanha, apesar de ser o berço da I4.0, ocupa o terceiro lugar com 12,junto com Portugal. 


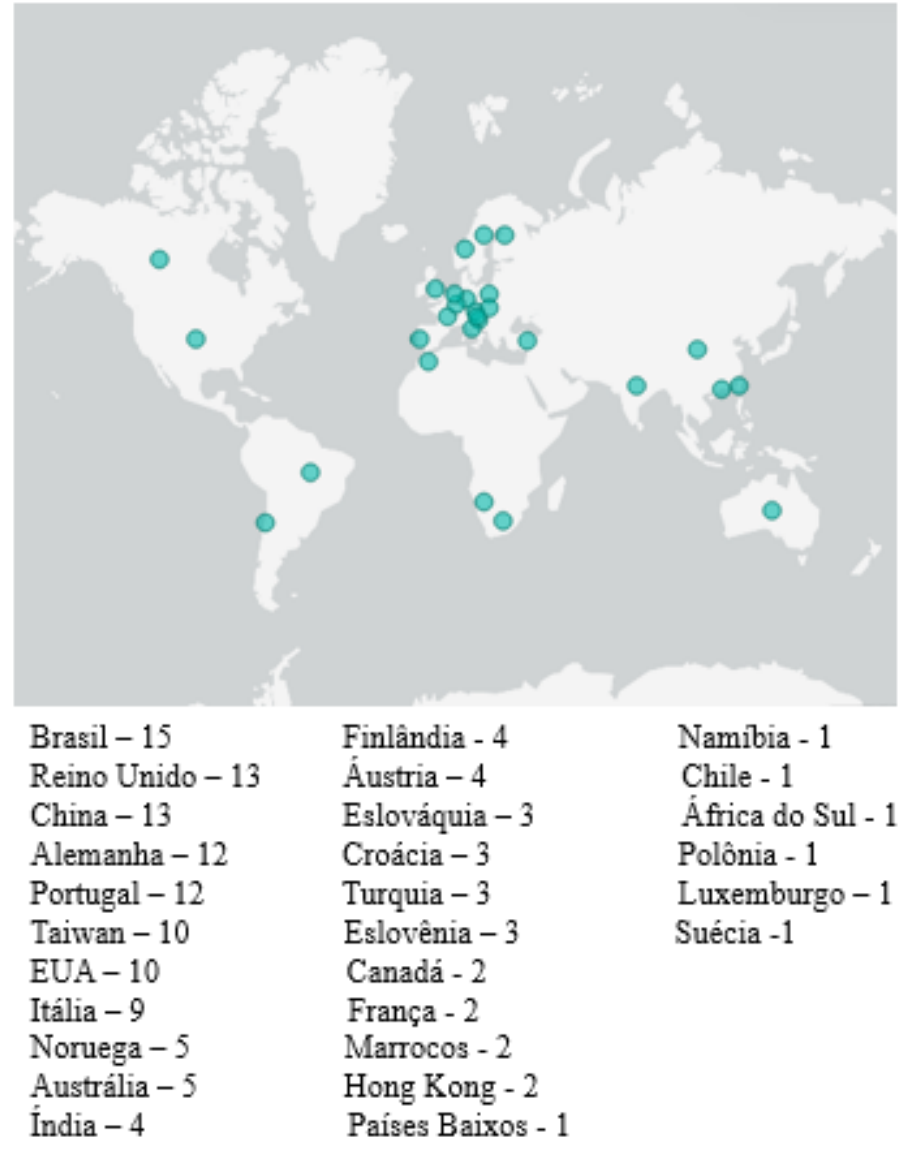

Figura 8: Origem dos autores

\subsection{Análise de conteúdo}

A seguir,éapresentadoo resultado da análise de conteúdo, que seguiu as recomendações de Seuring e Gold (2012).

\subsubsection{Fatores críticos de sucesso para o integração do LM com a 14.0}

Para Tortorella e Fettermann (2017), primeiro as empresas devem fazer a implementação LM para gerenciar melhor seus processos de mudança enquanto se movem rumo àI4.0. É necessário encontrar um equilíbrio adequado nessa mudança e a tecnologia e simplicidade devem existir simultaneamente.

Um fator crítico de sucesso ao se adotar as tecnologias da I4.0 com o lean é mudar a mentalidade de melhoria contínua nas empresas, ela deve estar mais 
consolidada(TORTORELLA et al., 2019a). Os autores relatam que se deve evitar a ilusão de que se pode apenas alcançar altos níveis de desempenho com a aquisição de tecnologias e não, também, mudando as práticas gerenciais.

Uma implementação bem sucedida do LM permite que a organização esteja preparada para iniciar a implementação das tecnologias da I4.0 (KAMBLE et al., 2019) e, também, ter um grande potencial para o sucesso e para a implementação duradoura da I4.0 (PEKARČÍKOVÁ et al., 2019).Rossini et al. (2019) realizaram uma survey e umas das conclusões é que empresas que adotaram fortemente as tecnologias da I4.0 são mais propensas a serem empresas que possuem um alto nível de LM. Logo, haver um bom ambiente LM instalado é uma condição facilitadora para a adoção das tecnologias da I4.0.Por fim, é destacado que o ambiente LM é um facilitador para a implementação da I4.0, que alavanca uma mudança radical no desempenho operacional.

Davies et al. (2017) enfatizam a importância da aceitação da mudança pelos funcionários. Eles enfatizam que, através da criação de uma cultura de melhoria contínua, a gestão e a força de trabalho como um todo não somente aceitarão a mudança, como, também, a impulsionarão ativamente.

Pekarčíkováet al. (2019) já ter implementado o LM é um grande fator de sucesso para a I4.0. Os avanços tecnológicos da I4.0 combinados com o LM facilitam as empresas a competirem com sucesso no mercado em um cenário paradoxal, com aplicativos de alta tecnologia, influenciados pela I4.0, e que possuem simplicidade, vinda do LM (TORTORELLA et al., 2019b).

Segundo Oliveira et al. (2017), para se obter o sucesso da implementação da I4.0, as empresas devem ter um alto grau de maturidade e conhecimento sobre as aplicações das práticas tradicionais do LM. Esse pensamento vai de encontro com o trabalho de Dombrowski et al. (2017). Eles argumentam que os processos das empresas devem ser definidos, eficientemente, antes que elas comecem a automatizar seus processos. Eles reforçam que LM constrói a base para a I4.0 e esta é capaz de complementar os avanços tecnológicos do LM.

Müller et al.(2017), relatam que processos interdisciplinares precisam de um entendimento comum entre o departamento técnico e o de tecnologia da informação. Isso é crítico do ponto de vista da digitalização. Veza et al. (2016) possuem um 
pensamento mais radical. Para eles, LM é obrigatório para a empresa que quiser avançar na I4.0. Isso se justifica pelo fato de que sem LM é mais provável que a empresa não possua conhecimentos sobre seus processos e seus principais indicadores. Eles ainda adicionam que para as empresas que não terminaram as instalações LM não poderão avançar rumo a I4.0.

Tezel e Aziz (2017) citam que, à medida que as novas tecnologias se tornam mais acessíveis e melhor integradas, as barreiras de integração serão superadas. Além disso, eles relatam que com a ajuda externa do governo, como por exemplo, com mandatos, novas tecnologias irão penetrar mais nas empresas.

Bell e Bell (2016) chegaram à conclusão de que somente empresas que entendem o seu propósito e o valor que oferecem aos clientes, podem utilizar a tecnologia big data da I4.0. Enfatizam, ainda, que a compreensão, intuição e empatia devem estar sempre presentes nos sistemas de gestão e na cultura da organização. Lee et al. (2016) relatam que a gestão do conhecimento é essencial para a empresa que busca instalações da smart factory.

A tabela 7 traz um a síntese de todos os fatores críticos de sucesso extraídas da amostra da pesquisa. Nota-se uma grande importância da implementação anterior do LM para que se obtenha sucesso na I4.0.

Tabela 7: Síntese dos Fatores Críticos de Sucesso

\begin{tabular}{|c|c|c|}
\hline $\begin{array}{l}\text { Fatores Críticos } \\
\text { de Sucesso: }\end{array}$ & Descrição: & Autores: \\
\hline $\begin{array}{l}\text { LM } \\
\text { implementado }\end{array}$ & $\begin{array}{l}\text { Com uma implementação bem sucedida do LM, a empresa } \\
\text { estará preparada para iniciar a implementação da I4.0. }\end{array}$ & Kamble et al. (2019) \\
\hline $\begin{array}{l}\text { LM } \\
\text { implementado }\end{array}$ & $\begin{array}{l}\text { Um ambiente LM instalado facilita a instalação das } \\
\text { tecnologias da I4.0. }\end{array}$ & Rossini et al. (2019) \\
\hline $\begin{array}{l}\text { LM } \\
\text { implementado }\end{array}$ & $\begin{array}{l}\text { Com uma implementação bem sucedida do LM, empresa } \\
\text { possui grande potencial para o sucesso e para a } \\
\text { implementação sustentável da I4.0. }\end{array}$ & $\begin{array}{l}\text { Pekarčíkováet } \\
\text { al.(2019) }\end{array}$ \\
\hline $\begin{array}{l}\text { Melhoria } \\
\text { contínua e } \\
\text { Mudança de } \\
\text { Práticas } \\
\text { Gerenciais }\end{array}$ & $\begin{array}{l}\text { Os gerentes devem adotar práticas de melhoria contínua } \\
\text { mais maduras. E devem mudar a sua postura. }\end{array}$ & $\begin{array}{l}\text { Tortorella et al. } \\
\text { (2019a) }\end{array}$ \\
\hline
\end{tabular}




\begin{tabular}{|c|c|c|}
\hline $\begin{array}{l}\text { Fatores Críticos } \\
\text { de Sucesso: }\end{array}$ & Descrição: & Autores: \\
\hline $\begin{array}{l}\text { LM } \\
\text { implementado }\end{array}$ & $\begin{array}{l}\text { A I4.0 combinada com o LM facilita as empresas a } \\
\text { competirem com sucesso no mercado, unindo aplicativos } \\
\text { de alta tecnologia e simplicidade. }\end{array}$ & $\begin{array}{l}\text { Tortorella et al. } \\
\text { (2019b) }\end{array}$ \\
\hline $\begin{array}{l}\text { LM } \\
\text { implementado }\end{array}$ & $\begin{array}{l}\text { Deve-se primeiro, implementar o LM para gerenciar } \\
\text { melhor os processos enquanto se move rumo a I4.0. É } \\
\text { necessário encontrar um equilíbrio adequado nessa } \\
\text { mudança e a tecnologia e simplicidade devem existir } \\
\text { simultaneamente. }\end{array}$ & $\begin{array}{l}\text { Tortorella e } \\
\text { Fettermann (2017) }\end{array}$ \\
\hline $\begin{array}{l}\text { Aceitação dos } \\
\text { funcionários e } \\
\text { LM } \\
\text { implementado }\end{array}$ & $\begin{array}{l}\text { Através da criação de uma cultura de melhoria contínua, a } \\
\text { gestão e a força de trabalho como um todo não somente } \\
\text { aceitarão a mudança, como, também, a impulsionarão, } \\
\text { ativamente. Por fim, é destacado que o ambiente LM é um } \\
\text { facilitador para a implementação da I4.0, que alavanca } \\
\text { uma mudança radical no desempenho operacional. }\end{array}$ & Davies et al. (2017) \\
\hline $\begin{array}{l}\text { LM } \\
\text { implementado }\end{array}$ & $\begin{array}{l}\text { Para se obter o sucesso da implementação da I4.0, as } \\
\text { empresas devem ter um alto grau de maturidade e } \\
\text { conhecimento sobre as aplicações das práticas } \\
\text { tradicionais do LM. }\end{array}$ & Oliveira et al. (2017) \\
\hline $\begin{array}{l}\text { LM } \\
\text { implementado }\end{array}$ & $\begin{array}{l}\text { LM constrói a base para a I4.0 e esta é capaz de } \\
\text { complementar os avanços tecnológicos do LM. Os } \\
\text { processos das empresas devem ser definidos, } \\
\text { eficientemente, antes que elas comecem a automatizar } \\
\text { seus processos. }\end{array}$ & $\begin{array}{l}\text { Dombrowski et al. } \\
\text { (2017) }\end{array}$ \\
\hline $\begin{array}{l}\text { Conexão entre as } \\
\text { áreas }\end{array}$ & $\begin{array}{l}\text { Existe um ponto de vista crítico para a digitalização: os } \\
\text { processos interdisciplinares precisam de um entendimento } \\
\text { comum entre o departamento técnico e o de tecnologia da } \\
\text { informação. }\end{array}$ & Müller et al.(2017) \\
\hline $\begin{array}{l}\text { LM } \\
\text { implementado }\end{array}$ & $\begin{array}{l}\text { LM é obrigatório para a empresa que quiser avançar na } \\
\text { I4.0. }\end{array}$ & Veza et al. (2016) \\
\hline $\begin{array}{l}\text { Gestão do } \\
\text { conhecimento }\end{array}$ & $\begin{array}{l}\text { A gestão do conhecimento é essencial para a empresa que } \\
\text { busca instalações da smart factory. }\end{array}$ & Lee et al. (2016) \\
\hline $\begin{array}{l}\text { Compreensão do } \\
\text { sistema }\end{array}$ & $\begin{array}{l}\text { Somente empresas que entendem o seu propósito e o valor } \\
\text { que oferecem aos clientes, podem utilizar a tecnologia big } \\
\text { data da I4.0. É importante apresença de compreensão, } \\
\text { intuição e empatia nos sistemas de gestão e na cultura da } \\
\text { organização. }\end{array}$ & Bell e Bell (2016) \\
\hline $\begin{array}{l}\text { Acessibilidade e } \\
\text { ajuda } \\
\text { governamental }\end{array}$ & $\begin{array}{l}\text { À medida que novas tecnologias se tornam mais } \\
\text { acessíveis e integradas, as barreiras de integração serão } \\
\text { superadas e a ajuda externa do governo, como por } \\
\text { exemplo, com mandatos, novas tecnologias irão penetrar } \\
\text { mais nas empresas. }\end{array}$ & Tezel e Aziz (2017) \\
\hline
\end{tabular}




\subsubsection{Barreiras e desafios para a implementação da integração do LM com a 14.0}

Segundo Tortorella et al. (2019a), a integração LM com I4.0 deve superar a contradição de que a primeira é baseada em baixa tecnologia e a segunda não. Uma barreira encontrada pelas empresas é o elevado nível de capital que as instalações I4.0 necessitam. A I4.0 força as empresas a reverem suas estratégias logo, as estratégias do ambiente LM devem ser adaptadas ou reconsideradas devido a implementação das tecnologias dessa revolução. O LM visa àestabilidade dos níveis de produção e uma baixa variabilidade nos tipos de produtos, por outro lado, a I4.0incentiva o nível de produção e a alta variabilidade de produtos.

Um desafio relatado por Kipper et al. (2019) é que os governos devem estar envolvidos na integração LM com I4.0. Para eles, isso é uma forma de facilitar e desenvolver formas de cooperação entre os setores e realizar esforços e investimentos com universidades e empresas.

Lugert et al. (2018) chegaram à conclusão de que a I4.0 é tecnologicamente orientada e deseja uma completa penetração da tecnologia da informação. O LM deseja reduzir a complexidade e baseia-se na padronização. Kolberg et al. (2017) relatam que LM, geralmente, é implementado com soluções sob medida para necessidades específicas da empresa eisso pode entrar em conflito com os esforços de alta tecnologia e capital intensivo da I4.0. Um desafio para as empresas é, ao implementarem o LM, pesarem inteligentemente as compensações da introdução de novas tecnologias (I4.0), em vez de ficar apenas em procedimentos operacionais padronizados e simples (TORTORELLA et al., 2019b)

Tezel e Aziz (2017) relatam diversas barreiras para a implementação desta integração. Primeira, existem questões de interoperabilidade entre as tecnologias emergentes. Segunda, o alto investimento inicial em tecnologia e custos de manutenção. Terceira, a falta de capital humano competente tanto nos processos LM, como nas tecnologias de informação emergentes. Quarta, a falta de melhores práticas e casos exemplares. Última, a falta de comprovação de que haverá retorno sobre o investimento.

Laux et al. (2017) mencionam, mais uma vez, a necessidade de trabalhadores qualificados e que estes são difíceis de serem encontrados. Como desafio, os autores 
mencionam que existem anormalidades na produção na conexão entre IoT e o jidoka, estas devem ser mais bem estudadas. Para Sahin et al. (2017), os desafios encontrados são: obter apoio entre os vários usuários e das múltiplas empresas de toda a cadeia de suprimentos, além disso, existem pessoas com menos habilidades técnicas.

Para Dombrowski et al. (2017), as empresas ainda estão analisando real potencial da I4.0 e estudando qual a tecnologia ideal e a que será mais promissora para o seu processo.

A tabela 8apresenta a síntese das barreiras e desafios encontrados.

Tabela 8: Síntese das Barreiras e Desafios

\begin{tabular}{|c|c|c|}
\hline $\begin{array}{l}\text { Barreiras e } \\
\text { Desafios: }\end{array}$ & Descrição: & Autores: \\
\hline $\begin{array}{l}\text { Contradição entre as } \\
\text { metodologias e custo }\end{array}$ & $\begin{array}{l}\text { A integração LM e I4.0 deve superar a contradição de } \\
\text { que a primeira é baseada em baixa tecnologia e a } \\
\text { segunda não. Uma barreira encontrada pelas empresas é } \\
\text { o elevado nível de capital que as instalações I } 4.0 \\
\text { necessitam. }\end{array}$ & $\begin{array}{l}\text { Tortorella et al. } \\
\text { (2019a) }\end{array}$ \\
\hline $\begin{array}{l}\text { Introduzir a nova } \\
\text { tecnologia de forma } \\
\text { inteligente }\end{array}$ & $\begin{array}{l}\text { A empresa deve sair do modo padronizado e simples } \\
\text { para que a introdução de novas tecnologias seja um } \\
\text { sucesso. }\end{array}$ & $\begin{array}{l}\text { Tortorella et al. } \\
\text { (2019b) }\end{array}$ \\
\hline $\begin{array}{l}\text { Estratégia } \\
\text { empresarial e } \\
\text { contradição entre as } \\
\text { metodologias }\end{array}$ & $\begin{array}{l}\text { A I4.0 força as empresas a reverem suas estratégias logo, } \\
\text { as estratégias do ambiente LM devem ser adaptadas ou } \\
\text { reconsideradas devido a implementação das tecnologias } \\
\text { dessa revolução. O LM visa à estabilidade dos níveis de } \\
\text { produção e uma baixa variabilidade nos tipos de } \\
\text { produtos, por outro lado, a I4.0 incentiva o nível de } \\
\text { produção e a alta variabilidade de produtos. }\end{array}$ & $\begin{array}{l}\text { Rosin et al. } \\
\text { (2019) }\end{array}$ \\
\hline $\begin{array}{l}\text { Falta de apoio } \\
\text { governamental }\end{array}$ & $\begin{array}{l}\text { Os governos devem estar envolvidos na integração LM } \\
\text { com I4.0. }\end{array}$ & $\begin{array}{l}\text { Kipper et al. } \\
(2019)\end{array}$ \\
\hline $\begin{array}{l}\text { Contradição entre as } \\
\text { metodologias }\end{array}$ & $\begin{array}{l}\text { I4.0 é uma revolução muito tecnológica. Baseia-se em } \\
\text { uma alta adoção da tecnologia da informação na } \\
\text { empresa. Por outro lado, o LM deseja reduzir a } \\
\text { complexidade e baseia-se na padronização. }\end{array}$ & $\begin{array}{l}\text { Lugert et al. } \\
(2018)\end{array}$ \\
\hline $\begin{array}{l}\text { Contradição entre as } \\
\text { metodologias }\end{array}$ & $\begin{array}{l}\text { O LM, geralmente, é implementado com soluções sob } \\
\text { medida (através de demanda) para necessidades } \\
\text { específicas da empresa, isso pode entrar em conflito com } \\
\text { os esforços de alta tecnologia e capital intensivo da I4.0. }\end{array}$ & $\begin{array}{l}\text { Kolberg et al. } \\
\text { (2017) }\end{array}$ \\
\hline
\end{tabular}




\begin{tabular}{|c|c|c|}
\hline $\begin{array}{l}\text { Barreiras e } \\
\text { Desafios: }\end{array}$ & Descrição: & Autores: \\
\hline $\begin{array}{l}\text { Custo, falta de capital } \\
\text { humano, casos de } \\
\text { sucesso e } \\
\text { comprovação de } \\
\text { retorno financeiro }\end{array}$ & $\begin{array}{l}\text { Existem diversas barreiras para a implementação. } \\
\text { Primeira, o alto investimento inicial em tecnologia e } \\
\text { custos de manutenção. Segunda, a falta de capital } \\
\text { humano competente tanto nos processos LM, como nas } \\
\text { tecnologias de informação emergentes. Terceira, a falta } \\
\text { de melhores práticas e casos exemplares. Última, a falta } \\
\text { de comprovação de que haverá retorno sobre o } \\
\text { investimento. }\end{array}$ & $\begin{array}{l}\text { Tezel e Aziz } \\
\text { (2017) }\end{array}$ \\
\hline $\begin{array}{l}\text { Obter apoio dos } \\
\text { diversos usuários e } \\
\text { falta de habilidade } \\
\text { técnica }\end{array}$ & $\begin{array}{l}\text { É complicado obter apoio entre os vários usuários da } \\
\text { empresa e das múltiplas empresas de toda a cadeia, } \\
\text { somado a isso, existem pessoas com menos habilidades } \\
\text { técnicas. }\end{array}$ & $\begin{array}{l}\text { Sahin et al. } \\
\text { (2017) }\end{array}$ \\
\hline $\begin{array}{l}\text { Falta de capital } \\
\text { humano e contradição } \\
\text { entre as metodologias }\end{array}$ & $\begin{array}{l}\text { Existe uma necessidade de trabalhadores qualificados e } \\
\text { que estes são difíceis de serem encontrados. Como } \\
\text { desafio, os autores mencionam que existem } \\
\text { anormalidades na produção na conexão entre IoT e o } \\
\text { jidoka, estas devem ser mais bem estudadas. }\end{array}$ & $\begin{array}{l}\text { Laux et al. } \\
\text { (2017) }\end{array}$ \\
\hline
\end{tabular}

\subsubsection{Benefícios da integração do LM com a 14.0}

Existem diversos benefícios do alinhamento LM com a I4.0. Os benefícios podem ser divididos nas seguintes categorias: desempenho operacional, desempenho financeiro, segurança e pessoas. No primeiro objetivo, segundo Hotrawaisaya et al. (2019), as práticas LM junto com a I4.0 melhoram a performance operacional das organizações. Pagliosa et al. (2019) e Tortorella e Fettermann (2017) também relatam ganhos operacionais.

Tortorella et al. (2019b) abordam diversos benefícios, tais como: desempenho operacional, a modularidade dos sistemas,que facilita ajustes de capacidades em momentos de flutuações sazonais, de forma que as práticas LM tendam a ser mais impactantes, pois a I4.0 permite uma maior compreensão das demandas dos clientes e acelera o compartilhamento de informações. Segundo Kipper et al. (2019) a combinação entre LM e I4.0 traz ganhos para a manutenção preditiva, tornando-a mais eficaz, devido ao uso de grandes quantidades de dados fornecidos pelo big data. 
Para Zhao et al. (2019) o uso da realidade aumentada para melhoria operacional traz ganhos como: reuniões virtuais, apresentações virtuais, controle on-line do setor de fabricação, automatização de processos operacionais e eliminação dos pontos fracos dos processos operacionais.Com o uso da I4.0 ocorre uma melhoria da produtividade (ROSIN et al., 2019).

Para Rossini et al. (2019), a adoção conjunta das duas visões leva a uma alta melhoria do desempenho operacional. Tortorella et al.(2019a) relatam que adoção de ambas as visões levam a níveis superiores de excelência o que geraria a necessidade da adoção de um processo de melhoria contínua.Além desses benefícios obtém-se, também, ganhos de flexibilidade (LUGERT et al., 2018).Zhang et al.(2018) relatam diversos benefícios da união lean e I4.0: melhora do gerenciamento dos armazéns, melhora da eficiência operacional do armazenamento, precisão aprimorada doa dados e redução do risco de erros humanos.

Buer et al.(2018a) construíram uma matriz relatando os benefícios da integração LM com I4.0, são eles: flexibilidade, produtividade, qualidade, redução de inventário e confiabilidade.Alguns desses benefícios entram em encontro com benefícios encontrados por Ma et al. (2017) que são: flexibilidade e confiabilidade.

Sony (2018) encontrou benefícios na integração vertical da I4.0 com os princípios LM. Para ele,será possível gerar valor para o cliente e, com isto, os recursos que são integrados serão utilizados da melhor forma possível. Davies et al. (2017) chega a conclusão de diversos benefícios operacionais por exemplo, a informação de que o estoque desejado foi atingido é obtida de forma automática com melhoria da eficiência, e redução de custos. Eles argumentam que o real objetivo ao se introduzir uma nova tecnologia na empresa é torná-la competitiva à medida que o tempo passa.

Chen (2017) em seu estudo de caso chegou à conclusão de que a integração LM com I4.0 melhora a rastreabilidade em uma cadeia de suprimentos alimentícia. Dentro de benefícios operacionais temos uma maior disponibilidade dos funcionários, devido a sensores nos equipamentos que, alinhados ao grande volume de dados disponível, conseguiram tomar decisões rápidas e obterem melhores resultados (OLIVEIRA et al., 2017). Uma característica da I4.0 são os modernos sistemas de TIC. Quando alinhados 
aos sistemas LM podem melhorar o desempenho da produção, melhorando a eficiência e os processos logísticos (DOMBROWSKI et al., 2017).

Podemos adicionar, ainda, as descobertas de Pagliosa et al. (2019). Segundo eles, o uso crescente de sistemas de informação e comunicação torna a engenharia digital mais flexível e a inovação de produtos rápida. Por exemplo, para Tortorella et al. (2019a) as tecnologias da I4.0 apoiam e facilitam as práticas LM de gestão da cadeia de suprimentos em relação a desenvolvimento e inovação de serviços relacionados aos clientes.

Mais um autor, Li (2019),ressalta que a união do LM com a I4.0 melhora a eficiência, reduz os defeitos e a melhoria contínua é enfatizada. Por fim, a integração dos dois segmentos melhora a coleta de dados, facilita a comunicação entre diferentes pessoas, melhora o processamento de informações e a exibição de dados (PEREIRA et al., 2019).

Na categoria de desempenho financeiro Hotrawaisaya et al. (2019) as práticas LM junto com a I4.0 melhoram a economia das empresas.O que vai de encontro com os estudos de Rosin et al. (2019), que relatam crescimento econômico.Mais uma vez a redução de custos é citada. Para Sahin et al. (2017) custos reduzem devido a diminuição do número de trabalhos atrasados pois, diminui o número de penalidadespagos por isso. Ma et al.(2017) e Buer et al.(2018a) também mencionam ganhos financeiros.

Dave et al. (2016) e Sahin et al. (2017) afirmam que o alinhamento entre LM e I4.0 acaba reduzindo os custos das empresas. Esses custos podem ser reduzidos através da diminuição dos resíduos, o que vai de encontro com LM (SANDERS et al., 2016). Através da união da tecnologia CPS da I4.0 com a metodologia LM pode-se controlar o escopo de investimento e manter os sistemas de tecnologia da informação existentes (MÜLLER et al., 2017). Para Anteet al. (2018) e Zhang et al. (2019), o alinhamento entre LM e I4.0 aumenta a produtividade econômica.

$\mathrm{Na}$ terceira categoria, a segurança, aconectividade entre as empresas aumentou com a I4.0, paralelamente, aumentou, também, a necessidade de se proteger contra ameaças cibernéticas, neste contexto existe a tecnologia cybersecutiry que protege as empresas nessa nova era (RÜßMANN et al., 2015; Kamble et al., 2019). 
O quarto, e último benefício, são as pessoas. Com a combinação entre o lean e a realidade aumentada ocorre o desenvolvimento da equipe, da marca, do aprimoramento da imagem da empresa e da liderança estratégica (ZHAO et al., 2019). Eles ainda, citam benefícios para a área de recursos humanos, tais como: recrutamento, treinamento, desenvolvimento e avaliação pessoal.Tortorella et al. (2019a) relatam de deve ocorrer uma mudança dos hábitos e das práticas gerenciais.

Segundo Müller et al. (2017), um ambiente de trabalho positivo é necessário rumo a mudança tecnológica e esta deve ser bem aceita pelos funcionários. Devido a esse novo ambiente integrado, a sociedade está preocupada, principalmente, em relação ao futuro do mercado de trabalho (VARELA et al., 2019). Essa união afeta a satisfação no trabalho (BUER et al., 2018a).

Com isso, nota-se que com uma implementação bem sucedida da união entre LM e I4.0 as empresas conseguirão obter impactos positivos em diversos campos de ação.

\subsubsection{Agenda de pesquisas futuras}

Com base na RSL, esta subseção apresenta as pesquisas futuras que podem ser realizadas para que se possa suprir as limitações encontradas através da análise dos artigos.

Tortorella et al. (2019a) sugerem que novas pesquisas sobre a integração devem ser realizadas em países emergentes com o objetivo de fornecer descobertas mais robustas que poderiam ser comparadas ao contexto das economias. Além disso, o novo trabalho deve possuir uma população mais ampla e dados atuais de indicadores de desempenho da cadeia de suprimentos, usar outras tecnologias que não foram abordadas em seu trabalho e, por fim, realizar uma comparação entre países emergentes e não emergentes. Rosin et al. (2019) sugerem que sejam realizados estudos de casos para analisar até que ponto as tecnologias da I4.0 melhoram o LM e a produtividade das empresas de manufatura.

Pagliosa et al. (2019) propõem três segmentos para pesquisas futuras: realização de estudos empíricos para comprovar a veracidade das sinergias propostas em seu trabalho entre LM e I4.0, categorização das tecnologias da I4.0 com o LM em diferentes níveis de fluxo de valor e mais estudos que examinem os efeitos do relacionamento LM 
com I4.0 no desempenho operacional. Tortorella et al. (2019b) aconselham que novas pesquisas devem envolver supervisores da linha de frente na classificação dos níveis de implementação do LM com a I4.0. Além disso, devem envolver variáveis adicionais do LM, tais como: envolvimento dos funcionários, fornecedores e relacionamento com cliente, gerenciamento da qualidade total e dos recursos humanos.

Varela et al. (2019) sugerem que novos trabalhos sobre LM, I4.0 e sustentabilidade social englobem mais países. Kamble et al. (2019) argumentam que trabalhos futuros devem considerar tecnologias específicas da I4.0 como variável moderadora para estudar o efeito LM no desempenho sustentável da organização. O trabalho realizou entrevistas no ambiente de indústrias farmacêutica, química e automobilística. Sugere-se que sejam realizados trabalhos em outros ramos. Para Kipper et al. (2019) futuros trabalhos devem ser realizados para desenvolver frameworks e estudos de caso a partir da integração LM com I4.0.

Rossini et al. (2019) aconselham que à medida que a adoção das tecnologias I4.0 torna-se mais madura, futuros estudos devem ser realizados para que, talvez, possam indicar uma melhor relação entre uma determinada tecnologia I4.0 e uma ferramenta LM e como isso pode afetar o desempenho. Sony (2018) aponta que futuras pesquisas devem explorar detalhes sobre os fatores críticos de sucesso para a integração LM e I4.0, baseada nos cinco princípios do LM.

Buer et al. (2018a) fazem diversas propostas para futuras pesquisas. Primeira, realizar quais são os impactos da I4.0 nas seguintes práticas LM: 5S, kaizen e pessoas. Segunda, estudar de forma mais profunda/específica os efeitos facilitadores LM na implementação da I4.0. Terceira, realizar estudos empíricos sobre as implicações no desempenho da integração LM e I4.0. Quarta, estudos devem ser concentrados em como os fatores ambientais afetam o desempenho e a compatibilidade entre LM e I4.0. Por fim, deve-se construir um framework para a implementação da integração entre LM e I4.0.

Kolberg et al. (2017) sugerem que se deve-se realizar mais estudos específicos entre as práticas LM e a I4.0. Dombrowski et al. (2017) sugerem a realização de uma análise mais profunda em relação às metas perseguidas na implementação da I4.0, durante o período de sua implementação nas empresas. Os autores argumentam que 
isso ajudarias as empresas a avaliarem possíveis melhorias em seus processos LM e I4.0. Tortorella e Fettermann (2017) sugerem a realização de mais pesquisas com diferentes empresas, com coleta e análise de dados mais elaborados. 


\section{Frameworks para integração entre o Lean Manufacturing e a Indústria 4.0}

Este capítulo apresenta, inicialmente, os resultados obtidos com o painel de especialistas que visou aperfeiçoar e validar os resultados obtidos com a revisão sistemática de literatura (vide capítulos 3 e 4 da dissertação). Em seguida, são apresentados os dois frameworks propostos para integração entre o LM e a I4.0.

\subsection{Aperfeiçoamento e validação dos frameworks com base no Painel comEspecialistas}

Inicialmente, o framework 1, nomeado de união de princípios, práticas e tecnologias, apresentava 14 caixas de combinações entre as práticas LM e as tecnologias I4.0. As tecnologias Machine Learning e Cyber-Security ainda não tinham sido utilizadas. Através da primeira entrevista, os princípios de cada caixa foram ajustados de acordo com o entendimento do entrevistado. Nenhuma combinação foi acrescentada. $\mathrm{Na}$ segunda entrevista, em algumas caixas de combinações, os princípios foram ajustados e Machine Learning passou a ser utilizado. Na terceira entrevista, mais seis combinações passaram a fazer deste framework. Porém, Cyber-Security continuou a não ser utilizado. Com a quarta entrevista, mais quatro combinações foram acrescentadas. Totalizando vinte e quatro combinações. Porém, Cyber-Security continuou a não ser utilizado. Na quinta entrevista, algumas combinações foram retiradas e outras acrescentadas, Cyber-Security passou a ser utilizado. Na última entrevista, chegou-se à conclusão de que a tecnologia Cyber-Security devia ser combinada com todas as caixas, afinal, a segurança deve ser uma preocupação constante no dia a dia da empresa.

É importante mencionar que, no começo, este trabalho tratava as tecnologias CPS e IoT de forma separada, pois na literatura alguns autores mencionam eles de forma separada outros de forma conjunta. Através do Painel, foi destacado que, realmente, a 
IoT é um caso especial de CPS e, com isso, essas tecnologias da I4.0 não podiam ser tratadas de forma separadas.

Algumas caixas de combinações foram retiradas outras foram adicionadas e, no final, oframework 1 ficou com quatorze combinações entre as práticas LM e tecnologias I4.0. Após essa primeira rodada de entrevista, foi enviado o framework 1 final para todas os participantes, as observações recebidas foram apenas em relação aos princípios que faziam parte de cada caixa de combinação. Com isso, o framework 1 foi aperfeiçoado pelos especialistas e passou por sua uma primeira validação.

O framework 2, denominado de Etapas de Implementação da Integração entre o LM e a I4.0, também passou por aperfeiçoamentos ao longo das entrevistas. Com a primeira entrevista, alguns fatores críticos de sucesso foram acrescentados. Na segunda entrevista, novamente, alguns fatores críticos de sucesso foram acrescentados além, de barreiras e desafios. Os impactos iniciais eram: desempenho operacional, desempenho financeiro, inovação, segurança e pessoas. Através da terceira entrevista, decidiu-se que inovação deveria estar dentro de desempenho operacional. $\mathrm{O}$ quarto entrevistado acrescentou fatores externos que afetavam o ambiente empresarial. Esses fatores são análises das características dos produtos vendidos, das características da produção e das características da cadeia de suprimentos. O quinto entrevistado acrescentou que esses fatores externos além de influenciarem a empresa, também eram influenciados por ela. Outra sugestão aceita, foi a de que todo esse processo é contínuo e sempre sofrerá melhorias. Além disso, ela também acrescentou fatores críticos de sucesso e barreias e desafios. Por fim, o último entrevistado acrescentou que existem fatores ambientais, tais como: comunidade e meio ambiente, que influenciam e são influenciados pela empresa. Após essa primeira rodada de entrevista, foi enviado o framework 2 final para todas os participantes, nenhuma observação acerca desse framework 2 foi recebida, com isso ele foi aperfeiçoado pelos especialistas e passou por sua uma primeira validação.

Além das perguntas feitas sobre os frameworks, foram adicionadas questões sobre o ambiente LM e I4.0, sobre o ambiente que o cerca, fornecedores e clientes. Para os entrevistados, o desempenho operacional é o mais fácil de ser percebido e através dele vem o desempenho financeiro. A segurança ainda é um fator e traz desconfiança para 
as empresas. Os ganhos em relação às pessoas ainda são um impacto difícil de ser percebido.

A participação conjunta com fornecedores e clientes é fundamental e depende da estratégia da empresa e do nível de maturidade da cadeia de suprimentos. Falta sinergia entre as partes interessadas. O esforço de integração deve ser mútuo. Deve-se começar pela integração interna para que, assim, possa ser feita a integração externa. Um fator importante que deve ser destacado é que os fornecedores possuem diversos clientes em sua carteira e para eles pode ser difícil atender as demandas de adaptação de cada empresa com as quais negociam. Muitas relações são temporárias, com isso, o compartilhamento de dados pode ser algo arriscado e isto afeta a compatibilidade entre as empresas. A baixa compatibilidade entre os sistemas da cadeia de suprimentos é um limitador para a integração LM com a I4.0.

Foram destacadas algumas questões importantes. Primeiro, muitas empresas começaram a adotar as tecnologias I4.0 em seu ambiente LM porque seus concorrentes já tinham começado a adotar e isso ocorreu sem muito planejamento. Segundo, pode acontecer de o esforço para se adotar a integração LM com I4.0 seja muito grande e a melhoria seja, apenas, em uma pequena parte/etapa do processo. Terceiro, é difícil para empresa identificar qual combinação entre as práticas LM e tecnologias I4.0 deve ser usada para que seu objetivo final seja alcançado: identificar qual é a combinação ideal que que culminará no menor gasto de recursos e trará um maior retorno. É importante que a empresa conheça bem os seus processos e problemas para encontrar a solução ideal e, assim, chegar ao resultado desejado. Quarto, a compatibilidade de sistemas não existe apenas entre os membros da cadeia de suprimentos, existe também dentro das empresas. Existem diversas empresas que operam com diversos sistemas diferentes que não se conectam e isso deve ser solucionado antes que elas possam se conectar com o ambiente externo.

Por fim, as opiniões de um especialista sempre eram mencionadas anonimamente nas demais entrevistas para que, assim, se pudesse ter uma segunda/terceira opinião. Isso acontecia em todos os casos em que as opiniões eram iguais ou divergentes. Esse trabalho sempre buscou ter uma opinião majoritária sobre os assuntos tratados. 


\subsection{Framework1:União dos princípios, práticas e tecnologias}

A partir da análise dos artigos selecionados na RSL, foi analisado quais princípios do LM e da I4.0 que cada um seguia. Em seguida, com a combinação das práticas LM e das tecnologias da I4.0, esses princípios foram agrupados. Muitos artigos abordaram de forma generalista o alinhamento LM com a I4.0, sem mencionar, detalhadamente, as tecnologias utilizadas de ambos conceitos. Através dos artigos e dos Painéis realizados, pôde-se combinar todas as práticas LM com as tecnologias da I4.0. As combinações, que possuem um número ao lado, correspondem aos artigos enumerados na Tabela 6 do Capítulo 4 e as demais foram agregadas através do Painel com Especialistas. Esse framework 1 é inspirado no trabalho de Farias et al. (2019) e a figura 9 representa, visualmente, essas combinações: 


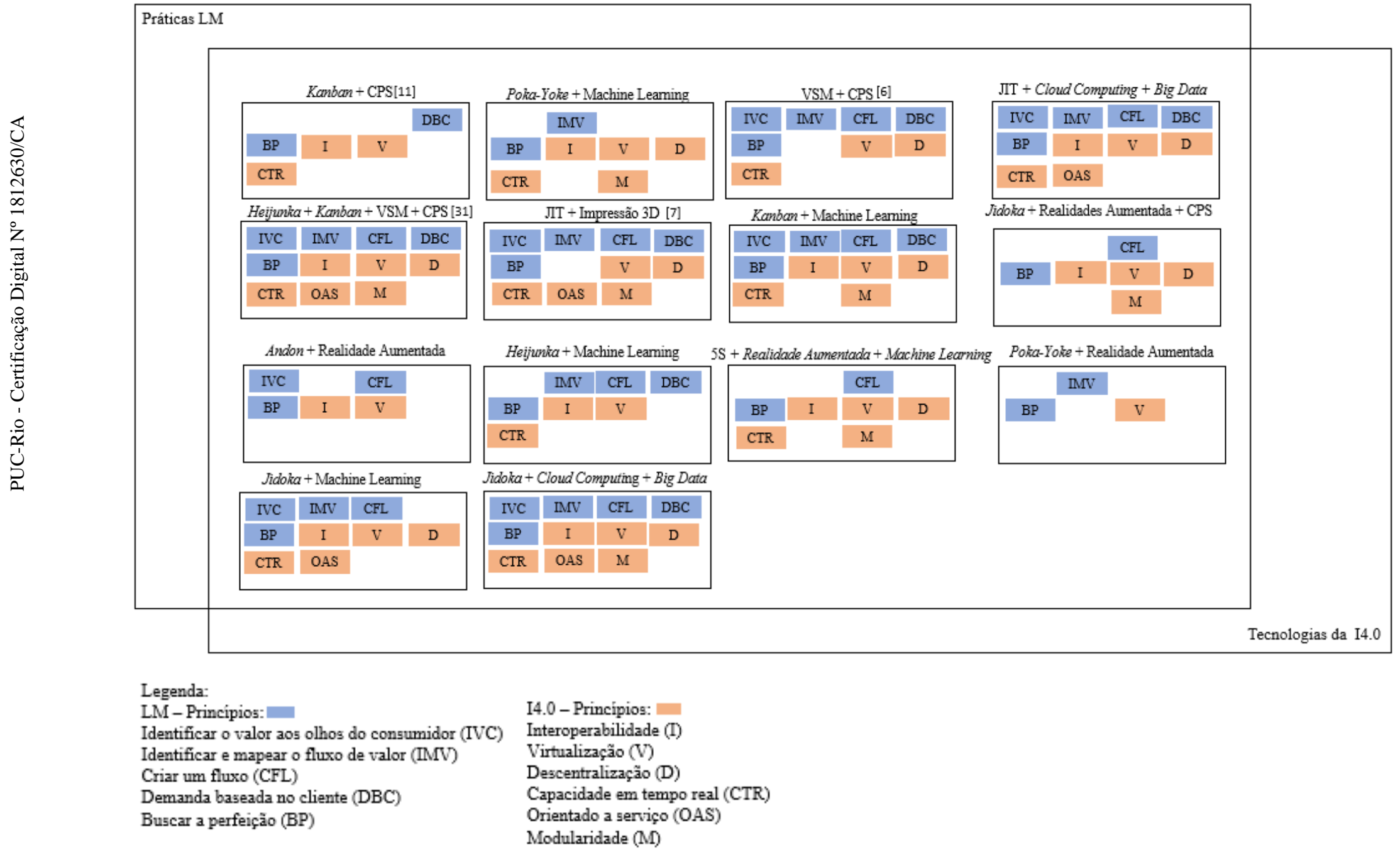

Figura 9: Framework1- União de princípios, práticas e tecnologias 
Kolberg et al. (2017) estudou a junção entre kanban e CPS. Kanban, na cultura japonesa, é muito utilizado para solucionar gargalos e atividades que não estão fluindo bem de uma para outra. Neste caso, se é usado para solucionar esse tipo de problema e junto com o CPS é uma boa combinação. Nos casos de uso como ferramenta de gestão, não é o recomendado. Huang et al. (2019) fizeram um estudo robusto, combinaram heijunka, kanban, VSM e CPS. Nesta segunda combinação, está sendo adicionada a orientação à demanda através do Heijunka, que nivela a produção de forma orientada para a demanda. Seu uso é recomendável para o fluxo de materiais e para desatar os gargalos (forma de serviço).

Andon e Realidade Aumentada, o primeiro refere-se à uma sinalização/lanterna japonesa em que se pode observar a gestão de resultados. Ocorre uma sinalização caso surja alguma anormalidade no processo. Com a Realidade Aumentada pode-se formar um modelo 3D, em que o objeto problemático seria sinalizado. A Realidade Aumentada, também, pode ser usada para colorir a produtividade da fábrica em tempo real, considerando a utilização de visualizadores 3D $(\mathrm{nD})$ para a gestão visual da produção. Contudo, deve-se ressaltar, que não é uma ferramenta de processo. Por fim, considera-se que a pessoa conhece a planta da fábrica.

O Jidoka e o Machine Learning também trazem ganhos para a empresa. Através do primeiro, ocorrerá a monitoração do fluxo contínuo. Com o Machine Learning, através da identificação de uma anomalia seu algoritmo, poderá ser treinado, baseado nos erros que apareceram no histórico e ser calibrado para se antecipar a possíveis problemas. Com base no histórico, identificará possíveis futuros problemas conferindo assim, robustez ao sistema.

Mais uma vez o Machine Learning é usado em uma combinação, desta vez com o Poka-Yoke. Pode-se identificar os defeitos de máquinas e, através de algoritmos, os erros futuros poderão ser previstos com base no passado. JIT foi combinado com a Impressão 3D, no trabalho de Chen e Lin (2017). A impressão 3D funciona muito bem em peças de alta relevância e baixo giro de estoque. Considerando um cenário JIT, neste contexto, é justificável o uso da Impressão 3D que é uma combinação importantíssima nas situações em que a peça é muito importante para o consumidor. 
Deve-se ressaltar que, com uma alta demanda, essa combinação não poderá ser usada, pois impressão 3D não possui essa capacidade. Logo, também não atenderá ao JIT.

A conexão do Heijunka com o Machine Learning agrega, positivamente, às empresas. Enquanto que o Heijunka é uma forma de controlar a variabilidade da chegada de trabalho e o Machine Learning ajuda a prever os dados futuros com base em dados do passado. Isso é bem utilizado para melhorar decisões de negócios, em relação à demanda da empresa. Deve-se realçar que, o Heijunka pode ser em utilizado em modelos centralizados e descentralizados, dependendo da política da empresa.

O trio Jidoka, Cloud Computing e Big Data também pode ser utilizado. Ressaltase que a duplicação dados para colocar na nuvem é algo oneroso. Neste caso, com o Big Data tem-se um modelo centralizado. Deve-se ficar atento para o fato de que existem outras tecnologias, mais baratas, que podem substituir o Big Data como, por exemplo, a Arquitetura de MicroServiços. Em adição, o modelo de Big Data não é orientado a serviço. Chen (2016) analisou a conexão entre o VSM e o CPS. Essa combinação pode ser bem utilizada para o fluxo de materiais. Para atividades de gestão e fluxo de informações o VSM não é efetivo, mas o CPS, sim.

Mais uma vez é utilizado o Kanban, mas com o Machine Learning. O primeiro destrava os gargalos e para se ter uma aprendizagem desta situação, pode-se usar o Machine Learning. Um meio para que os erros passados não se repitam. Dessa vez tem-se uma combinação robusta: 5S, Realidade Aumentada e Machine Learning. Isso pode ser usado como um mecanismo de marketing para que o empregado tenha o hábito correto no dia a dia. É recomendável a formulação de campanhas de instruções e de boas práticas no posto de trabalho, como uma forma de reciclagem. Deve-se enfatizar que, é difícil alguém fazer o 5S e investir parte do seu tempo para melhorálo. Através do Machine Learning uma previsão dos erros com base do passado pode ser feito para que o 5S seja melhorado. O computador terá todas as informações, usará esse conhecimento tácito dos colaboradores, acerca de eliminar desperdícios e fazer com que o computador aprenda. O computador através de um monitoramento irá decidir se a pessoa deve ou não voltar ao treinamento de boas práticas.

JIT, Cloud Computing e Big Data podem ser combinados para uma melhoria de processos, deve-se lembrar do algo custo do Big Data e que existem opções mais 
baratas. Através do Jidoka, da Realidade Aumentada e do CPS ocorre o monitoramento do fluxo continuo, identificação de anormalidades e, com a ajuda dos sensores, ocorrerá uma virtualização dos problemas do mundo real. É uma gestão visual do fluxo continuo. Com o Poka-Yoke e a Realidade Aumentada juntos atuam na identificação de defeitos.

Destaque para o Cyber-Security que deve estar inserido em todos os ambientes para que se tenha uma segurança das informações compartilhadas. Essa segurança deve existir dentro da empresa e entre as empresas.

Em relação aos princípios, nota-se que o Buscar a Perfeição (BP) sempre está presente, afinal é o fundamento primordial do LM. A melhoria contínua, kaizen, deve estar sempre presente. Quanto a I4.0, o princípio que foi mais utilizado foi a Virtualização (V), afinal essa revolução prima por isso, fazer a conexão entre o mundo real e o virtual.

Esse framework procurou ajudar profissionais a compreender melhor $\mathrm{o}$ alinhamento entre as práticas LM e as tecnologias I4.0. Através de sua análise pôde-se constatar quais aspectos organizacionais poderão melhorar através da implementação conjunta do LM com a I4.0. Dessa forma, pôde-se avaliar os futuros impactos organizacionais. A proposta é que ele sirva para auxiliar a tomada de decisão em relação a qual combinação ideal irá atender aos objetivos estratégicos da empresa.

\subsection{Framework2: Etapas de Implementação da Integração entre o LM e a 14.0}

O framework2 foi desenvolvido de acordo com as análises realizadas neste trabalho. Primeiro, identificou-se os fatores críticos de sucesso, as barreiras e os desafios existentes na empresa para a implementação do alinhamento entre o LM e a I4.0. Através dessa etapa, foi observado o que deveria ser feito para se atingir o objetivo final.

Em seguida, de acordo com a etapa anterior, selecionou-se as práticas, tecnologias que atendam às características identificadas na empresa (framework 1). Esse framework 2 é inspirado no trabalho de Souza e Alves (2018). A figura 10 representa o framework 2 , definindo as etapas que uma empresa deve seguir, se desejar 
implementar um ambiente integrado do LM com a I4.0.A Figura 11apresenta um exemplo com base na literatura estudada e no Painel com Especialistas. Os fatores críticos de sucesso, as barreiras e os desafios possuem uma numeração ao lado que corresponde às referências enumeradas na Tabela 6 do Capítulo 4. 
72

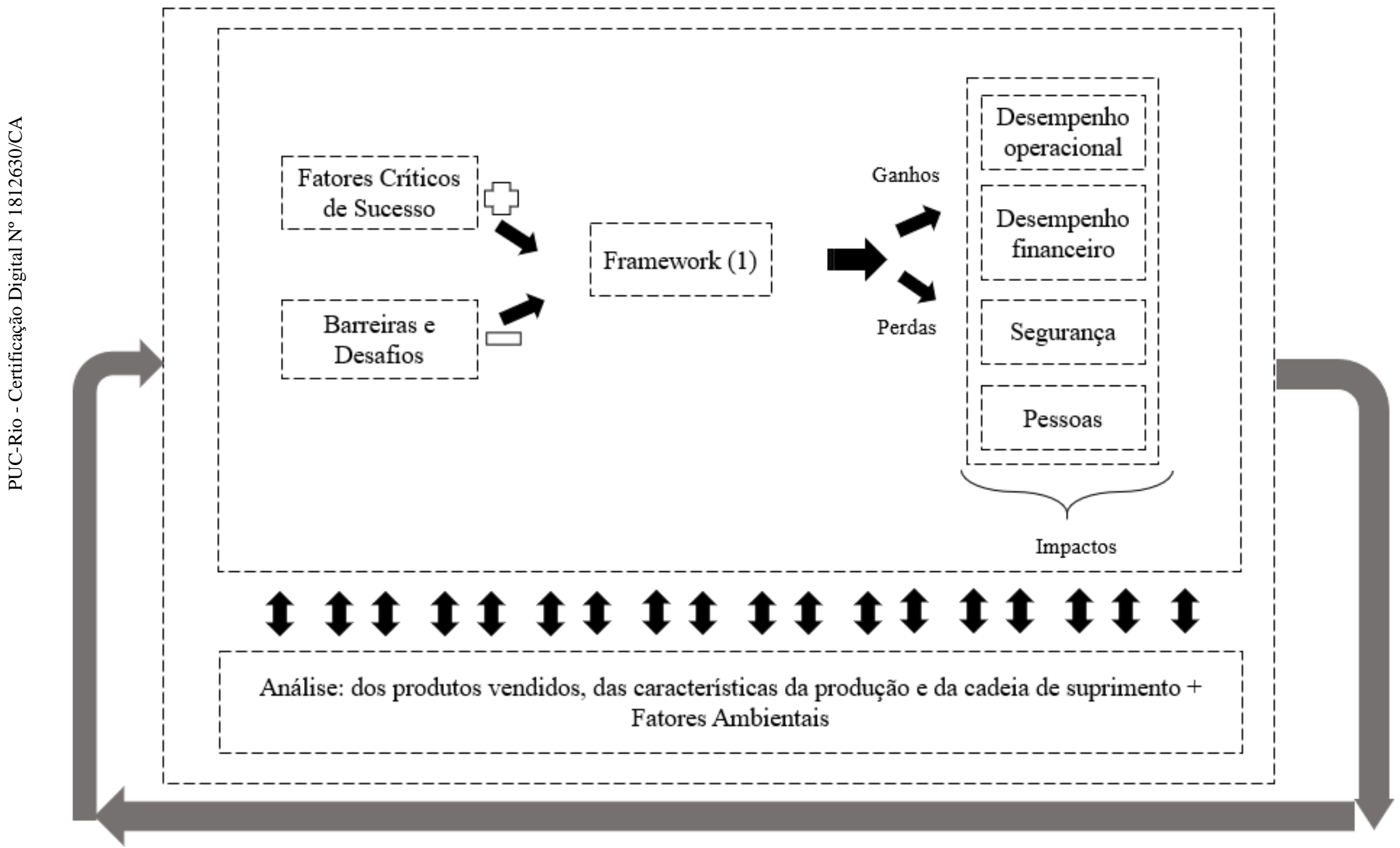

Figura 40: Framework2 - Etapas de Implementação da Integração entre o LM e a I4.0 


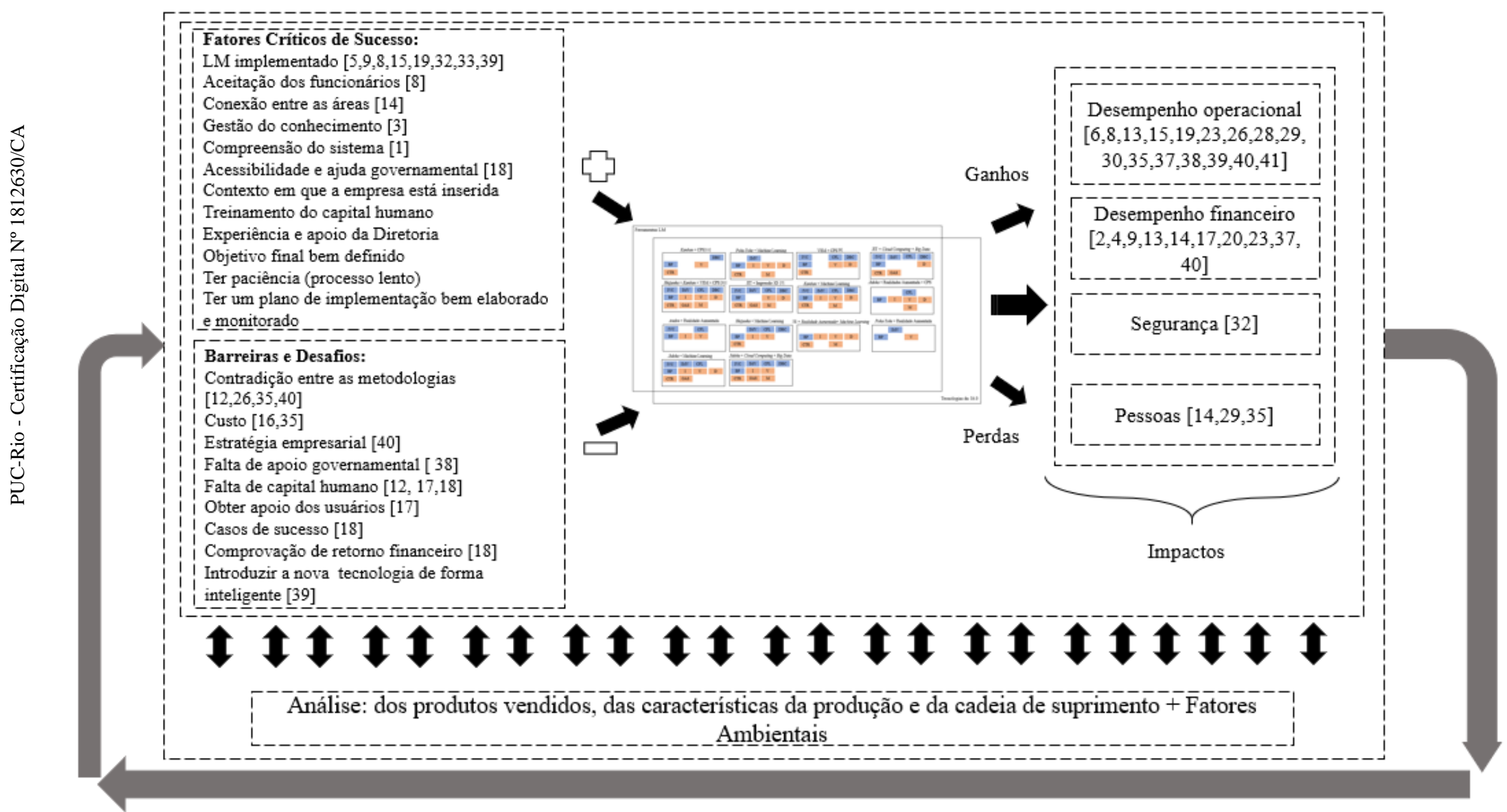

Figura 11: Exemplo do framework2-Etapas de Implementação da Integração entre o LM e a I4.0 
Com o auxílio da literatura e com o Painel de Especialistas, o framework 2 foi construído e aperfeiçoado. Primeiro, deve-se mapear os fatores críticos de sucesso, as barreiras e os desafios. Isso é fundamental para um bom gerenciamento da empresa. Devido a esse pensamento, concluiu-se que é, também, de suma importância entender os fatores críticos de sucesso e como, por exemplo, implementar o ambiente LM na empresa para, em seguida, instalar as tecnologias da I4.0.

É importante, também, identificar as barreiras que podem existir para a implementação do LM e da I4.0, pois é um novo ambiente que será instalado nas empresas. As empresas estarão mais preparadas para os desafios que podem surgir.

Em seguida, o framework 1 será consultado para que seja feito o alinhamento entre as práticas LM e as tecnologias da I4.0 que possam atender aos objetivos da empresa. Neste contexto, é importante a participação e a qualificação das pessoas. Para a união do LM com a I4.0, existe uma necessidade de trabalhadores qualificados e estes são difíceis de serem encontrados (LAUX et al. (2017). A I4.0 exige altos níveis de digitalização em todos os processos da empresa, pois entender as metas desejadas ajuda a própria organização a avaliar possíveis melhorias de processo (DOMBROWSKI,2017; VARELA et al., 2019). Por fim, como produto, espera-se alcançar impactos positivos, tais como: desempenho operacional, desempenho financeiro, segurança e pessoas (como, por exemplo, melhoria no ambiente de trabalho). Deve-se destacar que, se o processo não for aplicado corretamente, pode ocasionar perdas para a empresa.

Todo esse processo deve ser feito, simultaneamente, com a análise das características dos produtos vendidos, das características da produção e das características da cadeia de suprimentos. Cada segmento tem suas singularidades e, até mesmo dentro do próprio segmento, as características de uma empresa para outra mudam. Além disso, os fatores ambientais interferem em todo esse processo. Buer et al. (2018a) mencionam que com a união dos dois no sistema produtivo é provável que fatores ambientais influenciem na sua integração. Esses fatores ambientais podem ser descritos como a comunidade local e a preocupação com o meio ambiente. Tudo isso influencia e é influenciado pela integração. 
Por fim, toda essa análise é continua, deve ser feita e posteriormente analisada para futuras melhorias. LM preza pela busca à perfeição e a I4.0 prega a digitalização completa.

Através da análise da Figura 13 e do Painel com Especialistas, nota-se uma dificuldade, por parte da indústria e academia, de perceber os impactos que essa integração pode trazer. O impacto mais difícil de ser enxergado é o relacionado à segurança, seguido das pessoas, desempenho financeiro e, por fim, o desempenho operacional. 


\section{Conclusão}

Essa dissertação de mestrado tem como objetivo principal analisar os pontos de sinergia entre o Lean Manufacturing e a Indústria 4.0. Dois frameworks para a integração do Lean Manufacturing com a Indústria 4.0 na manufatura são propostos, suprindo uma carência na literatura. Espera-se que ambos ajudem empresas a melhorareme gestão de seus recursos e a sua tomada de decisão sobre qual combinação de ferramenta e tecnologia trará maiores benefícios. Isso se torna importante visto que as empresas, muitas vezes, possuem recursos limitados. A partir de uma Revisão Sistemática da Literatura foi construída uma primeira versão dos frameworks, que foram posteriormente aperfeiçoados por um Painel com Especialistas das áreas de Lean Manufacturing e da Indústria 4.0 para uma primeira etapa de validação.

A análise descritiva oferecida na dissertação aponta para um crescimento de artigos na literatura sobre o tema, com cada vez mais interesse por antigos de vieses práticos na academia. Dentre os países que mais publicam sobre o assunto, o Brasil, país emergente, ocupa o primeiro lugar. A Alemanha, lugar de origem da I4.0, ocupa o terceiro lugar.

A análise de conteúdo ajudou na construção dos frameworks. O primeiro framework tem por objetivo combinar as práticas LM com as tecnologias da I4.0 e, assim, fornece informações sobre quais princípios de ambas as vertentes ela atende. Paralelamente, é feita uma descrição de como cada combinação pode ser utilizada na empresa e como ela irá contribuir para a melhoria do seu ambiente de manufatura.O segundo framework começa com o mapeamento dos fatores críticos de sucesso e das barreiras e desafios para as empresas que é o ponto inicial para a implementação desse ambiente integrado do LM com a I4.0. O conhecimento dessas informações é de suma importância para o sucesso da implementação da integração o LM com a I4.0. De acordo com a pesquisa o principal fator crítico de sucesso é já ter um ambiente lean instalado de forma correta e funcionando corretamente. Em relação as barreias e desafios deve-se encontrar um meio termo pois existe uma contradição entre as metodologias: o LM preza pela simplicidade e a I4.0 utiliza muitas tecnologias. 
Com a realização da primeira etapa, deve-se utilizar o primeiro framework para encontrar a combinação ideal de ferramenta LM e tecnologia I4.0 para a empresa. Após isso teremos os impactos: desempenho operacional, desempenho financeiro, segurança e pessoas. Eles podem ser positivos ou negativos, isso depende se a implementação ocorreu de forma correta. Tudo isso é afetado e afeta o ambiente externo, deve-se estar atento aos produtos, a produção, a cadeia de suprimentos e aos fatores ambientais. Um detalhe de grande importância é que esse processo é iterativo, a empresa sempre vai buscar a melhoria contínua de seus processos.

Este trabalho visacontribuir positivamente à academia visto que apesar de ser um tema em pleno crescimento, ele ainda deve ser mais explorado com o objetivo de auxiliar futuros pesquisadores. Todo o seu potencial ainda não foi investigado e existe uma lacuna em relação aosframeworks de implementação do LM com a I4.0. As empresas estão sempre interessadas em estarem a frente de seus concorrentes, isso pode ser feito através da busca por melhoria contínua com novas tecnologias. Este trabalho, buscou também auxiliar as indústrias que visam integrar essas duas vertentes. Afinal, com boa orientação e uma aplicação correta as chances de sucesso aumentam.

Esse trabalho foi realizado através de uma RSL, onde algumas palavras-chave foram selecionadas e pode-se ampliar as buscas por mais artigos com novas palavras. Essa é, por outro lado, uma limitação deste trabalho. O Painel com Especialistas foi realizado com seis pessoas e, no futuro, pode-se utilizar mais estudiosos ou Grupo Focais para o melhoramento do resultado.Sugere-se também para pesquisas futuras considerar a aplicação dosframeworksno contexto industrial de manufatura.

\section{Referências Bibliográficas}

AHUETT-GARZA, H.; KURFESS, T. A brief discussion on the trends of habilitating technologies for Industry 4.0 and Smart manufacturing. Manufacturing Letters, v. 15, p.60-63, 2018. 
ALFALLA-LUQUE, R.; MARIN-GARCIA, J.; MEDINA-LOPES, C. An analysis of the direct and mediated effects of employee commitment and supply chain integration on organizational performance. International Journal of Production Economics, v. 162,p. 242-257, 2015.

ANTE, G.; FACCHINI, F.; MOSSA, G.; DIGIESI, S. Developing a key performance indicators tree for lean and smart production systems. IFAC-PapersOnLine, v. 51, n. 11, p. 13-18, 2018.

ANTONY,J.; GUPTA, S.; VIJAYA, S. M.; GIJO, E. V. Ten commandments of Lean Six Sigma: a practitioners' perspective. International Journal of Productivity and Performance Management, v. 67, p. 1033-1044, 2018.

ARCIDIACONO, G.; PIERONI, A. The Revolution Lean Six Sigma 4.0. International Journal on Advanced Science, Engineering and Information Technology, v.8 n. 1, p. 141-149, 2018.

BAMBER, L; DALE, B. G. Lean production: A study of application in a traditional manufacturing environment. Production Planning and Control, v. 11, n. 3, p. 291298, 2000.

BELL, S.; BELL, K. W. Big Data and Lean Thinking: Balancing Purpose, Process, and People. Cutter IT Journal, v. 29, n. 6, 2016.

BOYNTON, A.; ZMUD, R. Assessment of Critical Success Factors. Sloan management review, v. 25, p. 17-27, 1984.

BUER, S. -V.; STRANDHAGEN, J. O.; CHAN, F. T. S. The link between Industry 4.0 and lean manufacturing: mapping current research and establishing a research agenda. International Journal of Production Research, v. 56, n.8, p. 2924-2940, 2018a.

BUER, S. -V.; FRAGAPANE, G. I.; STRANDHAGEN, J. O. The Data-Driven Process Improvement Cycle: Using Digitalization for Continuous Improvement. IFACPapersOnLine, v. 51, n. 11, p. 1035-1040, 2018 b.

CAMGÖZ-AKDAĞ, H.; BELDEK, T.; KONYAHOĞLU, A. K. Process Improvent in a Radiology Department with Value Stream Mapping and its Linkage to Industry 4.0. IIAOB Journal, v. 9, n. 6, p. 36-41, 2018.

CHEN, R.-Y. An intelligent value stream-based approach to collaboration of food traceability cyber physical system by fog computing. Food Control, v. 71, p. 124-136, 2017.

CHEN, T.; LIN, Y. -C. Feasibility Evaluation and Optimization of a Smart Manufacturing System Based on 3D Printing: A Review. International Journal of Intelligent Systems, v.32, n. 4, p. 394-413, 2017. 
CHIARINI, A. Integrating lean thinking into ISO 9001: a first guideline. International Journal of Lean Six Sigma, v. 2, n. 2, p. 96-117, 2011.

COOK, D. J., MULROW, C. D; HAYNES, R. B. "Systematic Reviews: Synthesis of Best Evidence for Clinical Decisions." Annals of Internal Medicine 126 (5): 376-380, 1997.

COOPER, H. M.. Research Synthesis and Meta-Analysis. A Step-by-Step Approach. 4th ed. Thousand Oaks, CA: Sage, 2010

CRONIN, P., RYAN, F.; COUGHLAN, M. Undertaking a Literature Review: A Stepby-Step Approach.. British Journal of Nursing, v. 17, n.1, p. 38-43, 2008.

DAVE ,B.; KUBLER, S.; FRÄMLING, K.; KOSKELA, L. Opportunities for enhanced lean construction management using Internet of Things standards. Automation in Construction, v. 61, p. 86-97, 2016.

DAVIES, R.; COOLE, T.; SMITH, A. Review of socio-technical considerations to ensure successful

implementation of Industry 4.0. Procedia Manufacturing, v. 11, p. 1288-1295, 2017.

DENYER, D., TRANFIELD, D. Chapter 39: producing a systematic review. In: Buchanan, D., Bryman, A. (Eds.), The Sage Handbook of Organizational Research Methods. Sage Publications Ltd, London, 671-689, 2009.

DOMBROWSKI, U.; RICHTER, T.; KRENKEL, P. Interdependencies of Industrie 4.0 \& Lean Production Systems - a use cases analysis. Procedia Manufacturing, v. 11, p. 1061-1068, 2017.

FARIAS, L. M. S.; SANTOS, L. C. S.; GOHR, C. F.; OLIVEIRA, L. C.; AMORIM, M. H. S. Criteria and practices for lean and green performance assessment: Systematic review and conceptual framework. Journal of Cleaner Production, v. 218, p. 746762, 2019.

FERREIRA, F.; SCAVARDA, L.; CERYNO, P. LEIRAS, A. Supply chain risk analysis: a shipbuilding industry case. International Journal of Logistics Research and Applications, v. p.542-556, 2018.

FOIDL, H.; FELDERER, M. Research challenges of industry 4.0 for quality management. Lecture Notes in Business Information Processing, v. 245, p. 121-137, 2016.

FRANK, A.; DALENOGARE, L.; AYALA, N. Industry 4.0 technologies: implementation patterns in manufacturing companies. International Journal of Production Economics, v. 110, p. 15-26, 2019. 
GARZA-REYES, J. A. Lean and green - a systematic review of the state of the art literature.Journal of Cleaner Production, v. 102, p. 18-29, 2015.

HARRINGTON, P. Machine Learning in Action. Shelter Island: Manning, 2012.

HERMANN, M.; PENTEK, T.; OTTO, B. Design Principles for Industrie 4.0 Scenarios: A Literature Review. Proceedings of the Annual Hawaii International Conference on System Sciences, p. 3928-3937, 2016.

HOTRAWAISAYA, C.; PAKVICHAI, V.; SRIYAKUL, T. Lean Production Determinants and Performance Consequences of Implementation of Industry 4.0 in Thailand: Evidence from Manufacturing Sector. Int. J Sup. Chain. Mgt, v.8, 2019.

HUANG, Z.; KIM, J.; SADRI, A.; DOWEY, S.; DARGUSCH, M. S. Industry 4.0: Development of a multi-agent system for dynamic value stream mapping in SMEs. Journal of Manufacturing Systems, v. 52, p. 1-12, 2019.

HÜTTMEIR, A.; TREVILLE, S.; ACKERE, A.; MONNIER, L.; PRENNINGER, J. Trading off between heijunka and just-in-sequence. International Journal of Production Economics, v.118, p.501-507, 2009.

KAFERMANN, H.; WAHLSTER, W.; HELBIG, J. Securing the future of German manufacturing industry Recommendations for implementing the strategic initiative INDUSTRIE 4.0 Final report of the Industrie 4.0 Working Group, 2013.

KAGERMANN, H.; WAHLSTER, W.; HELBIG, J. Recommendations for implementing the strategic initiative Industrie 4.0. Acatech, p. 13-78, 2013.

KAMBLE, S.; GUNASEKARAN, A.; DHONE, N. C. Industry 4.0 and lean manufacturing practices for sustainable organisational performance in Indian manufacturing companies. International Journal of Production Research, 2019.

KAMBLE,S.; GUNASEKARAN, A.; GAWANKAR, S. Sustainable Industry 4.0 framework: A systematic literature review identifying the current trends and future perspectives. Process Safety and Environmental Protection, v. 117, p. 408-425, 2018.

KARRE, H.; HAMMER, M.; KLEIDIENST, M.; RAMSAUER, C. Transition towards an Industry 4.0 state of the LeanLab at Graz University of Technology. Procedia Manufacturing, v. 9,p. 206-213, 2017.

KIPPER, L.; FURSTENAU, L.; HOPPE, D.; FROZZA, R.; LEPSEN, S. Scopus scientific mapping production in industry 4.0 (2011-2018): a bibliometric analysis. International Journal of Production Research, 2019. 
KOLBEG, D.; KNOBLOCH, J.; ZÜHLKE, D. Towards a lean automation interface for Workstations. International Journal of Production Research, v. 55, n. 10, p. 2845-2856, 2017.

LAUX, C.; LI, N.; SELIGER, C.; SPRINGER, J. Impacting Big Data analytics in higher education through Six Sigma techniques. International Journal of Productivity and Performance Management, v. 66, n., 2017 5, p. 662-679.

LEE, R.; CHEN, I.-Y; NICHOLS, P. A NOVEL PRODUCTION PROCESS MODELING FOR ANALYTICS. International Journal of GEOMATE, v. 11, n. 24, p. 2370-2377, 2016.

LI, L.-R. Lean Smart Manufacturing in Taiwan-Focusing on the Bicycle Industry. Journal of Open Innovation: Technology, Market, and Complexity, v. 5, 2019.

LUGERT, A.; BATZ, A.; WINKLER, H. Empirical assessment of the future adequacy of value stream mapping in manufacturing industries. Journal of Manufacturing Technology Management, v. 29, n. 5, p. 886-906, 2018.

MA, J.; WANG, Q.; ZHAO, Z. SLAE-CPS: Smart Lean Automation Engine Enabled by Cyber-Physical Systems Technologies. Sensors (Switzerland), v.17, n. 7, 2017.

MAGON, R.; THOMÉ, A.; FERRER, A.; SCAVARDA, L. Sustainability and performance in operations management research. Journal of Cleaner Production, v.190, p. 104-117, 2018.

MASON, J. Qualitative researching. London: Sage, 2002.

MÜLLER, R.; VETTE, M. HÖRAUF, L.; SPEICHER, C.; NURKHARD, D. Lean information and communication tool to connect shop and top floor in small and medium-sized enterprises. Procedia Manufacturing, v. 11, p. 1043-1052, 2017.

MULROW, C. D. "Systematic Reviews: Rationale for Systematic Reviews.” BMJ 309 (6954): 597-599,1994.

OHNO, T. Toyota Production System: Beyond Large-scale Production, CRC Press, New York, NY,1988.

OLIVEIRA, J.; SÁ, J. C.; FERNANDES A. Continuous improvement through "Lean Tools" : An application in a mechanical company. Procedia Manufacturing, v. 13, p. 1082-1089, 2017.

PAGLIOSA, M.; TORTORELlA, G.; FERREIRA, J. Industry 4.0 and Lean Manufacturing A systematic literature review and future research directions. Journal of Manufacturing Technology Management, 2019.

PEREIRA, A.; DINIS-CARVALHO, J.; ALVES, A.; AREZES, P. How Industry 4.0 Can Enhance Lean Practices. FME Transactions, v. 47, p. 810-822, 2019. 
PEKARČÍKOVÁ, M.; TREBUŇA, P.;KLIMENT, M. DIGITALIZATION EFFECTS ON THE USABILITY OF LEAN TOOLS. Acta Logistica, v. 6, n. 1, p. 9-13, 2019.

POGAČNIK, B.; DUHOVNIK, J.; TAVČAR, J. Aircraft fault forecasting at maintenance serviceon the basis of historic data and aircraft parameters. Eksploatacja i Niezawodnosc, v. 19, n. 4, p. 624-633, 2017.

ROSIN, F.; FORGET, P.; LAMOURI, S.; PELLERIN, R. Impacts of Industry 4.0 technologies on Lean principles. International Journal of Production Research, 2019.

ROSSINI, M.; COSTA, F.; TORTORELLA, G.; PORTIOLI-STAUDACHER, A. The interrelation between Industry 4.0 and lean production: an empirical study on European manufacturers. International Journal of Advanced Manufacturing Technology, v.102, n. 9-12, p. 3963-3976, 2019.

RÜßMANN, M.; LORENZ, M.; GERBERT, P.; WALDNER, M.; JUSTUS, J.; ENGEL, P.; HARNISCH, M. Industry 4.0: The Future of Productivity and Growth in Manufacturing Industries. Boston Consulting Group, p. 9, 2015.

RYMASZEWSKA, A. The challenges of lean manufacturing implementation in SMEs. Benchmarking: An International Journal, v. 21, p.987-1002, 2014.

SAHIN, M.; KO, H. S.; LEE, H. F.; AZAMBUJA, M. A simulation case study on supply chain

management of a construction firm adopting cloud computing and RFID. International Journal of Industrial and Systems Engineering, v. 21, n. 2, p. 233254, 2017.

SAIDI, R.; SOULHI, A. APPLYING SIX SIGMA IN SMART FACTORY: LIMITS AND PROBLEMS. ARPN Journal of Engineering and Applied Sciences, v. 13, n.20, p. 8317-8326, 2018.

SANDERS, A.; ELANGESWARAN, C.; WULFSBERG, J. Industry 4.0 Implies Lean Manufacturing: Research Activities in Industry 4.0 Function as Enablers for Lean Manufacturing. Journal of Industrial Engineering and Management, v. 9, n. 3, p. 811-833, 2016.

SAIEG, P.; SOTELINO, E.; NASCIMENTO D.; CAIADO R. Interactions of Building Information Modeling, Lean and Sustainability on the Architectural, Engineering and Construction industry: A systematic review. Journal of Cleaner Production, v. 174, n. 20, p. $788-806,2018$.

SAUNDERS, M., LEWIS, P., THORNHILL, A. Research Methods for Business Students. Pearson Education Limited,2012. 
SAURIN T.; RIBEIRO J.; VIDOR G. A framework for assessing poka-yoke devices, Journal of manufacturing systems, v. 31, p. 358-366, 2012.

SCHUH, G.; GARTZEN, T.; RODENHAUSER, T.; MARKS, A. (2015). Promoting Work-based Learning through Industry 4.0. Procedia CIRP, v. 32, p. 82-87,2015.

SEURING, S.; GOLD, S. Conducting content-analysis based literature reviews in supply chain management. Supply Chain Management International Journal, v.17, p. 544-555, 2012.

SHAH, R.; WARD, P. T. Defining and developing measures of lean production. Journal of operations Management, v. 25, n. 4, p. 785-805, 2007.

SIDDAWAY, A. What Is a Systematic Literature Review and How Do I Do One?. 2014.

SOUZA, J. P. E.; ALVES, J. M. Lean-integrated management system: A model for sustainability Improvement. Journal of Cleaner Production, v. 172, p. 2667-2682, 2018.

SONY, M. Industry 4.0 and lean management: a proposed integration model and research propositions. Production and Manufacturing Research, v. 6, n.1, p. 416432, 2018.

STOCK, $\quad$ T.; $\quad$ SELIGER, $\quad$ G. $\quad$ Opportunities of Sustainable Manufacturing in Industry 4.0. Procedia CIRP, v. 40, p. Pages 536541, 2016.

TEZEL, A.; AZIZ, Z. From conventional to it based visual management: A conceptual discussion for lean construction. Journal of Information Technology in Construction, v. 22, p. 220-246, 2017.

THOMÉ, A.; SACAVARDA, L.; FERNANDEZ, N. SACAVARDA, A. Sales and operations planning: A research synthesis. International Journal of Production Economics, v. 138, p.1-13, 2012.

THOMÉ, A. M. T. T.; SCAVARDA, L. F. SCAVARDA, A. J. Conducting systematic literature review in operations management. Production Planning and Control, v. 27, n. 5, p. 408-420, 2016.

TORTORELLA, G. L.; FETTERMANN, D. Implementation of Industry 4.0 and lean production in Brazilian manufacturing companies. International Journal of Production Research, v. 56, n. 8, p. 2975-2987, 2018.

TORTORELLA, G.; MIORANDO, R.; CAWLEY, A. F. M. The moderating effect of Industry 4.0 on the relationship between lean supply chain management and 
performance improvement. Supply Chain Management, v. 24, n.2, p. 301-314, 2019a.

TORTORELLA, G.; GIGLIO, R.; van DUN, D. Industry 4.0 adoption as a moderator of the impact of lean practices on operational performance improvement. InternationalJournal of Operations and Production Management, v. 39, p. 860886, 2019 b.

TRANFIELD, D., DENYER, D., SMART, P. Towards a methodology for developing evidence informed management knowledge by means of systematic review. British Journal of Management, v. 14, n. 13, p. 207-222, 2003.

TÜRKES, M.; ONCIOIU, I.; ASLAM, H.; MARIN-PANTELESCU, A.; TOPOR, D.; CAPUSNEANU, S. Drivers and Barriers in Using Industry 4.0: A Perspective of SMEs in Romania. Processes, v. 7,2019.

VARELA, L.; ARAÚJO, A.; ÁVILA, P.; CASTRO, H. PUTNIK, G. Evaluation of the Relation between Lean Manufacturing, Industry 4.0, and Sustainability. Sustainability (Switzerland), v. 11, n. 5, 2019.

VEZA, I.; MLADINEO, M.; GJEL, N. Seletion of the Basic Lean Tools for Development of Croatian Model of Innovative Smart Enterprise. Tehnicki Vjesnik, v. 23, n. 5, p. 1317-1324, 2016.

WANG, K. Intelligent Predictive Maintenance (IPdM) System-Industry 4.0 Scenario. WIT Transactions on Engineering, v. 113, p. 259-268, 2016.

WOMARCK, J. P.; JONES, D. T. Beyond Toyota: How to Root Out Waste and Pursue Perfection. HARVARD BUSINESS REVIEW, 1996.

ZHAO, H.; ZHAO, Q.; SLUSARCZYK, B. Sustainability and digitalization of corporate management based on augmented/virtual reality ttools usage: China and other world IT companies experience. Sustainability (Switzerland), v. 11, 2019.

ZHANG, K.; QU, T.; ZHOU, D.; THÜRER, M.; LIU, Y.; NIE, D.; LI, C.; HUANG, G.Q. IoT-enabled dynamic lean control mechanism for typical production systems.Journal of Ambient Intelligence and Humanized Computing, v.10, n. 3, p. $1009-1023,2019$.

ZHENG, P.; WANG, H.; SANG, Z.; ZHONG, R.; LIU, Y.; LIU, C.; MUBAROK, K.; YU, S.; XU, X. Smartmanufacturing systems for Industry 4.0: Conceptual framework, scenarios, and future perspectives . Frontiers of Mechanical Engineering, v. 3, p. 137-150, 2018. 


\section{APÊNDICE I - Questionário da primeira rodada do Painel com Especialistas}

1- Qual a sua área de atuação?

2- Você possui experiência com processos que englobam Lean Manufacturing e Indústria 4.0 ?

3- Quanto tempo de experiência você possui?

4- Em relação ao framework 1, as combinações existentes entre as práticas LM e as tecnologias da I4.0 são satisfatórias? Elas realmente atendem aos princípios apresentados?

5- Ao analisar o framework 1 existe lack com tecnologias que ainda não foram combinadas na literatura. Na sua opinião, quais outras possíveis combinações poderiam ser realizadas? Quais princípios elas atenderiam?

6- Em relação ao framework 2, você confirma, como requisitos para a implementação LM com a I4.0, conhecimentos sobre os fatores críticos de sucesso, barreiras e desafios?

7- Existe alguma barreira ou desafio relevantes que as empresas enfrentam, mas que não tenham sido mencionados neste trabalho?

8- Com a existência de um processo LM funcionando em conjunto com a I4.0, o ambiente ganha desempenho operacional, desempenho financeiro, segurança e melhorias para as pessoas.Existe alguma melhora que ainda não foi detectada?

9- Na sua opinião, alguns dos ganhos citados anteriormente ainda não estão claros para as empresas? Quais os benefícios mais fáceis e quais os difíceis de serem atingidos?

10- Qual a sua opinião sobre a participação de fornecedores e clientes no processo de integração entre o LM e a I4.0?

11- Você acha que a dificuldade de compatibilidade entre os sistemas da cadeia de suprimentos como um todo ainda é alta?

12-Além do que foi perguntado, o que mais você sugere que poderia ser acrescentado aos modelos? 